\title{
Medida da secção de choque térmica e da integral de ressonância da reação ${ }^{41} \mathrm{~K}(\mathrm{n}, \gamma){ }^{42} \mathrm{~K}$
}

\author{
Felisberto Alves Ferreira Junior
}

Orientadora: Profa. Dra. Nora Lía Maidana

Dissertação de mestrado apresentada ao Instituto de Física para a obtenção do título de Mestre em Ciências

Banca Examinadora:

Profa. Dra. Nora Lía Maidana

(IFUSP)

Profa. Dra. Márcia de Almeida Rizzutto

(IFUSP)

Prof. Dr. Sérgio José Barbosa Duarte

(CBPF)

São Paulo

2008 
FICHA CATALOGRÁFICA

\section{Preparada pelo Serviço de Biblioteca e Informação} do Instituto de Física da Universidade de São Paulo

Ferreira Junior, Felisberto Alves

PMedida da secção de choque térmica e da integral de ressonância da reação ${ }^{41} \mathrm{~K}(\mathrm{n}, \mathrm{\gamma}){ }^{42} \mathrm{~K}$

- São Paulo - 2008

Dissertação - Universidade de São Paulo. Instituto de Física. Departamento de Física Experimental

Orientador: Profa. Dra. Nora Lia Maidana

Área de Concentração: Física Nuclear

Unitermos: 1. Física Nuclear; 2. Interações nucleares; 3. Reações nucleares

USP/IF/SBI-060/2008 
$\mathcal{A}$

Felisberto Alves Ferreira,

Neuza Gomes de Oliveira

$e$

Érica Yamashita 


\section{Agradecimentos:}

à Dra. Nora Lía Maidana por me orientar a cada segundo deste trabalho, me aconselhar sempre que necessário, me encorajar, compreender minhas limitações, elogiar minhas qualidades e por me mostrar que é possível encontrar satisfação pessoal e profissional ao mesmo tempo na vida acadêmica.

ao Dr. Vito Roberto Vanin por me acolher no Instituto de Física em 2002 e desde então estar sempre disposto a me ajudar em qualquer situação. Também o agradeço por me fazer entender que, como diria Oswald de Andrade, temos a ciência codificação da magia.

aos professores: Mauro Dias e Marina Koskinas pela ajuda essencial nas irradiações das amostras e sugestões para o bom andamento do trabalho.

aos meus pais Felisberto Alves Ferreira e Neuza Gomes de Oliveira por me darem apoio, incentivo, ajuda financeira, conselhos e principalmente carinho. Também os agradeço por se sacrificarem por mim não só nesses últimos dois anos, mas durante toda minha vida.

à minha família, por me incentivar e apoiar, em especial à Keyla de Oliveira, Marcos Alves, Edilaine Rúbia, José Maria e Jovercina Alves.

à Érica Yamashita por me incentivar diariamente, por me tratar com exímia bajulação, por me ensinar como me divertir e relaxar, e por ser minha musa ao longo desses anos. Também agradeço a Célia Nakano por ajudar a fazer eu me sentir um membro ilustre da família.

aos meus amigos: Ivanildo Antonio pela cumplicidade e companheirismo ao longo dos anos, Nathaly Lopes por trazer muita alegria, vitalidade e bons momentos de amizade, Fernando Rodrigues por me animar sempre, Renata da Costa pelas conversas sinceras e descontraídas, Leandro Mariano pelas discussões sobre espectroscopia gama e física em 
geral, Zwinglio Guimarães pelos incontáveis conselhos, ajudas e sessões de "estudo de estatística aplicada", Priscila Cheda pelos convites à diversão, Pedro Henrique pela cumplicidade e exemplo de educação, Viktor Janke pelas histórias compartilhadas e ajuda em continhas manhosas, e Felipe Frigeri por me provocar e permitir que eu faça o mesmo. Em especial agradeço aos amigos Nathaly, Leandro, Fernando, Zwinglio e Karen do Amaral por me devolverem para a mão de meu dono quando me declarei um goblin.

à Daniela Tolentino por me ajudar a aprender Mecânica Quântica e tentar me ensinar a nadar.

à Luzia Venturini pelas dicas e ajuda ao longo do trabalho.

à Rita pela ajuda na pesquisa de possíveis compostos e na preparação de amostras, além de incontáveis pequenas ajudas e conselhos.

aos funcionários Nancy, Wanda e Jorge por me ajudarem com as prensas do Laboratório de Dosimetria e do Laboratório de alvos do Péletron.

aos funcionários "Betão" e Wilson por construírem e ajudarem na manutenção do pastilhador.

aos funcionários do Laboratório do Acelerador Linear por se mostrarem prestativos, em especial à Juliana, Eduardo, Carlos, Antônio e Renato.

aos professores que sempre se demonstraram prestativos e me ajudaram ao longo desse trabalho: Otaviano Helene, Emerson Passos, Thereza Borello, Luis Carlos de Menezes, Josif Frenkel, Rosangela Itri, Marcos Nogueira Martins e Nilberto Medina.

aos colegas do ambiente de trabalho que sempre se dispuseram a ajudar e a trocar um dedinho de prosa: Leika Horii, Sileine, Leandro Beraldo, Raphael, André Serra, Washington, Wenderson, Diogo Tridapalli, Marco, Cristiane, Igino, Joseane, Jairo, Priscila Santos, Diogo, Amanda, Fabíola, Renato, Neivy e Gustavo.

às agencias de fomento CNPq e Fapesp pelo apoio e suporte financeiro. 
A todos que direta ou indiretamente colaboraram na execução deste trabalho e peço que me perdoem por eventuais omissões. 
Medida da secção de choque térmica e da integral

\section{de ressonância da reação ${ }^{41} \mathrm{~K}(\mathrm{n}, \gamma){ }^{42} \mathrm{~K}$}

\section{Resumo}

Pastilhas de nitrato de potássio foram irradiadas no núcleo do reator de pesquisas IEA-R1m do Instituto de Pesquisas Energéticas e Nucleares, IPEN/CNEN-SP, operando a 2 MW de potência, para determinar a secção de choque térmica e integral de ressonância da reação ${ }^{41} \mathrm{~K}(\mathrm{n}, \gamma)^{42} \mathrm{~K}$. O fluxo de nêutrons foi monitorado com folhas de liga ouro-alumínio. As atividades induzidas nos alvos foram determinadas por espectroscopia gama com detectores de germânio hiper puro. Os cálculos realizados se basearam no formalismo de Westcott. Foram realizadas simulações com o código MCNP (Monte Carlo N-Particle) para determinar a auto-blindagem e a depressão do fluxo de nêutrons nas pastilhas durante as irradiações e os fatores de correção da eficiência de detecção para fontes volumétricas, que leva em conta a absorção de raios gama nas mesmas. Foi efetuado um tratamento estatístico das incertezas envolvidas e determinadas as covariâncias entre os resultados, incluindo aquelas decorrentes das incertezas do padrão de referência (ouro). Os resultados obtidos foram comparados com os de outros autores. Foi testada a possibilidade de se observar o produto da reação ${ }^{41} \mathrm{~K}(\mathrm{n}, \gamma)^{42} \mathrm{~K}(\mathrm{n}, \gamma){ }^{43} \mathrm{~K}$. 


\section{Thermal cross-section and resonance integral of}

\section{the ${ }^{41} \mathrm{~K}(\mathrm{n}, \gamma){ }^{42} \mathrm{~K}$ reaction measurement}

\section{Abstract}

Pellets of potassium nitrate were irradiated in the IPEN/CNEN-SP (Instituto de Pesquisas Energeticas e Nucleares, Comissao de Energia Nuclear, Sao Paulo, SP) IEA$\mathrm{R} 1 \mathrm{~m}$ reactor core operating at $2 \mathrm{MW}$ power in order to determine the ${ }^{41} \mathrm{~K}(\mathrm{n}, \gamma)^{42} \mathrm{~K}$ reaction thermal cross-section and resonance integral. The neutron flux was monitored by Au-Al alloy foils, and the Westcott formalism was applied. Neutron self-shielding, flux depression and gamma-ray self-absorption in the relatively large samples, as well as the gamma-ray detection efficiency correction factor, were determined by simulation with MCNP code. The data reduction statistical methods included the determination of the covariances between the obtained results and the standard cross-sections used $(\mathrm{Au})$. The results were compared to those already published. The observation of the consecutive neutron capture reaction leading to ${ }^{43} \mathrm{~K}$ was tried. 
Capítulo 1: Introdução........................................................................ 1

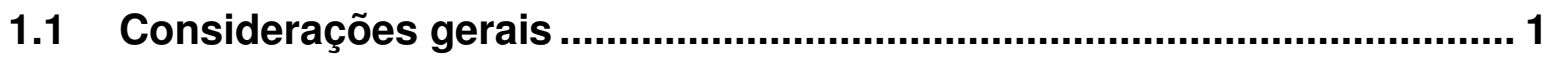

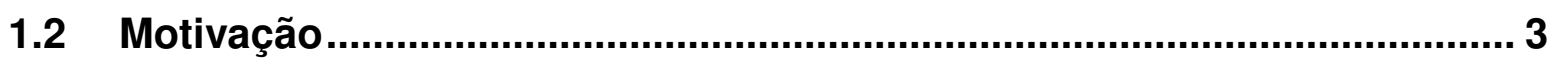

Capítulo 2: Teoria .......................................................................... 5

2.1 Espectros de nêutrons em um reator ...................................................... 5

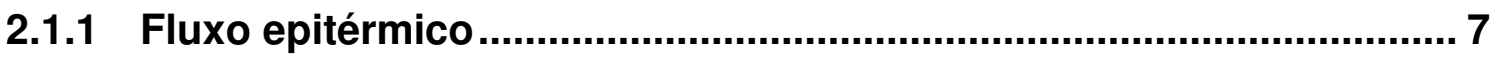

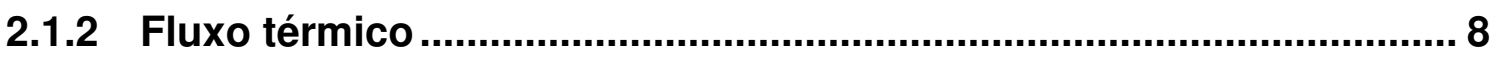

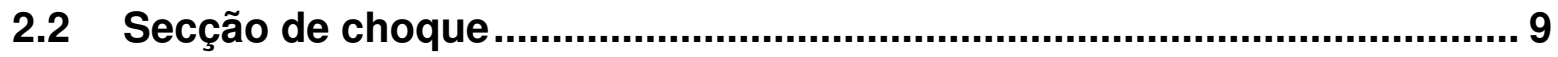

2.2.1 Formalismo de Westcott ............................................................... 10

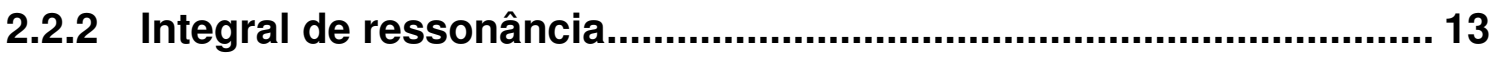

2.2.3 Método da diferença de cádmio ...................................................... 14

2.3 Atividade de um alvo irradiado por nêutrons ...................................... 15

Capítulo 3: Procedimento Experimental ........................................... 19

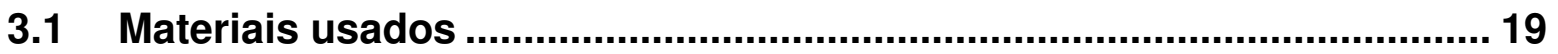

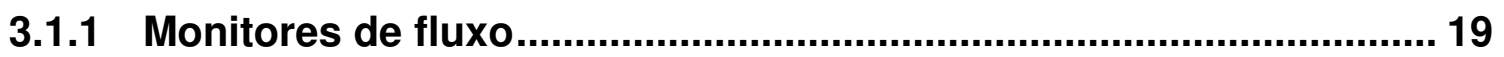

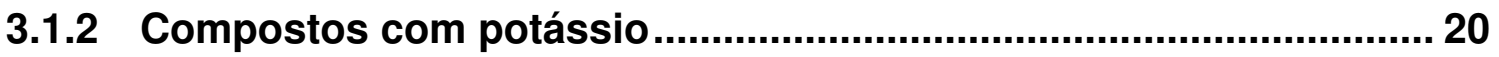

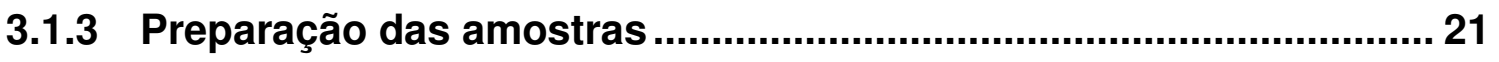

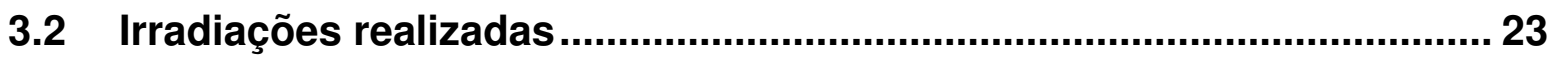

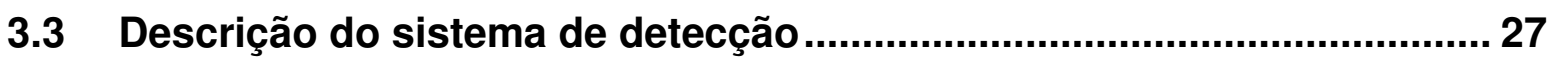

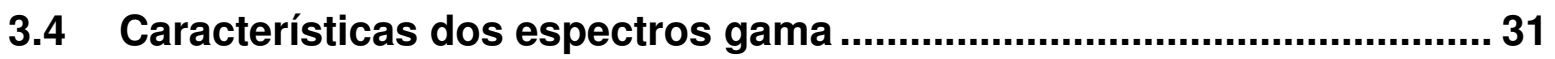

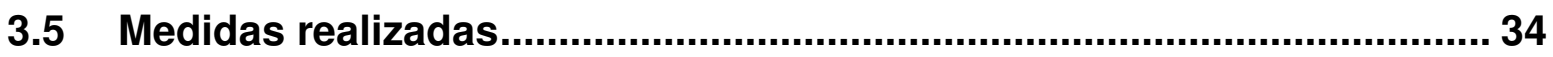

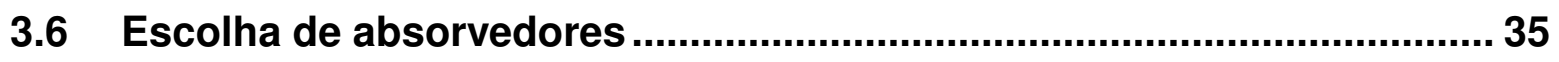

3.7 Processo de calibração dos detectores................................................... 39 
3.7.1 Determinação das áreas dos picos.

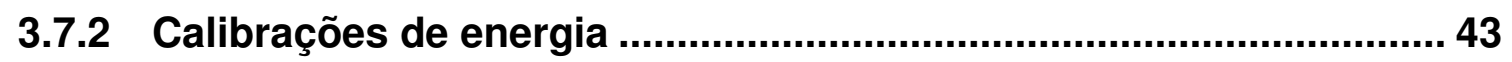

3.7.3 Correção de tempo morto ................................................................ 44

3.7.4 Medidas a taxas de contagem elevadas ...........................................46

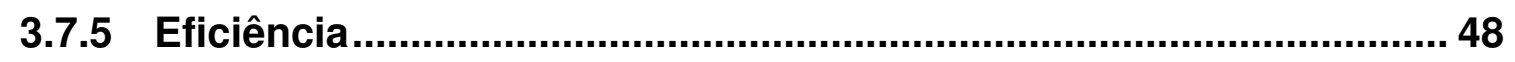

Capítulo 4: Simulações .................................................................50

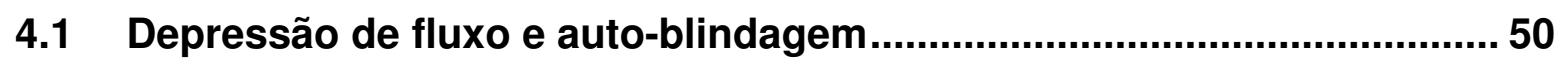

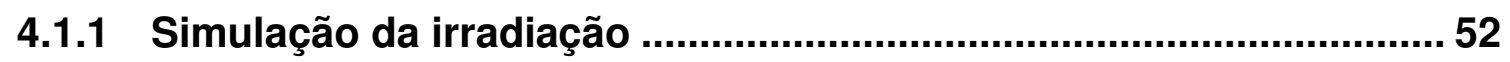

4.2 Correção da eficiência para fontes radioativas volumétricas .................56

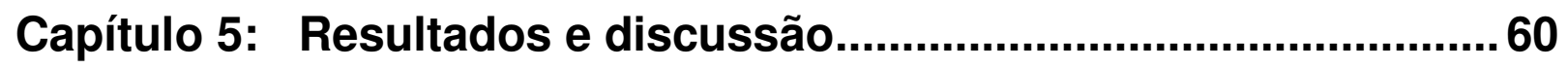

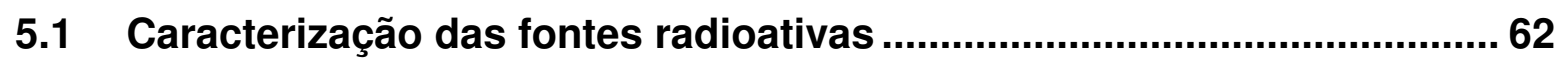

5.1.1 Identificação dos núcleos de interesse ............................................ 63

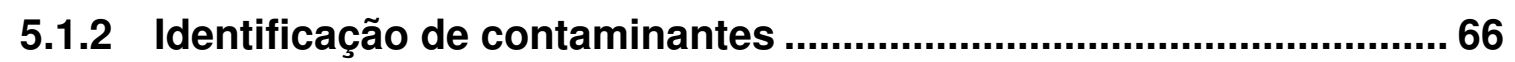

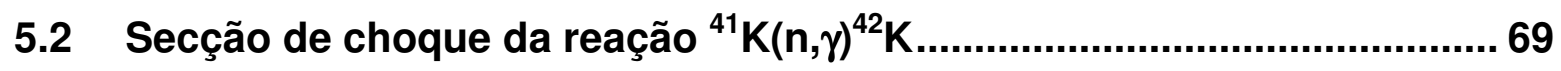

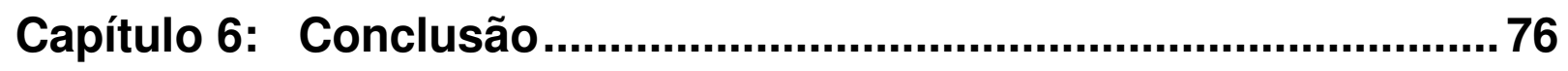

Apêndice A: Correção do efeito soma ........................................... 77

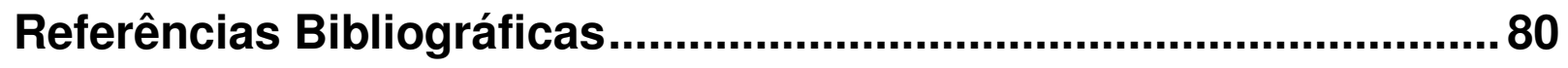




\section{Capítulo 1:Introdução}

\subsection{Considerações gerais}

No ano de 1930, Walther Bothe e Richard Becker descobriram um tipo de irradiação nuclear que em 1932 James Chadwick identificou e nomeou como sendo o nêutron, uma partícula com massa semelhante à do próton, mas sem carga elétrica. Logo em seguida, no mesmo ano, Werner Karl Heisenberg concluiu que o núcleo atômico é formado apenas por prótons e nêutrons [1]. A partir dessas descobertas nasceu a física dos nêutrons, que tem sido estudada e aperfeiçoada exaustivamente nas últimas décadas devido a abrangência de fenômenos relacionados e a aplicabilidade em novas tecnologias.

No âmbito experimental, o estudo de nêutrons se faz com fontes de nêutrons, em reatores de fissão e aceleradores de partículas. Os métodos utilizados para a observação dos nêutrons têm como base a intenção de forçá-los a interagir com a matéria, dado que é uma partícula sem carga e a observação é indireta.

O nêutron interage com a matéria através das forças nuclear e fraca. Porém, o processo de transporte de nêutrons na matéria depende basicamente da interação nuclear, ou seja, os nêutrons interagem com os núcleos dos átomos e não com suas camadas atômicas. As reações nucleares fundamentais com nêutrons são estudadas a partir da observação dos produtos de colisões entre nêutrons e núcleos. Dependendo da energia com que o nêutron incide no núcleo várias reações diferentes podem ocorrer, mas elas são classificadas em dois tipos [1]: processos de espalhamento, onde ocorrem colisões elásticas ou inelásticas entre nêutrons e núcleos; e processos de absorção, onde o nêutron 
desaparece dentro do núcleo e várias radiações secundárias surgem como conseqüência disso.

Uma das grandes áreas da física de nêutrons é o estudo da interação dos nêutrons com núcleos atômicos, o qual tem sido uma ferramenta muito importante em descobertas e apropriações, na forma de tecnologia, das propriedades da matéria.

A captura de nêutrons é um mecanismo importante na produção de novos elementos em reatores nucleares, na transmutação dos produtos de fissão, na obtenção de elementos utilizados em física médica e nos processos de nucleossíntese de interesse astrofísico [2-4].

Nesse contexto se faz importante o conceito de secção de choque, uma grandeza com dimensão de área que representa a probabilidade de interação do nêutron com um núcleo. O valor exato da secção de choque de captura de nêutrons de um certo elemento não pode ser determinado teoricamente; no entanto, a partir dos valores experimentais das seções de choque em algumas situações particulares, os modelos nucleares permitem estimar a sua dependência com a energia do nêutron. Assim, o estudo teórico do mecanismo da reação de captura de nêutrons permite, aliado aos dados experimentais, novas previsões.

Os processos de detecção de partículas costumam se relacionar às interações eletromagnéticas, fazendo com que a detecção de partículas dotadas de carga elétrica seja mais eficiente que a de partículas neutras, já que para essas serem detectadas devem interagir com a matéria de forma que o resultado possa ser observado por meio das interações de partículas carregadas. Os estudos e experimentos feitos neste trabalho envolvem basicamente a detecção de partículas neutras, mais especificamente nêutrons e fótons. 
A interação do nêutron com a matéria é observada neste trabalho por meio do processo de captura de nêutrons por núcleos atômicos, cujo produto costuma ser núcleos instáveis que decaem emitindo radiação beta e fótons gama.

Fótons gama, por terem energias maiores ou da ordem de $10^{-1} \mathrm{MeV}$, transferem energia para a matéria basicamente por meio de: efeito foto-elétrico, no qual o elétron absorve totalmente a energia do fóton, espalhamento Compton, no qual os fótons colidem com os elétrons transferindo parte de sua energia, e formação de pares elétron-pósitron para fótons com energia superior a 1,022 MeV.

\subsection{Motivação}

Os valores referenciados na bibliografia para a secção de choque de absorção de nêutrons térmicos e da integral de ressonância para a reação ${ }^{41} K(n, \gamma){ }^{42} K$ foram determinados por diferentes metodologias e em alguns casos apresentaram valores incompatíveis, como pode ser verificado na tabela 1. O presente trabalho pretende colaborar na determinação dessas secções de choque usando a análise da atividade induzida por nêutrons provindos de um reator de pesquisa do tipo piscina.

Tabela 1: Valores para secção de choque térmica, $\sigma_{0}$, e integral de ressonância, $I$, em barns

\begin{tabular}{ccc}
\multicolumn{3}{c}{ (1 barn=10 } \\
\hline Referência (ano) & $\left.\sigma_{0}{ }^{2}\right)$. & $I$ \\
\hline \hline KAPPE (1965) [5] & $1,500(45)$ & \\
KÖHLER (1966) [6] & $1,2(1)$ & $0,96(3)$ \\
RYVES (1969) [7] & $1,46(3)$ & $1,39(15)$ \\
KIM (1971) [8] & $1,28(6)$ & $1,25(4)$ \\
KAMINISHI (1982) [9] & $1,57(17)$ & \\
\hline
\end{tabular}


$\mathrm{O}{ }^{43} \mathrm{~K}$ é um isótopo normalmente obtido através de reações ${ }^{41} \mathrm{~K}(\mathrm{t}, \mathrm{p}){ }^{43} \mathrm{~K}$ [10], ${ }^{44} \mathrm{Ca}\left(\mathrm{d},{ }^{3} \mathrm{He}\right){ }^{43} \mathrm{~K}[11],{ }^{40} \mathrm{Ar}(\alpha, \mathrm{p}){ }^{43} \mathrm{~K}$ [12-13], ${ }^{44} \mathrm{Ca}(\mathrm{t}, \alpha){ }^{43} \mathrm{~K}[14],{ }^{9} \mathrm{Be}\left({ }^{36} \mathrm{~S}, \mathrm{np}\right){ }^{43} \mathrm{~K}[15] \mathrm{e}{ }^{44} \mathrm{Ca}(\mathrm{t}, \alpha){ }^{43} \mathrm{~K}$ [16]. Não foi encontrado na literatura relato da obtenção de ${ }^{43} \mathrm{~K}$ por captura sucessiva de nêutrons.

A captura sucessiva de nêutrons por um núcleo é um fenômeno de difícil observação devido a atividade do produto final ser muito pequena comparada ao material depois de irradiado. As medidas de secção de choque de captura de nêutrons pelo ${ }^{41} \mathrm{~K}$ se fazem necessárias pelo fato de que proverão dados mais confiáveis para o cálculo da secção de choque de captura de nêutrons pelo ${ }^{42} \mathrm{~K}$, cuja atividade deve ser bem determinada.

Para avaliar procedimentos experimentais, analisar resultados e tirar conclusões é necessário o conhecimento dos mecanismos de transporte de nêutrons, física nuclear, detecção de partículas e tratamento estatístico de dados. Tais estudos são importantes não só para o bom andamento do projeto proposto, mas também como conhecimento dessa área da física e das suas aplicações. 


\section{Capítulo 2:Teoria}

\subsection{Espectros de nêutrons em um reator}

Em pesquisas envolvendo reatores é essencial o conhecimento da distribuição de energia dos nêutrons assim como sua fluência (mais precisamente a taxa de fluência, comumente denominada "fluxo") para avaliar resultados experimentais. Porém, determinar esses valores, mesmo para apenas uma posição de interesse, com precisão não é tarefa trivial, tornando-se então impossível para todos os pontos do reator devido a variações da potência ao longo do tempo e da influência dos materiais e equipamentos que envolvem o funcionamento do reator. Com tais perturbações, é forçosa a utilização de monitores de fluxo em todo experimento no qual sejam relevantes esses dados.

Esses aspectos fazem dos reatores nucleares instalações únicas, portanto é necessário, para se comparar resultados experimentais obtidos em diferentes reatores, seguir procedimentos, unidades e correções padronizadas. No presente trabalho foi adotado o formalismo de Westcott.

O reator IEA-R1m do Instituto de Pesquisas Energéticas e Nucleares, IPEN/CNEN-SP é um reator de pesquisa de $5 \mathrm{MW}$ de potência operando a $2 \mathrm{MW}$ cujo moderador é água leve e o combustível é urânio enriquecido, com $20 \%$ de ${ }^{235} \mathrm{U}$.

Nêutrons livres tem meia vida de $885,7(8)$ segundos [17] e podem ser encontrados no fundo radioativo natural ou obtidos a partir de fontes radioativas, aceleradores de partículas e reatores nucleares. 
Os nêutrons podem ser classificados arbitrariamente segundo sua energia de forma a explicitar algumas características de seu espectro ou se adequar a experimentos. Segue abaixo uma possível classificação:

- nêutrons térmicos são os de energia até $1 \mathrm{eV}$; a maior parte deles é resultado do processo de moderação, que consiste em uma série de colisões entre os nêutrons e os núcleos do moderador até que haja um equilíbrio térmico. A distribuição de energia desses nêutrons pode ser aproximada por uma distribuição de Maxwell.

- nêutrons epitérmicos são os de energia entre 1 eV e $2 \mathrm{MeV}$; normalmente são os nêutrons que ainda estão em processo de moderação, sua distribuição de energia é aproximadamente proporcional ao inverso do valor da energia.

- nêutrons rápidos são os de energia entre $500 \mathrm{keV}$ e $20 \mathrm{MeV}$, normalmente provindos de reações nucleares dos elementos combustíveis.

O fluxo de nêutrons é caracterizado por uma grandeza que depende da energia cinética dos nêutrons e que pode ser prevista segundo sua origem. No caso de um reator nuclear pode se dizer que existem basicamente três tipos de fluxo de nêutrons: o de fissão, o epitérmico e o térmico.

A distribuição do fluxo de nêutrons da fissão por unidade de energia $\phi(E)$, que corresponde aos nêutrons não moderados produzidos no processo da fissão, é dado aproximadamente por [18]:

$$
\phi(E) d E=0,484 e^{-\frac{E}{E_{T}}} \sinh \left(\sqrt{\frac{2 E}{E_{T}}}\right) d E
$$


onde $E$ é a energia do nêutron em $\mathrm{MeV}$ e $E_{T}$ é uma energia de referência da ordem de $1 \mathrm{MeV}$. Porém, assim que esses nêutrons abandonam o elemento combustível o espectro começa a ser modificado pela interação deles com o moderador se tornando um espectro de nêutrons epitérmicos e posteriormente térmicos.

\subsubsection{Fluxo epitérmico}

A distribuição do fluxo de nêutrons por unidade de energia, ou simplesmente densidade de fluxo de nêutrons, em processo de moderação em um meio com integral de ressonância de captura desprezível pode ser aproximada por [19]:

$$
\phi(E) d E=\theta \frac{d E}{E}
$$

onde $\theta$ é uma constante. Assim, o fluxo epitérmico total, $\Phi_{e p i}$, é dado por:

$$
\Phi_{e p i}=\int_{E_{1}}^{E_{2}} \theta \frac{d E}{E}=\theta \ln \left(\frac{E_{2}}{E_{1}}\right)
$$

onde $E_{1}$ e $E_{2}$ são energias onde se supõe prevalecer este comportamento. Essa hipótese de que a distribuição da densidade de fluxo epitérmico depende do inverso da energia supõe válido que:

- o meio em que os nêutrons estão sendo moderados é homogêneo e infinito;

- as fontes de nêutrons rápidos estão homogeneamente distribuídas no espaço;

- o poder de moderação do meio não depende da energia;

- durante o processo de moderação não existe absorção e 
- as partículas do moderador se comportam como partículas livres com a mesma massa que os nêutrons.

Na prática, essas afirmações não são obedecidas a risca, então a densidade do fluxo epitérmico numa determinada posição de irradiação não é descrita exatamente como o inverso da energia, mas pode ser melhor aproximada por:

$$
\phi(E) d E=\theta \frac{d E}{E^{1+\alpha}}
$$

onde $\alpha$ é um parâmetro que depende da distância ao elemento combustível e das condições de contorno do meio moderador e outros materiais próximos à posição em análise.

\subsubsection{Fluxo térmico}

Se considerarmos que os nêutrons se comportam como um gás ideal quando moderados, a distribuição da densidade de nêutrons é dada pela distribuição de Maxwell e conseqüentemente a distribuição da densidade do fluxo de nêutrons pode ser bem descrita por [1]:

$$
\phi(E) d E=\Phi_{t h} e^{-\frac{E}{E_{T}}} \frac{E}{E_{T}} \frac{d E}{E_{T}}
$$

onde $\Phi_{t h}$ é a integral da densidade do fluxo de nêutrons sobre todas as energias possíveis, chamado de fluxo térmico, e $E_{T}$ é a energia mais provável dos nêutrons, dada por:

$$
E_{T}=k T
$$


onde $k$ é a Constante de Boltzmann e $T$ é a temperatura dos nêutrons no moderador, dada por $T=T_{m}\left(1+0,02044 k T_{m}\right)$, e $T_{m}$ é a temperatura do moderador (água) [20].

\subsection{Secção de choque}

A secção de choque é um conceito geral para a probabilidade de interação de uma ou mais partículas com outra partícula ou conjunto de partículas. No presente trabalho, lidaremos com a secção de choque de interação entre nêutrons e núcleos atômicos, mais especificamente para a reação de captura $(n, \gamma)$.

A taxa de reações produzidas por nêutrons incidentes sobre um material, $R$, pode ser expressa como [21]:

$$
R=N_{0} \int_{E_{1}}^{E_{2}} \sigma(E) \phi(E) d E
$$

onde $N_{0}$ é o número de átomos alvo, $\sigma(E)$ é a secção de choque dependente da energia e $\phi(E)$ é o fluxo de nêutrons por unidade de energia, também chamado de densidade de fluxo.

Para a maioria dos elementos que se conhece a secção de choque, esta apresenta uma relação inversa com a velocidade dos nêutrons, v, que estão bombardeando o alvo, também chamada de comportamento $1 / v$ da secção de choque ou simplesmente lei $1 / v$. Então basta um valor de secção de choque para uma certa velocidade de nêutrons na região térmica e se pode deduzir o valor da secção de choque para qualquer velocidade de nêutrons. A velocidade convencionada para troca de informações no meio científico e comparações entre diferentes medições é $2200 \mathrm{~m} / \mathrm{s}$, correspondente a uma temperatura de moderador $T_{0}=20,44{ }^{\circ} \mathrm{C}$ e conseqüentemente a uma energia cinética de nêutrons de 0,025 
eV. A secção de choque para essa velocidade é chamada de secção de choque térmica, que simbolizaremos como $\sigma_{0}$ ao longo deste trabalho

Considerando a equação (7), se sobre um material estiver incidindo um feixe monocromático de nêutrons com energia de $0,025 \mathrm{eV}$, a secção de choque térmica será dada então por:

$$
\sigma_{0}=\frac{R}{N_{0} \phi_{0}}
$$

onde $\Phi_{0}$ é o fluxo de nêutrons com energia $0,025 \mathrm{eV}$, também chamado de fluxo convencional, cuja relação com o fluxo em equilíbrio térmico com os átomos do moderador é dada por:

$$
\Phi_{t h}=\phi_{0} \sqrt{\frac{4 T}{\pi T_{0}}}
$$

Porém, as irradiações realizadas no presente trabalho não correspondem à descrição acima, portanto foi necessário usar um formalismo de ativação de nêutrons para determinar a secção de choque térmica.

\subsubsection{Formalismo de Westcott}

Considerando que o fluxo de nêutrons fora do elemento combustível de um reator é composto por nêutrons termalizados e por nêutrons ainda em processo de termalização, chamados epitérmicos, então convenciona-se escrever a distribuição da densidade de nêutrons como [22-24]: 


$$
n(v)=(1-f) n_{M}(v)+f n_{e}(v)
$$

onde $f$ é a fração da distribuição epitérmica na densidade total de nêutrons, $n_{M}(v)$ é a distribuição Maxwelliana e $n_{e}(v)$ é a função de distribuição da densidade de nêutrons epitérmicos que é dada por:

$$
n_{e}(v)=\frac{n \Delta}{v^{2}} \sqrt{\frac{2 k T \mu}{m}}
$$

onde $n$ é a densidade de nêutrons total, $\mu$ é um fator que depende do material moderador e $\Delta$ é uma função degrau para valores altos de energia de nêutron dada por:

$$
\Delta=\frac{1}{\left(1+\frac{\mu k T}{E}\right)}
$$

A partir dessas convenções é possível definir uma secção de choque efetiva $\hat{\sigma}$ para a reação, dada por:

$$
\frac{R}{N_{0}}=\int_{0}^{\infty} n(v) \sigma(v) v d v \Rightarrow \frac{R}{N_{0}}=\phi_{0} \hat{\sigma}
$$

Considerando a equação (10), a equação (13) pode ser escrita como:

$$
\frac{R}{N_{0}}=(1-f) \int_{0}^{\infty} n_{M}(v) \sigma(v) v d v+f \int_{0}^{\infty} n_{e}(v) \sigma(v) v d v=\phi_{0} \sigma_{0}(g+r s)
$$

onde $g, r$ e $s$ são fatores definidos como: 


$$
\begin{gathered}
g=\frac{1}{v_{0} \sigma_{0}} \int_{0}^{\infty} n_{M}(v) \sigma(v) v d v=\frac{\hat{\sigma}_{m}}{\sigma_{0}} \\
r=\frac{f \sqrt{\pi \mu}}{4} \\
s=\frac{2}{v_{0} \sigma_{0}} \sqrt{\frac{2 k T}{m \pi}} \int_{0}^{\infty}\left[\sigma(v)-\frac{v_{0} \hat{\sigma}_{m}}{v}\right] \Delta \frac{d E}{E}
\end{gathered}
$$

onde $\Delta$ é dada pela equação (12), evitando que a integral divirja, $\hat{\sigma}_{m}$ é a secção de choque térmica efetiva quando o fluxo de nêutrons é puramente térmico, $g$ representa uma correção para o caso da secção de choque do material absorvedor não ser proporcional ao inverso da velocidade do nêutron, $r$ é um fator relacionado a razão entre os fluxos térmico e epitérmico e $s$ é um fator proporcional a razão entre a integral das regiões ressonantes e a secção de choque térmica. A partir desse formalismo define-se então uma grandeza $I_{0}$, conhecida como integral de ressonância reduzida, que representa a probabilidade de interação entre os nêutrons epitérmicos e os núcleos devido às ressonâncias (pequenas faixas de energia onde a secção de choque apresenta probabilidade de interação muito maior que as proporcionais ao inverso da velocidade) e é dada por:

$$
I_{0}=\int_{0}^{\infty}\left[\sigma(v)-\frac{v_{0} \hat{\sigma}_{m}}{v}\right] \Delta \frac{d E}{E}
$$


Para muitos núcleos, a secção de choque apresenta ressonâncias, então se faz também interessante a determinação da integral da secção de choque ao longo de todas as energias possíveis dos nêutrons. Em análise por ativação de nêutrons se convenciona usar uma integral ao longo da região de ressonância para nêutrons epicádmios, que por simplicidade será chamada nesse trabalho apenas de integral de ressonância, que é definida por:

$$
I=\int_{E_{\mathrm{Cd}}}^{2 \mathrm{MeV}} \frac{\sigma(E)}{E} d E
$$

onde $E_{C d}$ é a energia de corte de cádmio, que depende da espessura do cádmio usado na medida. No presente trabalho foram usadas cápsulas de cádmio com 0,05 cm cuja energia de corte de cádmio é aproximadamente 0,55 eV.

Considerando as equações (2) e (19), pode-se concluir a seguinte relação:

$$
\Phi_{e p i}=\frac{R}{N_{0} I} \ln \left(\frac{2}{E_{C d}}\right), E_{C d} \text { em MeV. }
$$

Considerando o parâmetro de correção da densidade de fluxo $\alpha$ da fórmula (4), a integral de ressonância corrigida, $I(\alpha)$, é dada por:

$$
I(\alpha)=\left(\frac{\bar{E}_{r}}{E_{e V}}\right)^{\alpha} I-\left(\frac{\bar{E}_{r}}{E_{C d}}\right)^{\alpha} \frac{2 \sigma_{0}}{2 \alpha+1} \sqrt{\frac{E_{0}}{E_{C d}}}+2 \sigma_{0} \sqrt{\frac{E_{0}}{E_{C d}}}
$$


onde $\bar{E}_{r}$ é a energia efetiva de ressonância, que para a reação ${ }^{197} \mathrm{Au}(\mathrm{n}, \gamma){ }^{198} \mathrm{Au}$ é $5,65 \mathrm{eV}$ e para a reação ${ }^{41} \mathrm{~K}(\mathrm{n}, \gamma){ }^{42} \mathrm{~K}$ é $2960 \mathrm{eV}$ [25], $E_{e V}$ é uma energia de referência adotada como $1 \mathrm{eV}[26]$ e $E_{0}=0,025 \mathrm{eV}$ é a energia térmica.

\subsubsection{Método da diferença de cádmio}

O cádmio natural é composto de oito isótopos e um deles é o ${ }^{113} \mathrm{Cd}$ (com abundância de $12,22 \%$ ), cuja secção de choque térmica é $2,06(4) \times 10^{4}$ barns e com integral de ressonância da ordem de $10^{2}$ barns. Essas características fazem desse material um bom filtro para medidas de secção de choque, pois ele apresenta uma das maiores probabilidades de interação para nêutrons térmicos entre os núcleos estáveis, entretanto, não é um filtro perfeito.

O método da diferença de cádmio consiste em fazer duas irradiações simultâneas do mesmo material acompanhado de monitores de fluxo idênticos, sendo um conjunto de amostra e monitor envolto pela cápsula de cádmio e outro conjunto descoberto. Após a irradiação são determinadas as atividades induzidas nos alvos e a razão entre a atividade de um material irradiado nu, $A_{\text {total }}$, e a atividade do material irradiado sob cádmio, $A_{C d}$, os dois com mesma massa, é chamada de razão de cádmio, $R_{C d}$ :

$$
R_{C d}=\frac{A_{\text {total }}}{A_{C d}}=\frac{g+r s}{r\left(s+\frac{1}{K} \sqrt{\frac{T}{T_{0}}}\right)}
$$

onde $K$ é um fator que corrige a transmissão através do cádmio de nêutrons com energia abaixo da energia de corte de cádmio e, portanto, depende da espessura da cápsula de cádmio usada. No presente trabalho, foram usadas cápsulas com espessura de 0,508 mm 
que corresponde a $K=2,0728$ [22]. Pode se observar, então, que por esse método é possível determinar o valor do fator $r$, da razão de cádmio do monitor de fluxo e, em seguida, o valor de $s$ da reação de interesse usando a razão das atividades das amostras. Além disso, a razão de cádmio possibilita a determinação do fluxo térmico através da relação:

$$
\Phi_{t h}=\frac{\left(A_{S}-F_{C d} A_{C d}\right) R^{\prime}}{N_{0} \sigma_{0}(g+r s)\left(R^{\prime}-1\right)} \sqrt{\frac{4 T}{\pi T_{0}}}
$$

onde $A_{S}$ é a atividade saturada do monitor de fluxo descoberto, $A_{C d}$ é a atividade saturada do monitor de fluxo irradiado sob a cobertura de cádmio, $F_{C d}$ é um fator de correção para a razão de cádmio e $R^{\prime}$ é a razão de cádmio para um absorvedor ideal dada por:

$$
R^{\prime}=\frac{K}{r} \sqrt{\frac{T_{0}}{T}}
$$

\subsection{Atividade de um alvo irradiado por nêutrons}

O processo de captura de nêutrons consiste na integração de um nêutron a um núcleo atômico formando um novo núcleo em estado excitado e muitas vezes instável. Para alvos feitos de núcleos estáveis que, após a irradiação, resultam em núcleos radioativos, a variação em relação ao tempo do número de núcleos alvo $N_{0}$ e núcleos produto $N_{1}$ radioativos com constante de decaimento $\lambda_{1}$ é dada em notação matricial por: 


$$
\frac{d}{d t}\left[\begin{array}{c}
N_{0} \\
N_{1}
\end{array}\right]=\left[\begin{array}{cc}
-\hat{\sigma}_{1} \phi_{0} & 0 \\
\hat{\sigma}_{1} \phi_{0} & -\lambda_{1}
\end{array}\right]\left[\begin{array}{c}
N_{0} \\
N_{1}
\end{array}\right] \Rightarrow\left\{\begin{array}{c}
\frac{d N_{0}}{d t}=-\hat{\sigma}_{1} \phi_{0} N_{0} \\
\frac{d N_{1}}{d t}=\hat{\sigma}_{1} \phi_{0} N_{0}-\lambda_{1} N_{1}
\end{array}\right.
$$

onde $\hat{\sigma}_{1}$ é a secção de choque de absorção de nêutrons do núcleo alvo. Essas equações diferenciais têm como solução [27]:

$$
\begin{gathered}
N_{0}(t)=N_{0} e^{-\hat{\sigma}_{1} \phi_{0} t} \\
N_{1}(t)=\frac{N_{0} \hat{\sigma}_{1} \phi_{0}}{\lambda_{1}-\hat{\sigma}_{1} \phi_{0}}\left(e^{-\hat{\sigma}_{1} \phi_{0} t}-e^{-\lambda_{1} t}\right)
\end{gathered}
$$

Considerando que as secções de choque normalmente são da ordem de barns, o fluxo do reator de pesquisa como o usado é da ordem de $10^{13}$ nêutrons $/ \mathrm{cm}^{2} \mathrm{~s}$ e as irradiações têm um tempo de duração máxima da ordem $10^{5} \mathrm{~s}$, pode ser adotado que $N_{0}(t)=N_{0}$, logo a solução da equação (25) pode ser aproximada para:

$$
N_{1}(t)=\frac{N_{0} \hat{\sigma}_{1} \phi_{0}}{\lambda_{1}}\left(1-e^{-\lambda_{1} t}\right)
$$

Um dos fenômenos possíveis durante uma irradiação que pode mudar as condições de contorno do processo de captura de nêutron é o da múltipla captura de nêutrons, onde 0 núcleo produto de uma reação absorve, por sua vez, outro nêutron e assim por diante. A rigor, esse processo é sempre possível, mas a probabilidade de haver captura sucessiva de nêutrons normalmente é muito pequena, a ponto de poder ser desprezada para fins práticos. 
Porém, há exceções, quando a variação dos números de núcleos radioativos formados é dada por:

$$
\frac{d}{d t}\left[\begin{array}{l}
N_{0} \\
N_{1} \\
N_{2}
\end{array}\right]=\left[\begin{array}{ccc}
-\hat{\sigma}_{1} \phi_{0} & 0 & 0 \\
\hat{\sigma}_{1} \phi_{0} & -\left(\lambda_{1}+\hat{\sigma}_{2} \phi_{0}\right) & 0 \\
0 & \hat{\sigma}_{2} \phi_{0} & -\lambda_{2}
\end{array}\right]\left[\begin{array}{l}
N_{0} \\
N_{1} \\
N_{2}
\end{array}\right] \Rightarrow\left\{\begin{array}{c}
\frac{d N_{0}}{d t}=-\hat{\sigma}_{1} \phi_{0} N_{0} \\
\frac{d N_{1}}{d t}=\hat{\sigma}_{1} \phi_{0} N_{0}-\left(\lambda_{1}+\hat{\sigma}_{2} \phi_{0}\right) N_{1} \\
\frac{d N_{2}}{d t}=\hat{\sigma}_{2} \phi_{0} N_{1}-\lambda_{2} N_{2}
\end{array}\right.
$$

onde $\hat{\sigma}_{2}$ é a secção de choque do núcleo produto da primeira captura (considerada desprezível no processo de captura simples), $N_{2}$ é o número de núcleos radioativos formados pela dupla captura e com constante de decaimento $\lambda_{2}$. A solução para a primeira equação diferencial é dada em (26) e as duas seguintes são dadas por:

$$
\begin{gathered}
N_{1}(t)=\frac{N_{0} \hat{\sigma}_{1} \phi_{0}}{\lambda_{1}+\left(\hat{\sigma}_{2}-\hat{\sigma}_{1}\right) \phi_{0}}\left(e^{-\hat{\sigma}_{1} \phi_{0} t}-e^{-\left(\hat{\sigma}_{2} \phi_{0}+\lambda_{1}\right) t}\right) \\
N_{2}(t)=N_{0} \hat{\sigma}_{2} \hat{\sigma}_{1} \phi_{0}^{2}\left(\frac{e^{-\hat{\sigma}_{1} \phi_{0} t}}{\left[\lambda_{1}+\left(\hat{\sigma}_{2}-\hat{\sigma}_{1}\right) \phi_{0}\right]\left[\lambda_{2}-\hat{\sigma}_{1} \phi_{0}\right]}+\right. \\
\left.-\frac{e^{-\left(\hat{\sigma}_{2} \phi_{0}+\lambda_{1}\right) t}}{\left[\lambda_{1}+\left(\hat{\sigma}_{2}-\hat{\sigma}_{1}\right) \phi_{0}\right]\left[\lambda_{2}-\lambda_{1}-\hat{\sigma}_{2} \phi_{0}\right]}+\frac{e^{-\lambda_{2} t}}{\left[\lambda_{2}-\hat{\sigma}_{1} \phi_{0}\right]\left[\lambda_{2}-\lambda_{1}-\hat{\sigma}_{2} \phi_{0}\right]}\right)
\end{gathered}
$$

Após o término da irradiação, o número de núcleos alvos se mantém constante e os núcleos produto passam a obedecer a lei do decaimento exponencial, que pode ser escrito como:

$$
A\left(t_{e}\right)=A_{0, i} e^{-\lambda_{i} t_{e}}=\lambda N_{f, i} e^{-\lambda_{i} t_{e}}
$$


onde $A_{0, i}$ é a atividade do nuclídeo produto $i$ no fim da irradiação, $N_{f, i}$ é o número de núcleos formados ao longo da irradiação e $t_{e}$ é o tempo transcorrido após a irradiação, também denominado tempo de espera.

É possível calcular a atividade das fontes radioativas considerando a equação (30) em que o número de decaimentos, $N_{d}$, durante um certo tempo, $\Delta t$, é dado por:

$$
N_{d}=\int_{t}^{t+\Delta t} A(t) d t=\lambda N_{f} \int_{t}^{t+\Delta t} e^{-\lambda t_{e}} d t \Rightarrow N_{d}=N_{f} e^{-\lambda t_{e}}\left(1-e^{-\lambda \Delta t}\right)
$$

Porém o detector não é capaz de contar todos os decaimentos, então a relação entre a área $S_{\gamma}$ do pico observado no espectro gama correspondente a um fóton emitido pela fonte e o número de decaimentos é dado por:

$$
S_{\gamma}=\varepsilon_{\gamma} I_{\gamma} N_{d}
$$

onde $\varepsilon_{\gamma}$ e $I_{\gamma}$ são respectivamente a eficiência de pico e a probabilidade de emissão por decaimento correspondentes à energia do fóton. Dessa forma então, é possível calcular a atividade de uma amostra a partir da área obtida através de espectroscopia. 


\section{Capítulo 3:Procedimento Experimental}

\subsection{Materiais usados}

Os materiais usados como alvo para irradiações eram de alta pureza e podem ser classificados em dois tipos: monitores de fluxo e compostos de potássio.

\subsubsection{Monitores de fluxo}

As ligas metálicas de Au-Al usadas foram feitas pela Reactor Experiment Inc. e são padronizadas em forma de discos com $12,7 \mathrm{~mm}$ de diâmetro, 0,127(1) milímetros de espessura, aproximadamente $40 \mathrm{mg}$ de massa e com 99,9763\% de pureza onde 0,1143(1)\% é de ouro e o restante de alumínio. Este material produz uma perturbação desprezível no fluxo de nêutrons na posição de irradiação devido à baixa concentração de átomos de ouro e ao alumínio possuir uma secção de choque térmica baixa $(0,230(3)$ barns [28]), o que caracteriza um meio pouco absorvedor. O fluxo é obtido após a determinação da atividade gama do ${ }^{198} \mathrm{Au}$ induzida no monitor.

A reação ${ }^{197} \mathrm{Au}(\mathrm{n}, \gamma){ }^{198} \mathrm{Au}$ é usada como referência na área de análise por ativação de nêutrons. Sua secção de choque de absorção de nêutrons tem um comportamento $1 / v$ na região térmica. A secção de choque térmica de captura dessa reação é 98,65(9) barns [29] e a integral de ressonância 1560(40) barns [28]. O núcleo residual de ${ }^{198} \mathrm{Au}$ decai para ${ }^{198} \mathrm{Hg}$ por meio do decaimento $\beta^{-}(n \rightarrow p+e+\bar{v})$ com meia vida de 2,6943(8) dias, após o qual é emitido um fóton de $411,8044(11) \mathrm{keV}$, cuja probabilidade de emissão por decaimento é $95,57(47) \%[30]$ 


\subsubsection{Compostos com potássio}

Os compostos químicos adotados foram selecionados a partir de um conjunto de compostos possíveis de serem irradiados. Os critérios de seleção incluíram facilidade no manuseio, proporção de átomos de potássio no composto, estabilidade do material e possíveis produtos radioativos indesejados (contaminantes). Os elementos eleitos foram o nitrato de potássio $\left(\mathrm{KNO}_{3}\right)$ e o carbonato de potássio $\left(\mathrm{K}_{2} \mathrm{CO}_{3}\right)$, ambos em forma de pó.

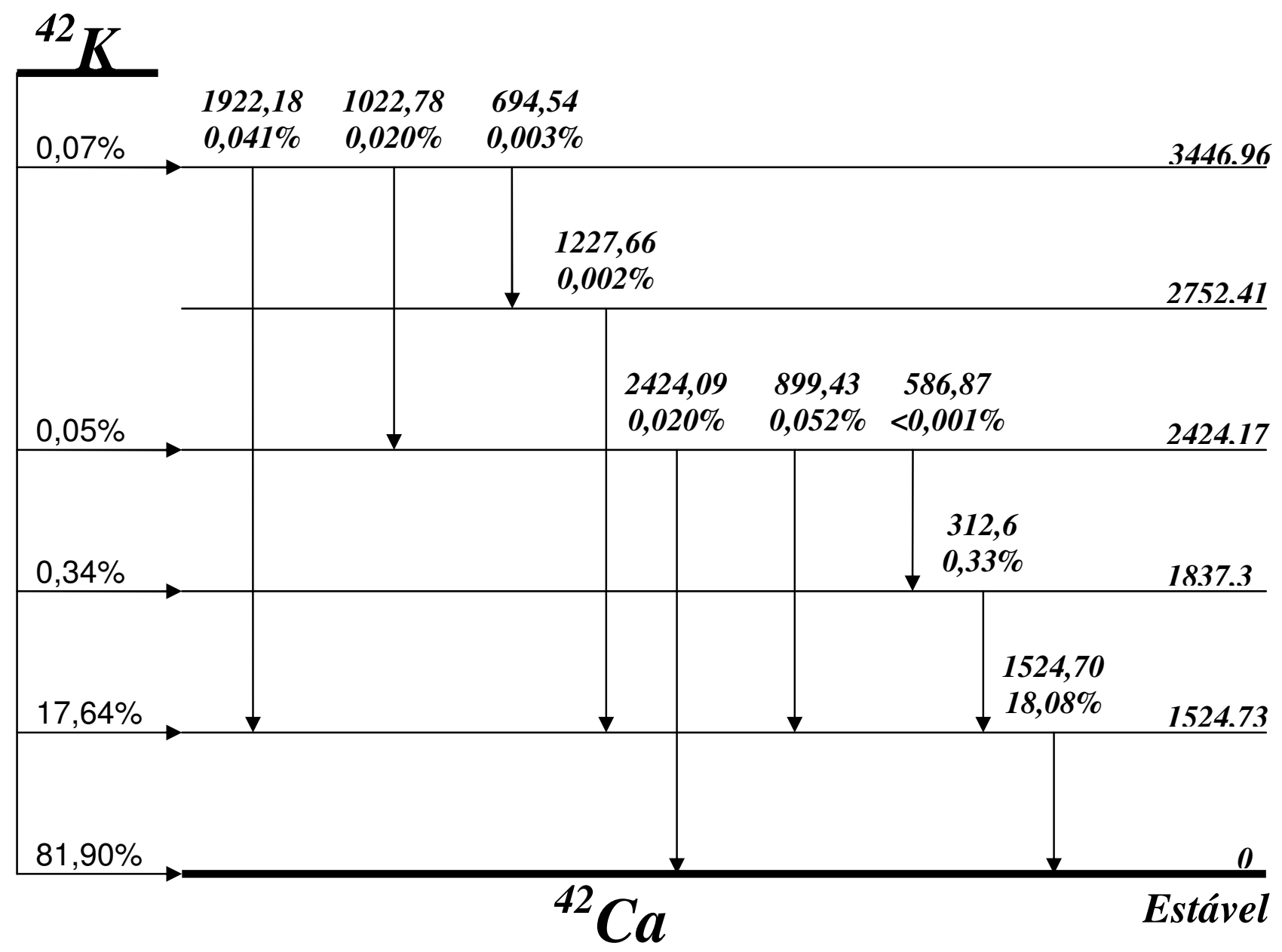

Figura 1: Esquema simplificado do decaimento do ${ }^{42} \mathrm{~K}$. As energias das transições e dos níveis estão em keV.

O núcleo de ${ }^{42} \mathrm{~K}$ decai para ${ }^{42} \mathrm{Ca}$ por meio de um decaimento $\beta^{-}$com meia vida de 12,360(12) horas [31] emitindo fótons $\gamma$ de 1524,6(3) keV e 312,60(25) keV, cujas 
probabilidades de emissão por decaimento são $18,08(9) \%$ e $0,33(11) \%$, respectivamente. $O$ esquema de decaimento está mostrado na figura 1.

\subsubsection{Preparação das amostras}

Os alvos usados nas irradiações foram nitrato de potássio e carbonato de potássio em pó, comprimidos em pastilhas cilíndricas visando manter o formato da amostra ao longo do processo experimental. A compressão dos compostos para a irradiação de teste foi realizada no laboratório de Dosimetria do Departamento de Física Nuclear do IFUSP com uma prensa MID 15T/130 da Schwing Siwa associada a um dispositivo de aço denominado "pastilhador", que se compõe basicamente de duas bases e pistões que se encaixam a orifícios da base superior onde se coloca o pó que, depois de prensado, resulta em pastilhas com diâmetro de $5 \mathrm{~mm}$ e altura variável entre 1 e $3 \mathrm{~mm}$. Para as irradiações seguintes, foi utilizada uma prensa 00-25 da Beckman do Laboratório de Alvos do Departamento de Física Nuclear do IFUSP associada a um pastilhador de aço inox projetado e construído durante o presente trabalho para se obter pastilhas com diâmetro de $6 \mathrm{~mm}$ e suportar pressões de até $170 \times 10^{3} \mathrm{~kg} / \mathrm{m}^{2}$, apresentado na figura 2 .
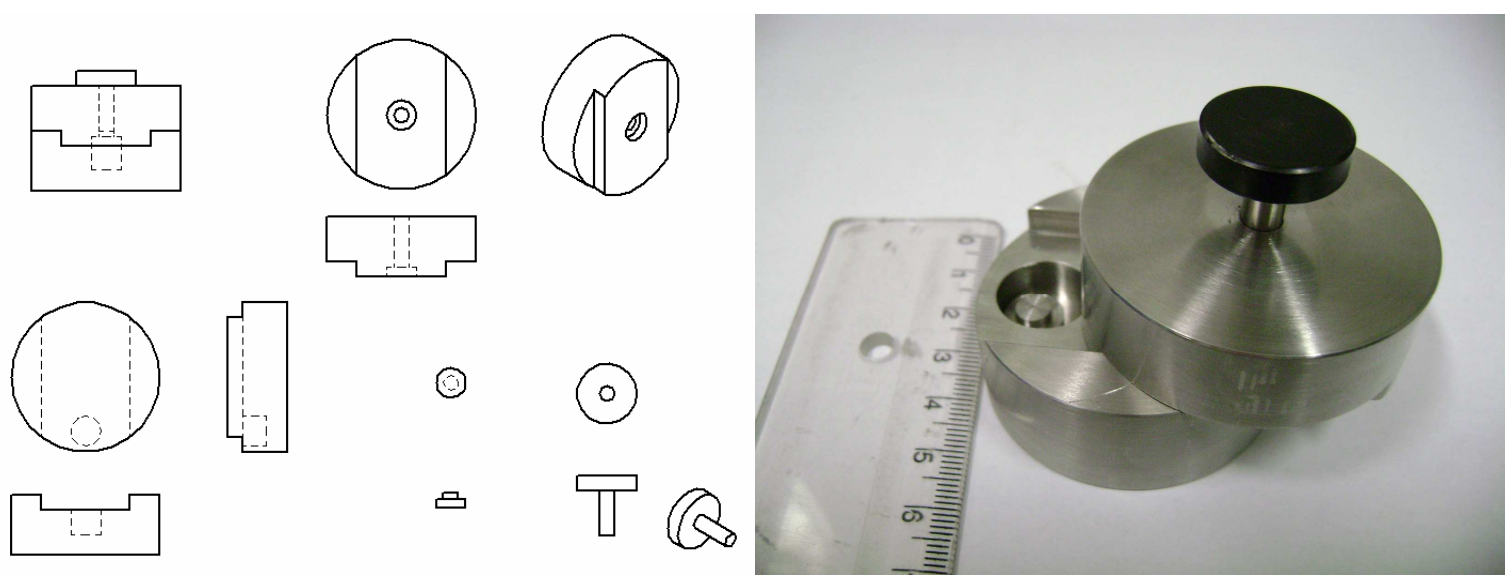

Figura 2: Esquema de peças e fotografia do pastilhador. 
As folhas de Au-Al foram cortadas em pedaços de tamanhos convenientes ao dispositivo de irradiação de forma que cada disco foi cortado em quatro pedaços desiguais com uma tesoura comum. Então as folhas foram limpas com álcool etílico seguido de um banho em água destilada e finalmente secas com lenços de papel. Esse processo de limpeza é necessário para prevenir que resíduos na superfície das folhas sejam ativados durante a irradiação e possam interferir nas medidas de atividade.

Os materiais irradiados, nitrato de potássio e carbonato de potássio, apresentam $39 \%$ e $57 \%$ de potássio natural em massa, respectivamente [32]. O isótopo ${ }^{41} \mathrm{~K}$ é estável e representa $6,7 \%$ da composição do potássio natural; portanto, considerando que o material utilizado era de alta pureza, por volta de $3 \%$ do alvo era ${ }^{41} \mathrm{~K}$. Os valores de secção de choque apresentados na bibliografia para $0{ }^{41} \mathrm{~K}$ são da ordem de 1,5 barn. Portanto, foi estimado a partir de valores típicos de fluxo do reator IEA-R1m que as pastilhas deveriam ter massas da ordem de dezenas de miligramas para que o produto da reação ${ }^{41} \mathrm{~K}(\mathrm{n}, \gamma)^{42} \mathrm{~K}$ fosse observado.

A massa de todo o material irradiado foi medida separadamente, antes que ele fosse acondicionado, com uma balança analítica comercial da marca Micronal do tipo Mettler H20T com precisão de 0,05 mg e com uma balança digital da marca Sartorius modelo MC21S com precisão de 0,02 mg.

Os valores obtidos nas pesagens dos alvos foram corrigidos considerando o empuxo que o ar exerce em cada corpo. Segundo o Princípio de Arquimedes, o valor real da massa $m$ de um corpo é dada pela relação:

$$
m=\frac{m_{e f}^{2}}{m_{e f}-\rho_{a r} V}
$$


onde $m_{e f}$ é a massa medida na balança, $\rho_{a r}=1,1 \mathrm{~g} / \mathrm{cm}^{3}$ é a densidade do ar e $V$ é o volume do corpo pesado. As correções nas massas são da ordem de $0,1 \%$, significativas considerando que as incertezas da balança são da ordem de $0,01 \%$.

As cinco primeiras irradiações contavam com um monitor de fluxo próximo a cada pastilha e ambos foram acondicionados isoladamente dentro de um invólucro de polietileno selado para facilitar o manuseio no preparo do dispositivo de irradiação e evitar possíveis contaminações e/ou perda de material após a irradiação; depois disso todo o material foi limpo com álcool etílico e em seguida embrulhado em papel alumínio com espessura da ordem de 0,05 mm. Já as duas últimas irradiações consistiam apenas na pastilha de nitrato de potássio envolvida por uma folha de alumínio, dado que nestas duas últimas pretendia-se apenas observar o produto da reação ${ }^{41} \mathrm{~K}(\mathrm{n}, \gamma){ }^{42} \mathrm{~K}(\mathrm{n}, \gamma){ }^{43} \mathrm{~K}$.

\subsection{Irradiações realizadas}

As irradiações foram feitas com as pastilhas com seus respectivos monitores de fluxo próximas ao núcleo do reator de pesquisas IEA-R1 do IPEN-CNEN/SP durante um tempo determinado. Antes de serem inseridos na piscina do reator, os alvos foram colocados dentro de cilindros de alumínio ("coelhos") e em seguida selados, com exceção da segunda irradiação cujo coelho era feito de plástico, por se tratar de uma irradiação no sistema de tubos pneumáticos. Ao longo de todo o trabalho foram irradiadas oito pastilhas de nitrato de potássio e uma de carbonato de potássio; os valores das grandezas relevantes em cada irradiação são apresentados na tabela 2. 
Tabela 2: Valores medidos de massas e tempos relevantes nas irradiações realizadas.

\begin{tabular}{|c|c|c|c|c|c|c|}
\hline \multirow[b]{2}{*}{ Irradiação } & \multicolumn{2}{|c|}{ Massa da pastilha (mg) } & \multicolumn{2}{|c|}{ Massa da liga (mg) } & \multicolumn{2}{|c|}{ Tempo } \\
\hline & Nua & Sob cádmio & Nua & Sob cádmio & $\begin{array}{l}\text { irradiação } \\
\text { (minutos) }\end{array}$ & $\begin{array}{l}\text { espera } \\
\text { (horas) }\end{array}$ \\
\hline $1 \mathrm{a}$ & $113,94(1)$ & - & $3,682(10)$ & - & $13(6)$ & 8 \\
\hline $2 a$ & $388(3)$ & - & $3,682(10)$ & $5,78(10)$ & $30,0(2)$ & 2 \\
\hline $3 a$ & $32,76(1)$ & $107,66(1)$ & $8,854(10)$ & $7,848(10)$ & $60,0(12)$ & 21 \\
\hline $4 a$ & - & $40,13(1)$ & - & $8,854(10)$ & $60,0(12)$ & 20 \\
\hline $5 a$ & $72,00(1)$ & $54,11(1)$ & $4,19(2)$ & $7,53(2)$ & $60,0(12)$ & 20 \\
\hline $6 a$ & $104,93(1)$ & - & - & - & $720(14)$ & 87 \\
\hline $7 a$ & $103,71(1)$ & - & - & - & $2880(60)$ & 130 \\
\hline
\end{tabular}

Algumas irradiações contaram com invólucros de cádmio padronizados que consistiam em duas peças com $0,5 \mathrm{~mm}$ de espessura formando um cilindro com $3 \mathrm{~mm}$ de altura e $5 \mathrm{~mm}$ de raio. A distância entre as amostras nuas e as envolvidas por cádmio nos dispositivos de irradiação variou de 3 a $5 \mathrm{~cm}$; essa distância é necessária para que a depressão no fluxo de nêutrons causada pela presença do cádmio não interfira na medida das amostras nuas, porém essa distância deve ser pequena para que se possa supor que o valor do fluxo médio ao redor de todo o dispositivo seja o mesmo[19].

A primeira irradiação teve como objetivo fazer um teste do procedimento experimental adotado e fazer uma medida preliminar de secção de choque efetiva, por isso contou apenas com a pastilha e o monitor de fluxo.

A segunda irradiação teve como objetivo testar a utilização de um composto químico com maior teor de potássio, o carbonato de potássio. O peso dessa pastilha foi medido duas vezes com um intervalo de um dia e os valores foram 388,9(5) mg na primeira medida e 418,39(5) mg na segunda. Pelo fato do carbonato de potássio ser um composto 
higroscópico, essa diferença entre as duas pesagens foi interpretada como absorção de água do ar pela pastilha. Considerando a variação da massa e o tempo entre as medidas foi estimado um valor para a incerteza dessa massa, como pode ser observado na $2^{\underline{a}}$ coluna da tabela 2. Essa irradiação foi realizada na Estação de Irradiação 4, que utiliza um sistema pneumático para posicionamento das amostras próximo ao núcleo do reator. As amostras foram fixadas dentro do coelho de polietileno com um pedaço de espuma para evitar possíveis movimentos dos materiais e manter cápsula de cádmio a aproximadamente $5 \mathrm{~cm}$ de distância do material nu.

Nessas duas primeiras irradiações foi possível observar a reação ${ }^{41} \mathrm{~K}(\mathrm{n}, \gamma){ }^{42} \mathrm{~K}$ e foi possível tirar algumas conclusões quanto ao método mais conveniente de irradiação: o carbonato de potássio se tornou úmido rapidamente, dificultando seu manuseio para confecção de pastilhas e prejudicando a confiança na medida da massa; outro fator relevante nas irradiações foi que não há limite de tempo para as irradiações nas prateleiras próximas ao núcleo do reator, além disso, o fluxo é superior ao alcançado na estação de irradiação que possui um limite de tempo de 30 minutos. Dadas essas observações, foi descartado o uso do carbonato de potássio assim como o da estação de irradiação. As irradiações seguintes foram realizadas nas prateleiras próximas ao caroço do reator e sendo o material escolhido o nitrato de potássio.

A terceira irradiação teve o objetivo de medir a secção de choque térmica e a integral de ressonância da reação ${ }^{41} \mathrm{~K}(\mathrm{n}, \gamma){ }^{42} \mathrm{~K}$ através do método da diferença de cádmio. A cápsula de cádmio contendo uma das pastilhas, acompanhada de monitor de fluxo, e a outra pastilha, acompanhada de um segundo monitor de fluxo, foram dispostas dentro do coelho com uma distância de aproximadamente $3 \mathrm{~cm}$ entre elas, cujo esquema é mostrado na figura 3. 


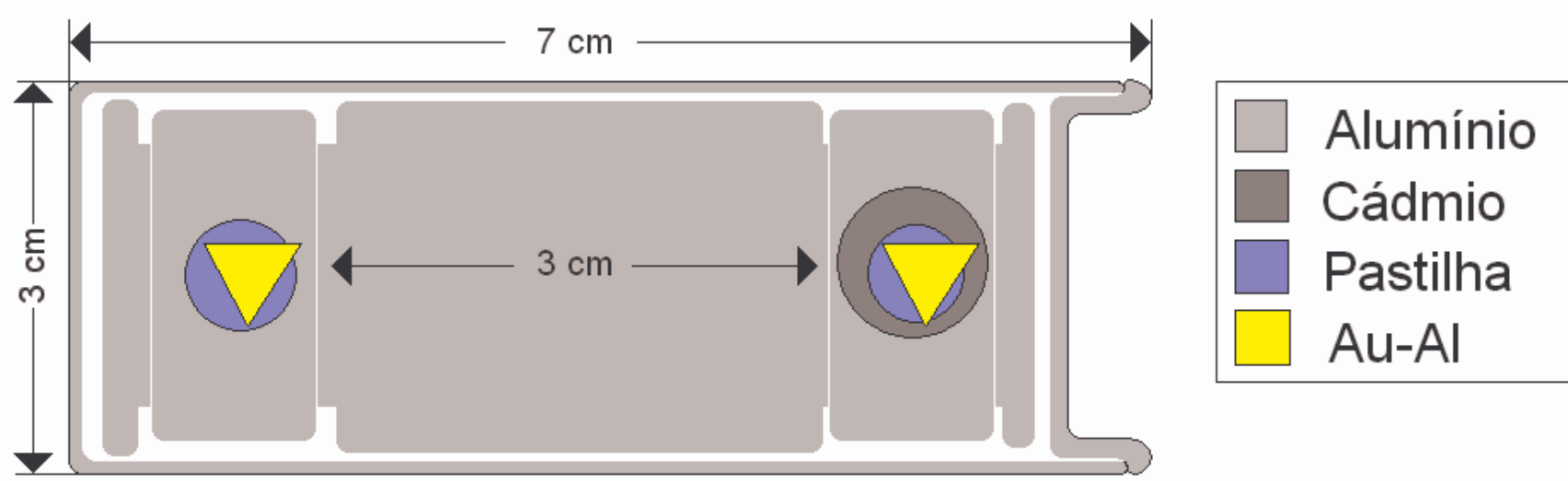

Figura 3: Esquema da posição dos alvos no dispositivo de irradiação.

A quarta irradiação teve como objetivo confirmar os resultados da terceira irradiação, então foi irradiado pelo mesmo tempo um dispositivo idêntico ao anterior mas com as massas dos alvos diferentes, devido a confecção dos mesmos não permitir a reprodução do valor das massas. Porém a água da piscina do reator entrou no coelho e fez com que os invólucros das pastilhas grudassem com os invólucros dos monitores de fluxo. O conjunto que estava no interior do cádmio foi separado, mas o que foi irradiado sem cádmio foi destruído na tentativa de separação dos alvos.

Como a quarta irradiação não alcançou os objetivos pretendidos, foi realizada então uma quinta irradiação com mesmo tempo de duração das duas anteriores e com mesmo esquema de disposição dos alvos, mas com uma folha adicional de alumínio entre cada pastilha e monitor para evitar o acidente ocorrido na quarta irradiação.

As duas últimas irradiações tiveram como objetivo observar a reação ${ }^{41} \mathrm{~K}(\mathrm{n}, \gamma){ }^{42} \mathrm{~K}(\mathrm{n}, \gamma){ }^{43} \mathrm{~K}$, por isso tiveram tempos de irradiação bem maiores que as anteriores. Essas irradiações não foram acompanhadas de monitores de fluxo, dado que o objetivo não era o de determinar a secção de choque da reação ${ }^{42} \mathrm{~K}(\mathrm{n}, \gamma){ }^{43} \mathrm{~K}$. 


\subsection{Descrição do sistema de detecção}

Para observar a radiação gama foram utilizados detectores que consistem em cristais semicondutores sob alta tensão. Semicondutores são materiais cujos elétrons preenchem todas os estados de energia ligados possíveis, formando a chamada banda de valência, e para deixarem de participar das ligações covalentes entre os átomos, se tornando um elétron de condução, necessitam de pouca energia, de forma que em alguns casos até mesmo a energia térmica é suficiente (para evitar isso tais detectores são mantidos a baixas temperaturas). Quando um elétron do semicondutor migra para a banda de condução ele deixa um lugar vago, denominado buraco, que pode ser considerado como portador de carga positiva; a combinação desses fenômenos é chamada de par elétron-buraco.

Os fótons depositam sua energia ou parte dela no cristal criando pares elétronsburacos. Os elétrons que migram para a banda de condução dessa forma são altamente energéticos e perdem sua energia criando outros pares elétrons-buracos. $O$ processo de detecção consiste em coletar esses pares elétrons-buracos que são criados em quantidade proporcional à energia depositada pelo fóton ao longo do cristal. Por fim, o resultado da interação do fóton com o detector é um pulso elétrico com tensão proporcional à energia depositada pelo fóton na interação; caso o fóton tenha sido totalmente absorvido pelo detector, o pulso será proporcional à energia do fóton.

Detectores de germânio hiper puro (HPGe - High Purity Germanium) consistem basicamente em um monocristal de germânio sob alta tensão com um furo em uma das bases onde se encaixa uma barra cilíndrica de cobre, cuja extremidade oposta fica mergulhada em nitrogênio líquido para manter o cristal a baixa temperatura; essa barra é chamada de dedo frio. O cristal é também conectado a um sistema de amplificação de pulsos resultantes da coleta de cargas no cristal. Todo esse aparato fica encapsulado em 
um cilindro de alumínio com conectores para os cabos de tensão e comunicação com o amplificador e uma abertura para o dedo frio ficar mergulhado em nitrogênio dentro de um dewar, como mostrado na figura 4.
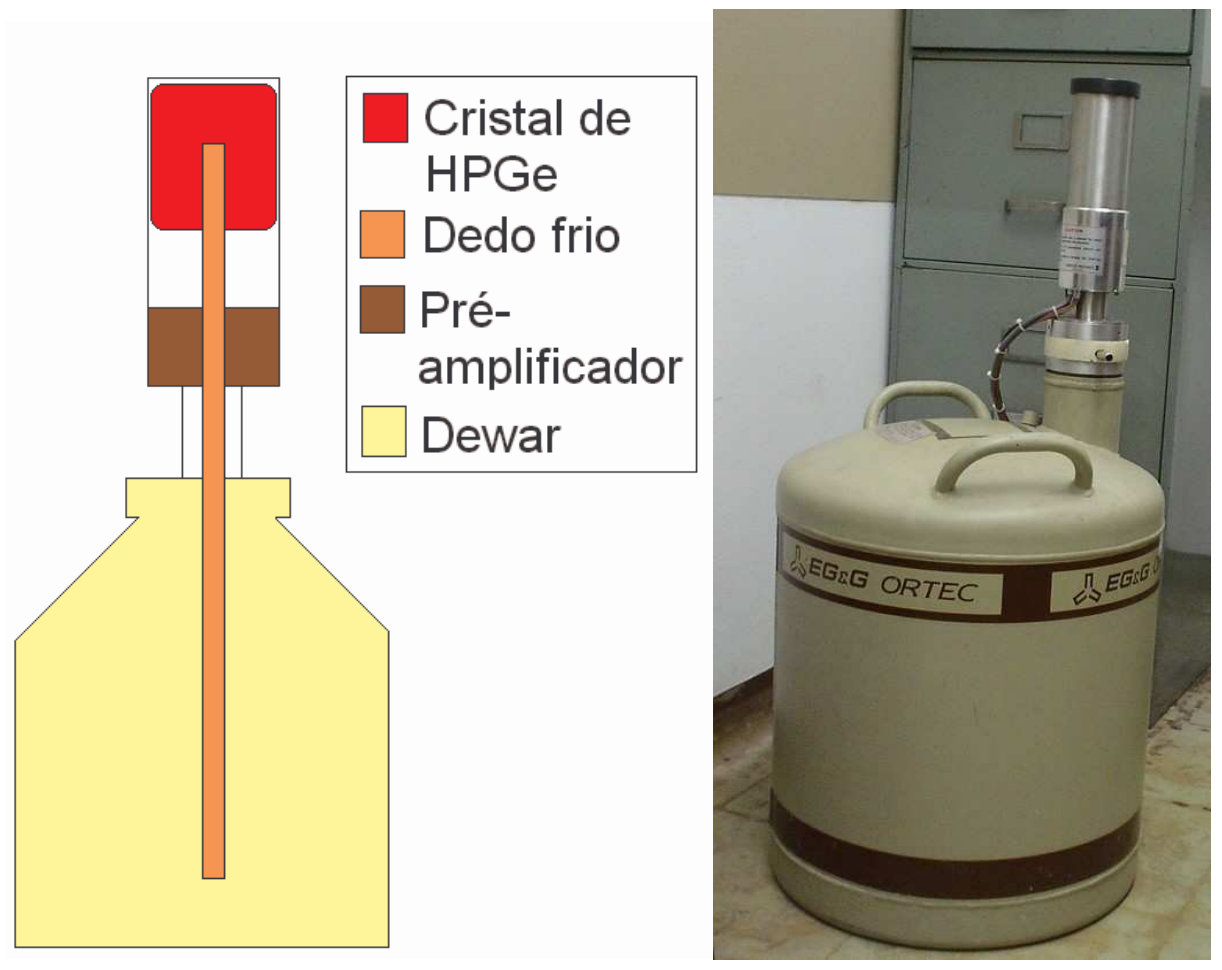

Figura 4: Esquema e fotografia de um detector HPGe com eixo do cristal na vertical.

Foram utilizados 3 detectores de HPGe diferentes para as medidas: dois da marca ORTEC com cristais de $163 \mathrm{~cm}^{3}$ de volume sensível e uma camada morta de 0,7 mm [33], sob tensão de $2 \mathrm{kV}$, sendo um com eixo vertical (nomeado nesse trabalho de detector 1) e outro com eixo horizontal (detector 2); o terceiro deles da marca EURISYS MEASURES tipo EGC45-200-TR com um cristal de $196 \mathrm{~cm}^{3}$ de volume sensível [34], sob tensão de $-5 \mathrm{kV}$ com eixo da cápsula na horizontal (detector 3 ).

Todas as medidas foram realizadas dentro de blindagens montadas com blocos de chumbo $\left(5 \times 10 \times 20 \mathrm{~cm}^{3}\right)$ e chapas de ferro. O objetivo dessas blindagens é diminuir a interferência da radiação natural do ambiente nas medidas. 
Os sistemas de detecção como um todo consistem então em detectores conectados a módulos eletrônicos acoplados a CAMACs (Computer Automated Measurement and Control) que por sua vez estão conectados a micro computadores para armazenar e analisar os espectros obtidos, como mostrado na figura 5.

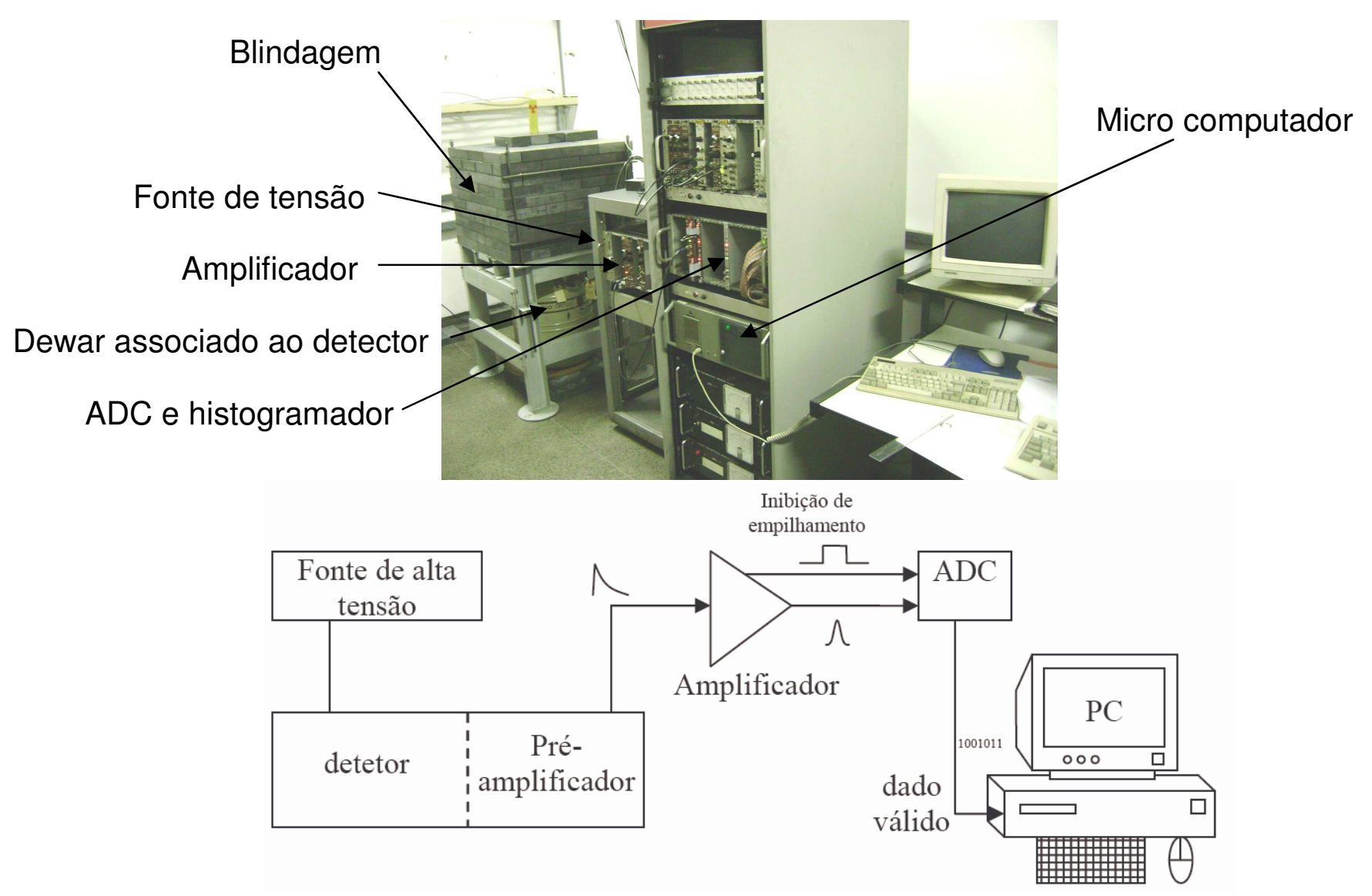

Figura 5: Fotografia e esquema [35] do sistema para medida da radiação gama com detector HPGe.

Os módulos eletrônicos usados foram: fonte de tensão, amplificador ORTEC 572, um conversor analógico-digital ORTEC ADC114 e histogramador HM413 que armazena os dados em 16000 canais. O microcomputador utilizado na aquisição é um IBMPC. Por meio de uma interface desenvolvida no laboratório [36] é possível programar o sistema de aquisição de forma a controlar o tempo de duração de cada medida, o número de medidas, o intervalo entre as medidas e o local a serem armazenados os espectros. 
Para realizar as medidas, as fontes radioativas são colocadas em suportes rígidos com geometria reprodutível, mostrada na figura 6. As distâncias em que as fontes foram medidas são eleitas com base no número de contagens que se pretende obter considerando a taxa de decaimento das amostras, o limite da taxa de contagem que o detector pode discriminar e minimizar a correção por efeito de soma, assim como o tempo morto da aquisição de dados.

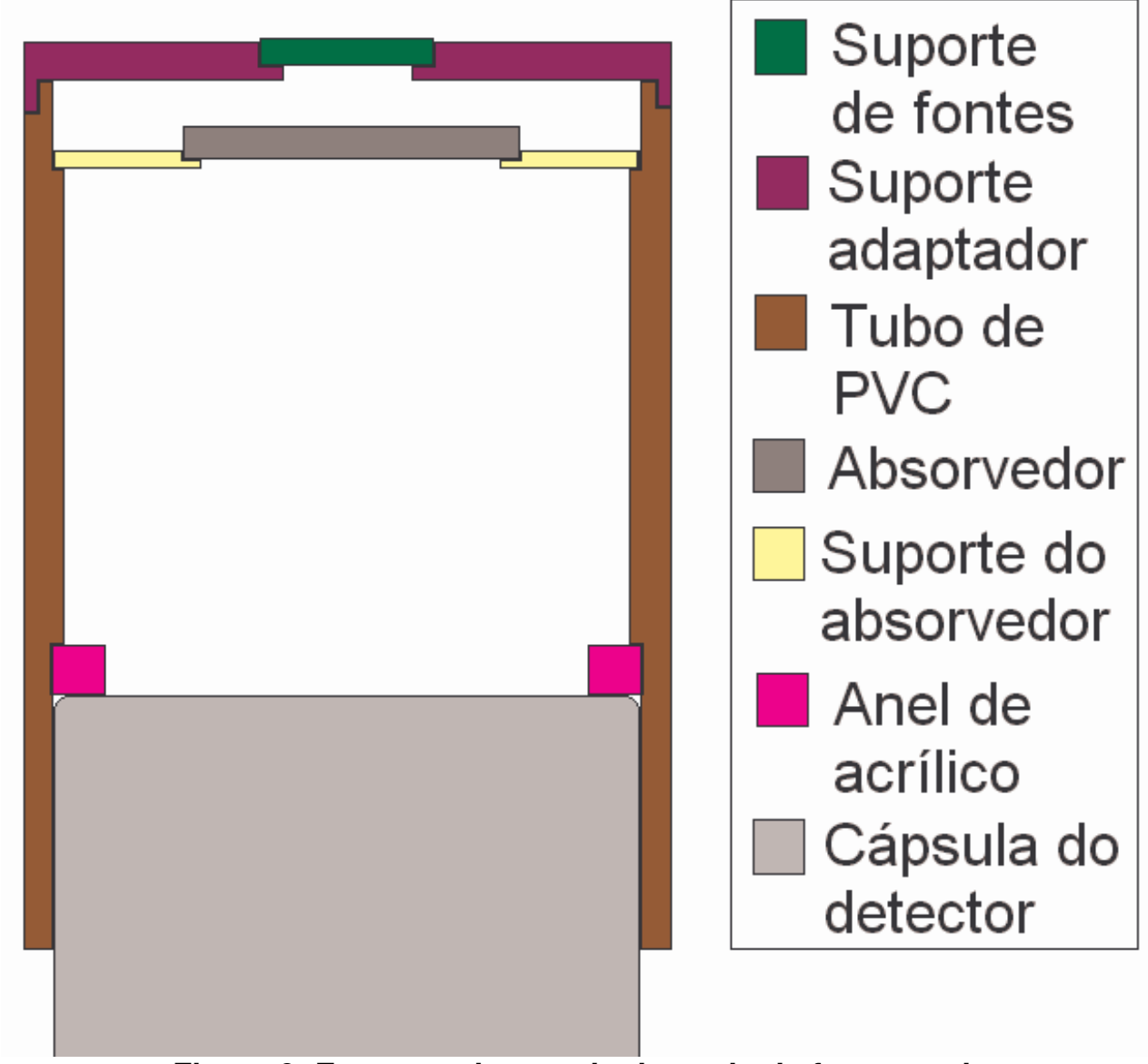

Figura 6: Esquema do arranjo de apoio de fonte usado.

A distância fonte-detector deve se manter constante ao longo das medidas com precisão de décimo de milímetro [37], então foram construídos dispositivos de apoio de fontes que posicionem o centro das fontes de calibração no mesmo ponto (já que existem 
diferentes formatos) e na mesma posição que as fontes a serem medidas; esses suportes são apresentados na figura 7.

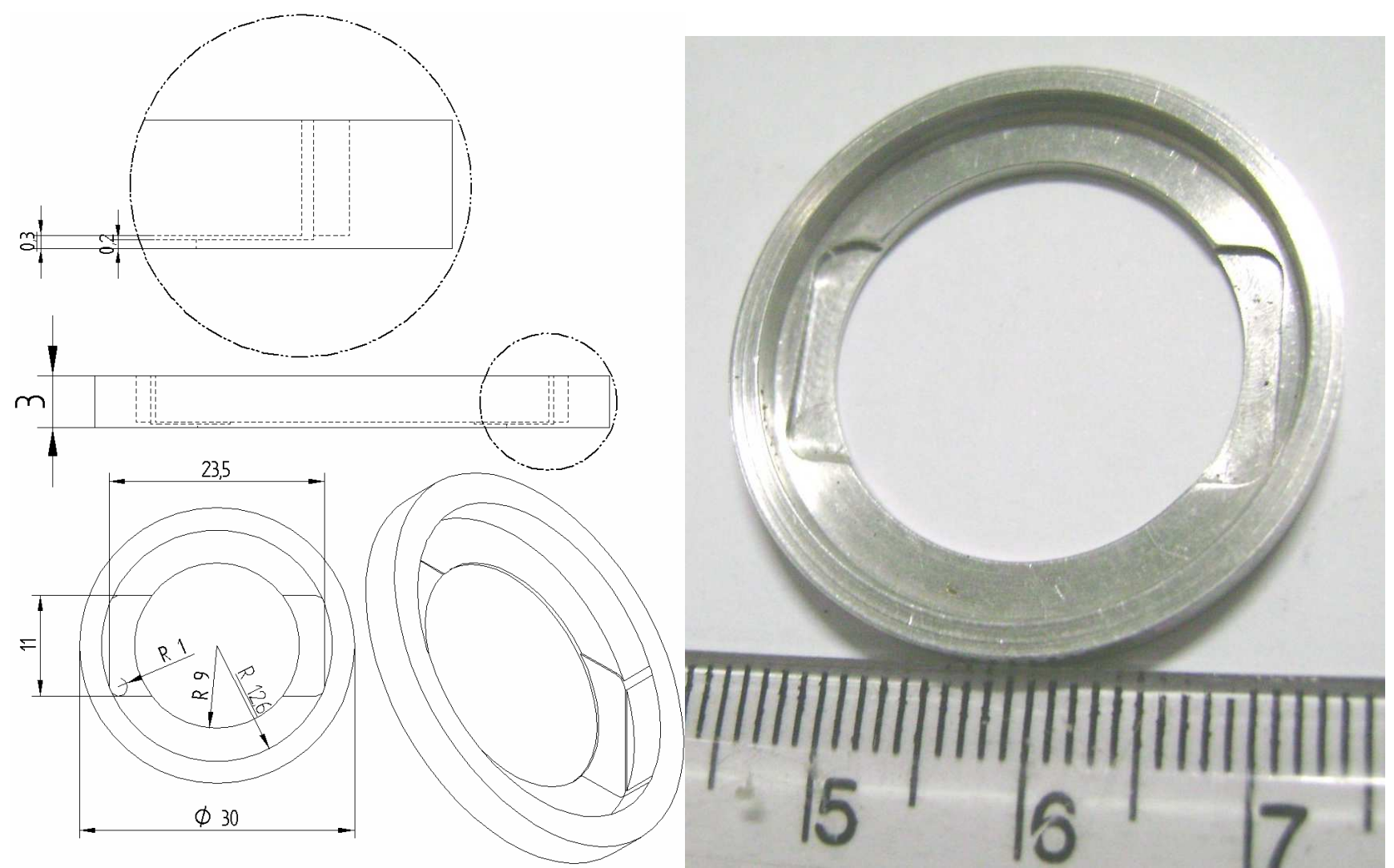

Figura 7: Esquema e fotografia dos suportes de fontes projetados e construídos para realizar as medidas.

\subsection{Características dos espectros gama}

Os raios gama interagem com o detector sendo absorvidos ou espelhados pelo cristal de germânio sob tensão. A figura 8 mostra um gráfico dos coeficientes de absorção para cada um dos três processo principais de atenuação de um feixe de raios gama no Germânio por cada uma dessas formas de interação. O resultado dessa interação é observado no espectro gama. 


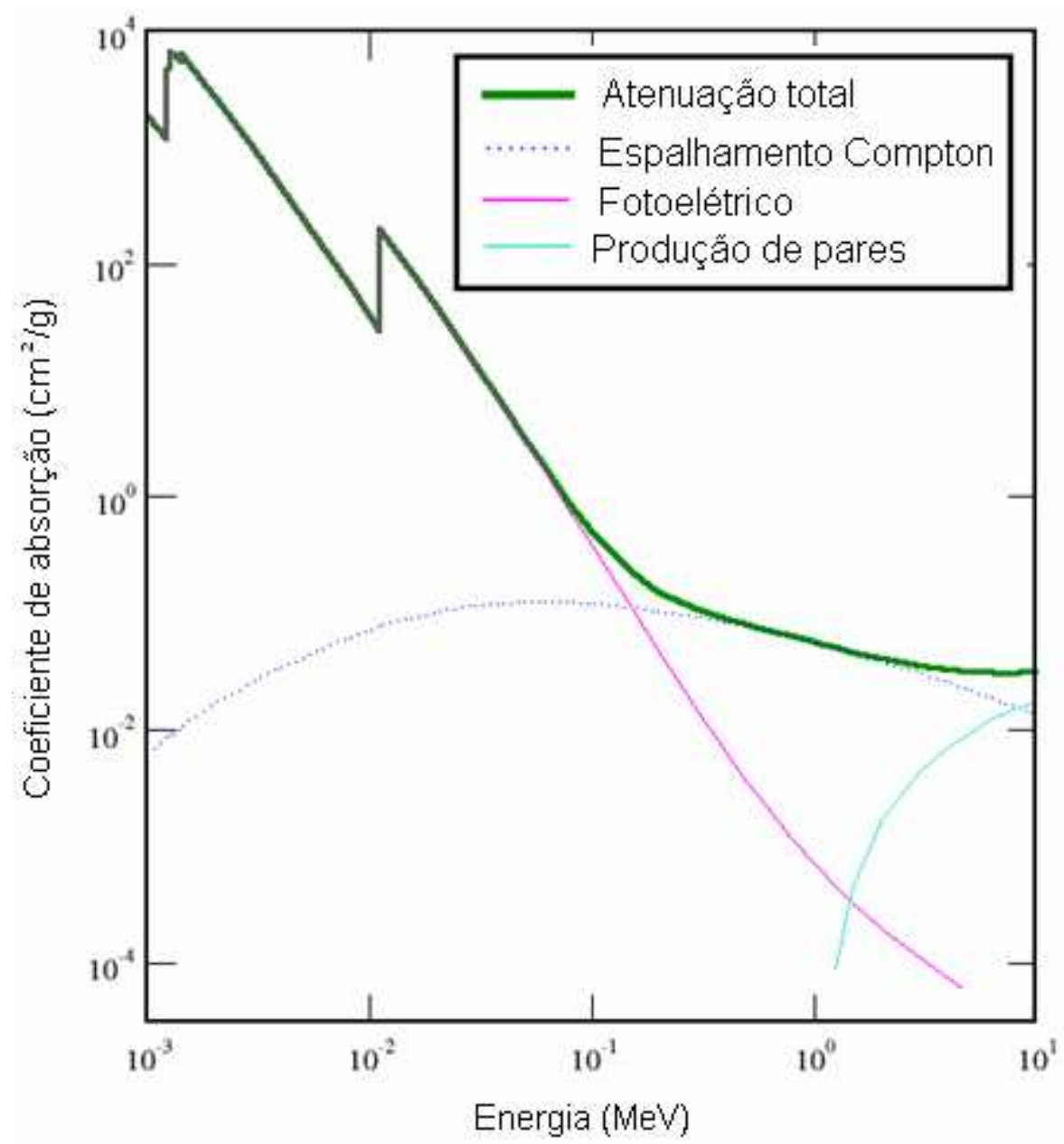

Figura 8: Coeficientes de absorção para diferentes formas de interação de raios gama com o Germânio [38]

O processo de detecção de fótons gama com detectores HPGe pode ser descrito em poucas palavras como a identificação das energias dos fótons que interagem com o cristal de germânio por meio dos pulsos que o detector processa. Como a tensão de saída do préamplificador é proporcional à energia depositada pelo fóton detectado, é possível fazer histogramas de pequenas faixas de valores de tensão, chamados espectros gama, e associar as estruturas observadas nos espectros a fenômenos físicos.

Quando toda a energia do fóton é depositada no cristal, resulta em uma contagem no canal correspondente à energia do fóton. Então, dependendo da intensidade de fótons de certa energia, é possível observar no espectro gama um pico de contagens com forma 
gaussiana ou aproximadamente gaussiana, devido o processo de detecção estar sujeito a um número muito grande de pequenas flutuações; esse pico é chamado de pico de absorção total de energia. Considerando a posição dos picos no espectro e o número de contagens contidos neles é possível inferir sobre suas energias e probabilidades de emissão por decaimento através de comparações com fontes padrão de radiação.

Pode haver casos em que o pico observado não corresponde a um tipo de fóton detectado, mas sim a dois ou mais fótons detectados ao mesmo tempo, resultando em um pico na posição correspondente à soma das energias dos diferentes fótons detectados ao mesmo tempo, denominado pico soma.

Outra estrutura que se observa no espectro gama é a borda Compton, que corresponde ao espalhamento Compton dos fótons nos elétrons do cristal. Neste fenômeno, os fótons não depositam totalmente sua energia no cristal, dando origem a contagens abaixo da região do pico com uma distribuição característica.

Para fótons com energia maior que 1,022 MeV é possível a observação no espectro gama do fenômeno de produção de pares elétron-pósitron por meio da presença de picos correspondendo a energias menores que a do pico de absorção total de energia por diferenças de múltiplos de 0,511 MeV. Esses picos ocorrem porque após a criação do par e depósito de sua energia no cristal, o elétron é recolhido como carga na banda de condução e o pósitron se aniquila com um elétron dando origem a dois fótons de 0,511 MeV; se um desses fótons sai do detector sem interagir, é contado um fóton com energia 0,511 MeV menor que o fóton original, dando origem ao pico de primeiro escape; os casos em que os dois fótons saem do detector sem interagir dão origem ao pico do segundo escape. Por outro lado, quando o par elétron-pósitron é criado fora do cristal pode ocorrer de um dos 
fótons de aniquilação ser detectado, resultando então em uma contagem para um pico com energia de $0,511 \mathrm{MeV}$.

A junção de todas essas estruturas resulta em espectros com muita informação cuja análise não é trivial. Há também fenômenos que não foram descritos acima, devido a natureza do presente trabalho, mas apresentam estruturas de muita relevância em alguns casos. A figura 9 exemplifica as estruturas comentadas acima para uma fonte de calibração de ${ }^{60} \mathrm{Co}$ mostra a resolução obtida com o sistema de detecção utilizado.

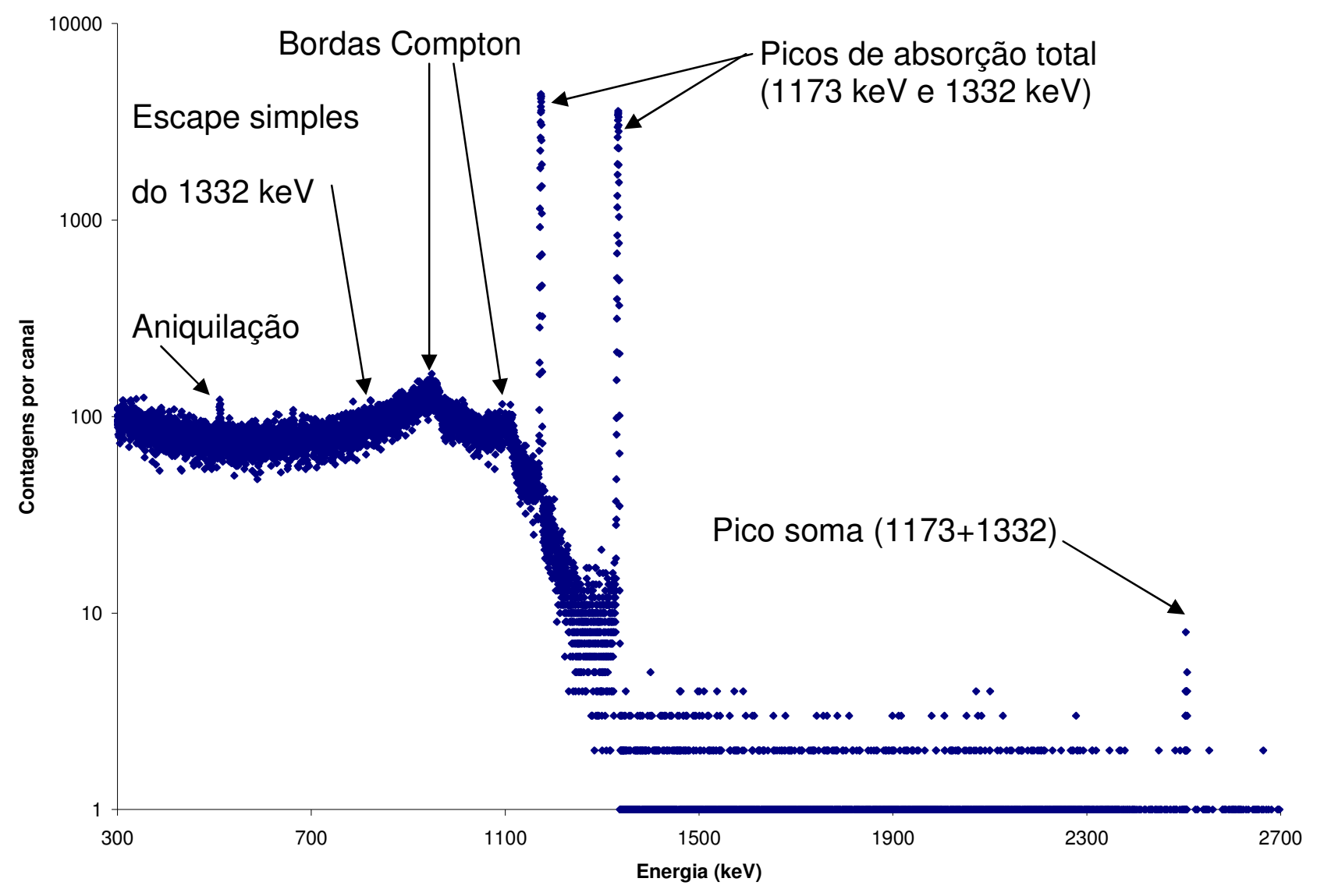

Figura 9: Espectro gama do ${ }^{60} \mathrm{Co}$ com resolução de $18 \mathrm{keV} /$ canal.

\subsection{Medidas realizadas}

A atividade das pastilhas irradiadas foi determinada por meio de séries de 1 a 30 medidas com tempos de 1800 a 3600 s. A distância entre a fonte e a superfície da cápsula 
do detector variou de 2 a $15 \mathrm{~cm}$; nas medições de cada irradiação foi adotada uma distância conveniente, na qual a taxa de detecção estivesse abaixo de 30 mil contagens por segundo. Um exemplo de espectro obtido nessas medidas é mostrado na figura 10.

Para as cinco primeiras irradiações foram obtidos novos espectros após 2 a 7 dias da medida inicial, com o objetivo de confirmar a identificação de alguns contaminantes e tentar observar o produto da reação ${ }^{41} \mathrm{~K}(\mathrm{n}, \gamma){ }^{42} \mathrm{~K}(\mathrm{n}, \gamma)^{43} \mathrm{~K}$.

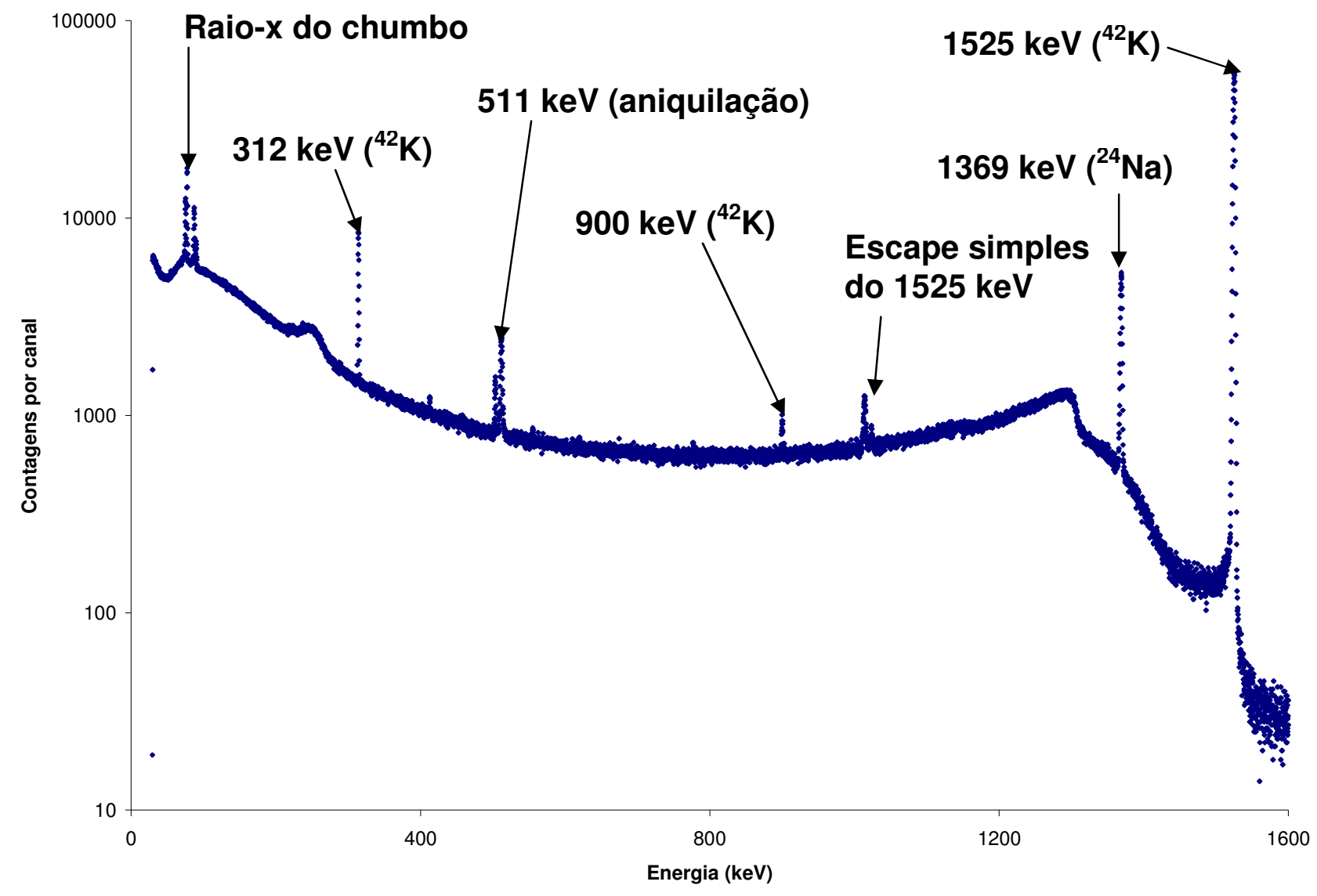

Figura 10: Espectro da atividade gama induzida por nêutrons numa pastilha de KNO3. Tempo de medida de 1 hora e $14 \mathrm{~cm}$ de distância fonte-detector com resolução de 0,17 keV/canal.

\subsection{Escolha de absorvedores}

Como visto na secção 3.1 .2 , o ${ }^{42} \mathrm{~K}$ decai pela emissão de elétrons com energia máxima de 3525,4 keV. Elétrons nessa faixa de energia possuem grande probabilidade de 
interagir com a matéria, portanto uma parte significativa deles acaba sendo barrada ou perde grande parte de sua energia no percurso da fonte até o cristal do detector. Por esses motivos o efeito da radiação beta pode ser desprezado em muitas medidas de espectroscopia gama quando os elétrons possuem energias baixas. Mas, dado que um fóton gama proveniente de um determinado nível de energia é emitido num intervalo de tempo muito curto após a emissão do beta característico para esse nível, há uma probabilidade significativa de ambas as partículas serem detectadas ao mesmo tempo. Assim, após a segunda irradiação foram feitas medidas com altas taxas de contagens e o efeito da soma do fóton de interesse com a radiação beta ficou evidente no espectro, como mostrado na figura 11. Então, com o intuito de evitar esse efeito foram realizados experimentos para escolher o absorvedor mais conveniente.

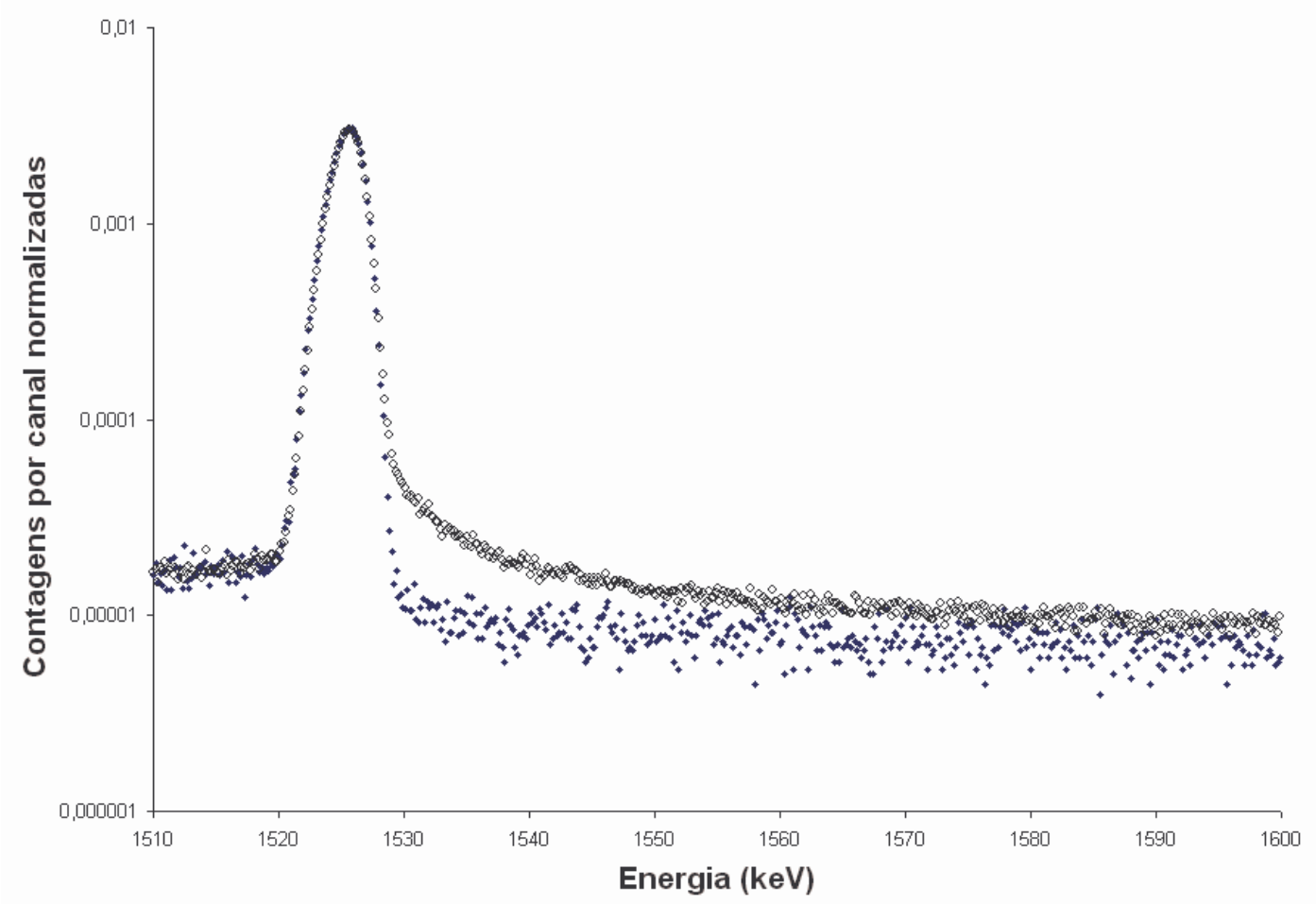

Figura 11: Formas do pico de absorção total para diferentes taxas de contagem: os marcadores vazados correspondem a um medida com $12 \mathrm{kHz}$ de taxa e os cheios a uma medida com $1 \mathrm{kHz}$ de taxa. 
A série inicial de experimentos pretendia eleger o material mais conveniente para 0 absorvedor, entre acrílico e alumínio. Os experimentos consistiram então em fazer medidas com fontes calibradas de ${ }^{152} \mathrm{Eu}$ e ${ }^{90} \mathrm{Sr}$, este último um emissor beta puro com elétrons de energia máxima de $0,5 \mathrm{MeV}$, com objetivo de observar o efeito do decaimento beta sobre 0 espectro e medir quanto esse efeito pode ser minimizado por absorvedores de alumínio e acrílico.

Foi observado que a radiação beta deforma todo o espectro gama tendo maior influência sobre a região de menor energia do espectro. Os absorvedores também mostraram ter maior influência sobre as radiações de baixa energia e conseqüentemente barram alguns fótons, como mostrado na figura 12.

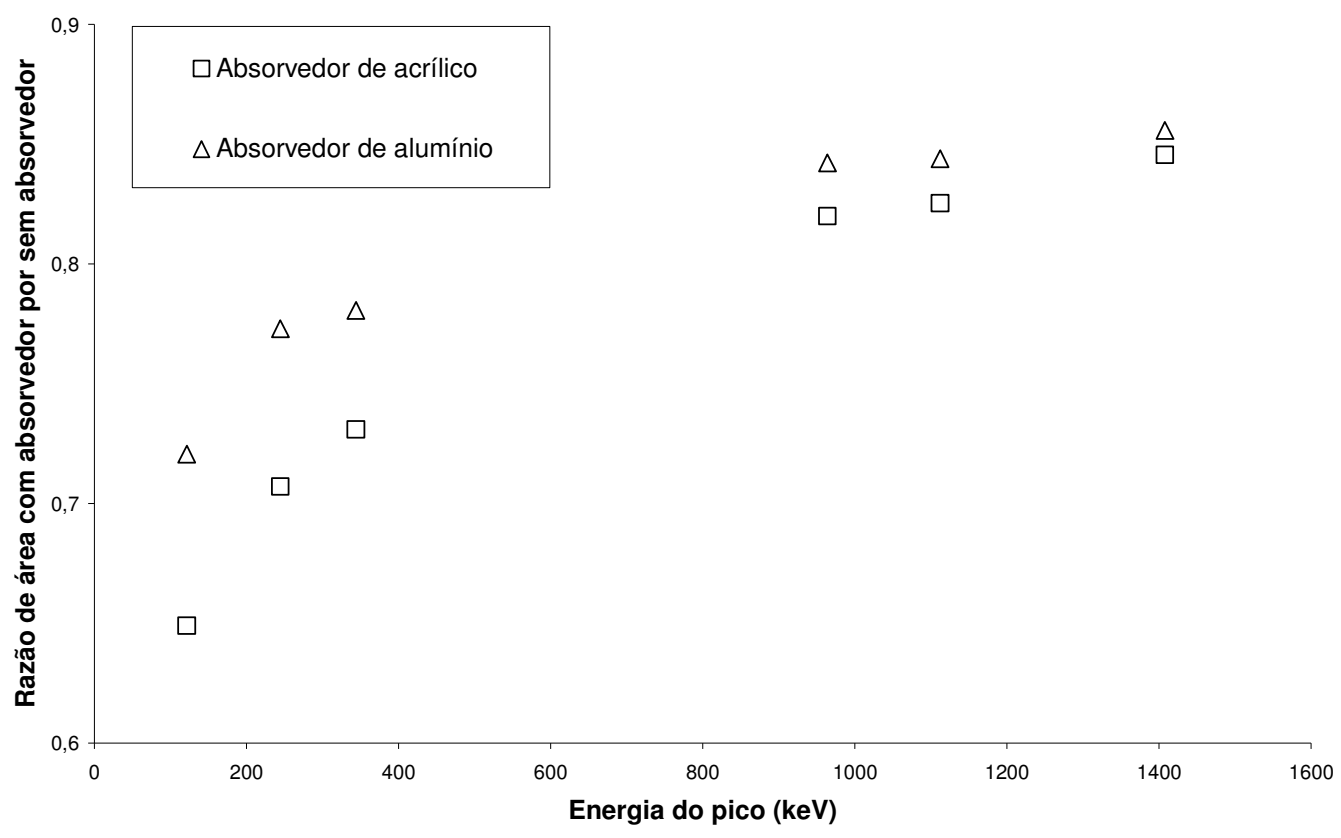

Figura 12: Comparação da capacidade de interação com raios gama de dois absorvedores para os fótons de uma fonte de ${ }^{152} \mathrm{Eu}$. Incertezas menores que os tamanhos dos pontos.

Como o poder de freiamento dos elétrons no acrílico é menor que o do alumínio, é necessária mais massa de acrílico que de alumínio para barrar uma mesma porcentagem dessa radiação, portanto o absorvedor de acrílico usado nos experimentos era mais espesso 
que o de alumínio; o resultado é que a atenuação dos fótons gama no absorvedor de acrílico foi maior que no absorvedor de alumínio, como visto na figura 12. Isso fez com que o absorvedor de alumínio fosse escolhido como o mais conveniente para as medidas futuras.

Eleito o alumínio, foi então construído um suporte em acrílico para os absorvedores padronizados de alumínio (Tracerlab, Waltham 54, Mass. U.S.A.), como mostrado na figura 13, que se encaixou entre as fontes e o tubo de PVC utilizado como suporte, como mostrado na figura 6.

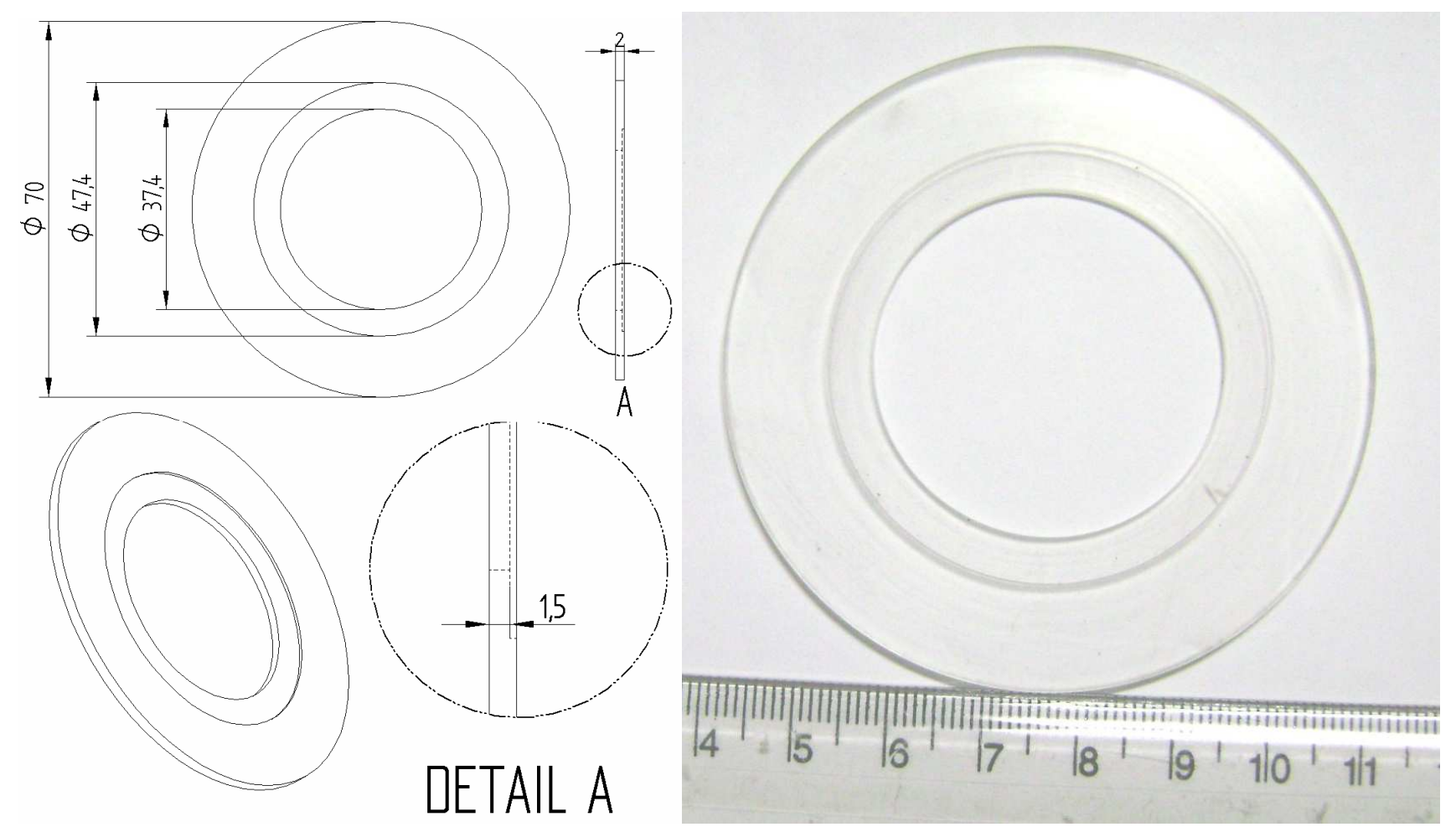

Figura 13: Esquema e fotografia do suporte do absorvedor

Foram feitas medidas para observar o comportamento do espectro de elétrons para várias espessuras diferentes de absorvedores, como mostrado na figura 14. Essa segunda série de experimentos foi realizada somente com a fonte de ${ }^{90} \mathrm{Sr}$ a uma distância de $14 \mathrm{~cm}$ do detector e a 0,6 cm de distância do absorvedor, similar ao esquema de geometria mostrado na figura 6 . 


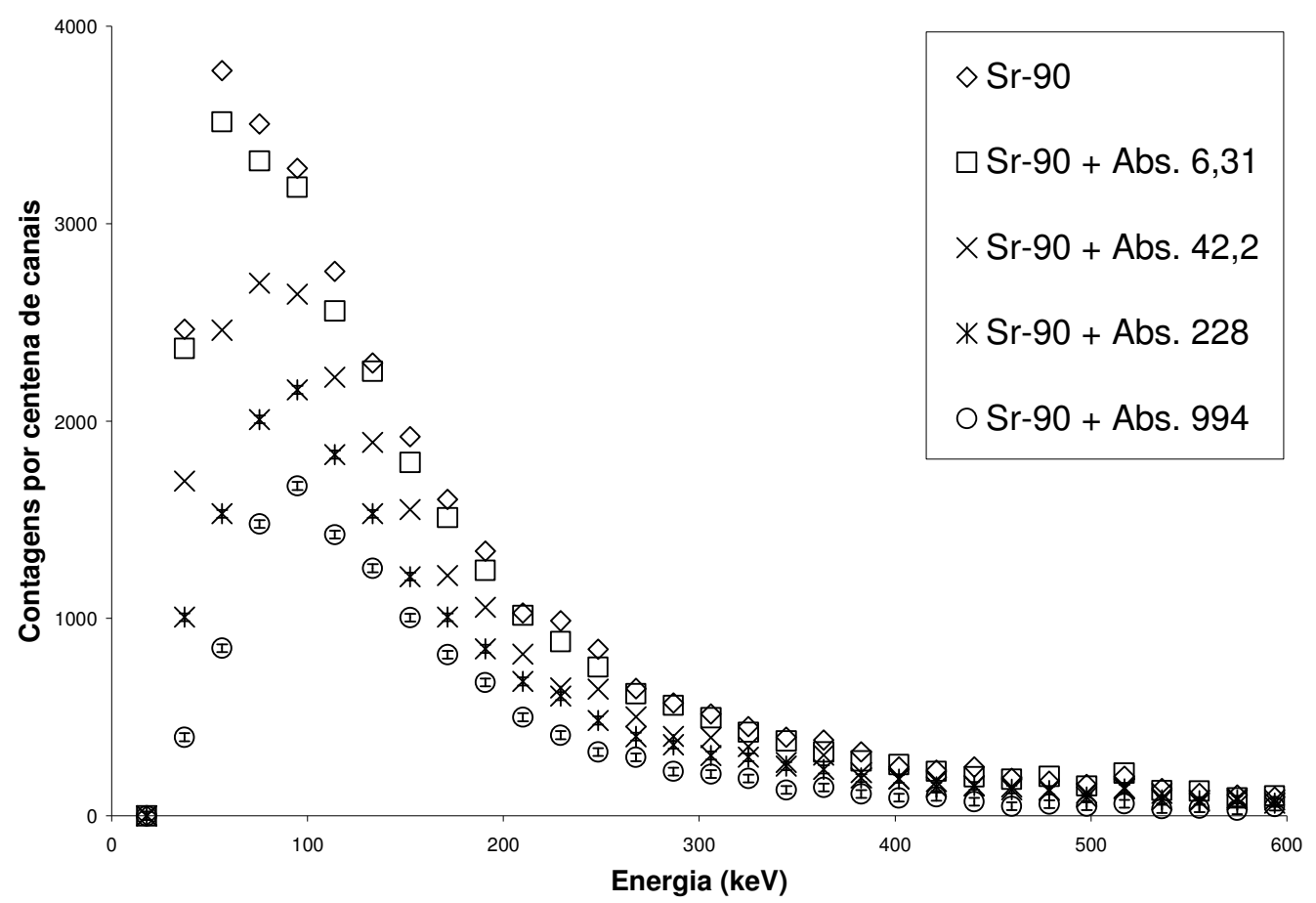

Figura 14: Espectros $\beta$ detectados no HPGe com diferentes absorvedores, cuja densidade superficial é mostrada em $\mathrm{mg} / \mathrm{cm}^{2}$. Incertezas menores que os tamanhos dos pontos.

O absorvedor eleito e utilizado nas medidas correspondentes às cinco irradiações posteriores foi o de densidade superficial de $523 \mathrm{mg} / \mathrm{cm}^{2}$, por ter a maior densidade superficial dentre os absorvedores com espessura conveniente ao arranjo experimental.

\subsection{Processo de calibração dos detectores}

A calibração dos detectores consistiu em medidas de curta duração (de 1 a 30 minutos), nas mesmas condições das medidas que se pretendeu fazer, de fontes com atividades calibradas, chamadas fontes de referência ou de calibração. As fontes de calibração usadas foram ${ }^{60} \mathrm{Co},{ }^{133} \mathrm{Ba},{ }^{137} \mathrm{Cs},{ }^{152} \mathrm{Eu}$ e ${ }^{207} \mathrm{Bi}$, cujas principais características são apresentadas na tabela 3 . 
Tabela 3: Radionuclídeos utilizados como fonte padrão[39].

\begin{tabular}{|c|c|c|c|}
\hline Nuclídeo & $\begin{array}{l}\text { Meia-vida } \\
\text { (anos) }\end{array}$ & $\begin{array}{c}\text { Energia Gama } \\
\qquad(\mathrm{keV})\end{array}$ & $\begin{array}{l}\text { Intensidade gama } \\
\text { por decaimento (\%) }\end{array}$ \\
\hline \multirow[t]{2}{*}{${ }^{60} \mathrm{Co}$} & $5,2747(4)$ & $1173,228(3)$ & $99,85(3)$ \\
\hline & & $1332,492(4)$ & $99,9826(6)$ \\
\hline \multirow[t]{5}{*}{${ }^{133} \mathrm{Ba}$} & $10,523(19)$ & $80,9971(12)$ & $34,1(3)$ \\
\hline & & $276,3997(13)$ & $7,164(22)$ \\
\hline & & $302,8510(6)$ & $18,33(6)$ \\
\hline & & $356,0134(6)$ & $62,05(19)$ \\
\hline & & $383,8480(12)$ & $8,94(3)$ \\
\hline${ }^{137} \mathrm{Cs}$ & $30,08(9)$ & $661,657(3)$ & $85,10(20)$ \\
\hline \multirow[t]{10}{*}{${ }^{152} \mathrm{Eu}$} & $13,537(6)$ & $121,7817(3)$ & $28,67(15)$ \\
\hline & & $244,6975(8)$ & $7,61(4)$ \\
\hline & & $344,2785(12)$ & $26,6(5)$ \\
\hline & & $411,1163(11)$ & $2,237(25)$ \\
\hline & & $443,965(3)$ & $2,830(23)$ \\
\hline & & $778,9040(18)$ & $12,96(14)$ \\
\hline & & $867,373(3)$ & $4,26(3)$ \\
\hline & & $964,079(18)$ & $14,65(7)$ \\
\hline & & $1112,069(3)$ & $13,69(7)$ \\
\hline & & $1408,006(3)$ & $21,07(10)$ \\
\hline \multirow[t]{3}{*}{${ }^{207} \mathrm{Bi}$} & $32,9(14)$ & $569,698(2)$ & $97,76(3)$ \\
\hline & & $1063,656(3)$ & $74,6(5)$ \\
\hline & & $1770,228(9)$ & $6,87(3)$ \\
\hline
\end{tabular}

Também foram realizadas medidas longas (de 12 a 60 horas de duração, com taxa de contagem média de 3 contagens por segundo) sem nenhuma fonte radioativa próxima ao detector, para observar a irradiação natural do ambiente; essa medida (multiplicada por um 
fator de equivalência dos tempos de medida) é normalmente subtraída das medidas com fontes para evitar que a radiação de fundo seja incluída indesejavelmente na área dos picos de interesse, em caso de coincidir no espectro a posição de um pico de radiação de fundo com um pico da fonte radioativa de interesse.

\subsubsection{Determinação das áreas dos picos}

Considerando que a eficiência do detector não mudou no decorrer das medidas realizadas e que sua dependência com a energia pode ser representada por uma função contínua, é possível relacionar as atividades de diferentes fontes por meio de uma calibração de eficiência de pico. Como visto na secção 2.3, a atividade de uma fonte é determinada a partir do valor da área do pico apresentado no espectro.

Os métodos de determinar a área de um pico são: ajustar uma função aos pontos experimentais e considerar a integral sobre essa curva como a área, ou fazer uma soma das contagens que compõem o pico e subtrair as contagens devido ao contínuo, chamado de "área a mão". Esses dois métodos são equivalentes [40], então no presente trabalho ambos foram utilizados da forma que fosse mais conveniente.

O ajuste de função ao pico foi usado em picos com até $10^{5}$ contagens de área total; a função ajustada foi uma gaussiana com cauda exponencial à esquerda e duas funções de fundo diferentes, um polinômio de grau menor ou igual a 2 mais uma função degrau, como mostrado na figura 15. Os picos foram ajustados usando o programa IDEFIX [41] por meio de uma interface WINDOWS, IDEFIX from WINDOWS [42]. 


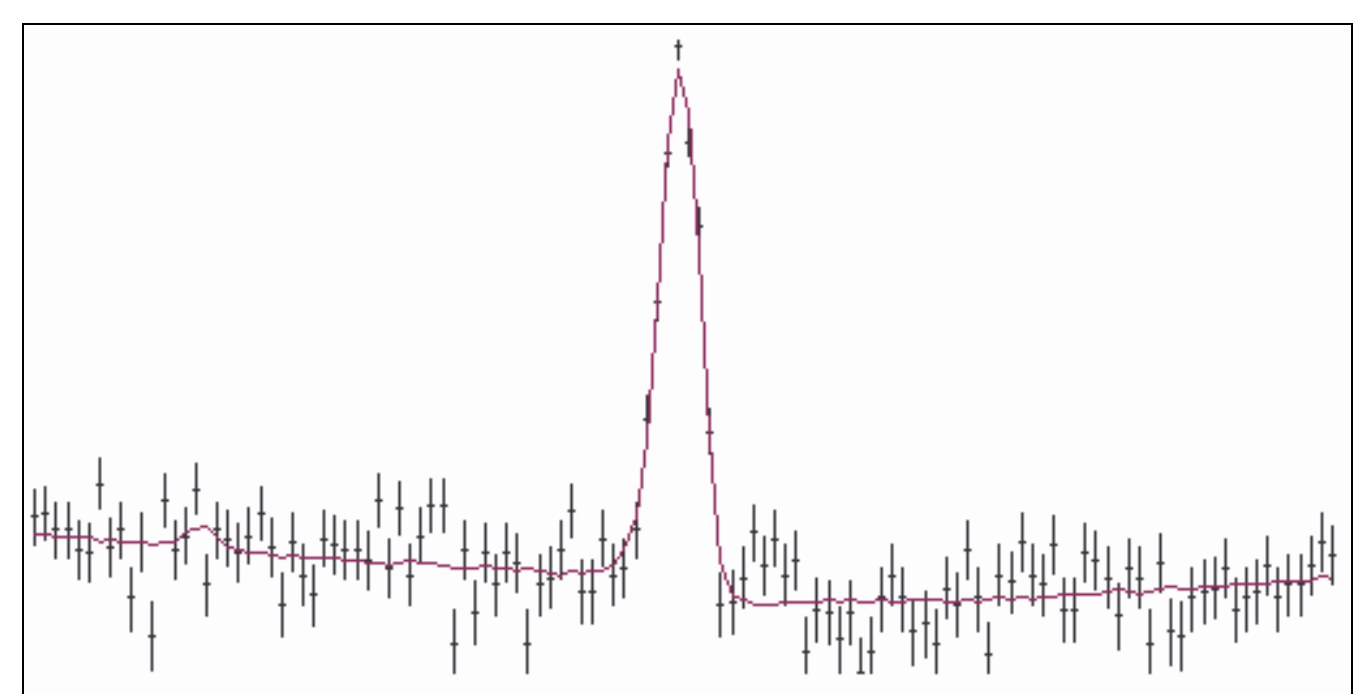

Figura 15: Gráfico ilustrativo dado pelo programa IDEFIX mostrando um ajuste de função às contagens do pico de absorção total. Nas abcissas são representados os canais e nas ordenadas as contagens por canal.

Para picos com mais de $10^{5}$ contagens de área total, alguns efeitos secundários de detecção (como elétrons secundários e coleta imperfeita de carga [43]) ficam pronunciados na forma do pico e as funções de ajuste não podem mais ser usadas pois o $\chi^{2}$ passa a ter valor elevado sistematicamente. Nessas condições foi adotado o método de determinação de área a mão. Esse método consiste em identificar o canal com maior número de contagens como sendo o centro do pico e a partir do seu número de contagens estimar o número de canais que correspondem a uma largura a meia altura (FWHM- full width at half maximum) simplesmente contando o número de canais existentes entre os dois canais que contêm aproximadamente metade das contagens do centróide, e então considerar como pertencentes ao pico todas as contagens de até duas FWHM de distância do canal central, descontando desse valor a média de contagens de fundo ao redor do pico, como mostrado na figura 16. Se um pico tem a forma gaussiana, a probabilidade das contagens estar dentro de uma FWHM é $76,2 \%$ e de estar a duas FWHM é 98,1\%. Como a incerteza típica das áreas dos picos é da ordem de alguns por cento, então considerar que a área do pico está 
limitada a duas FWHM não deve comprometer o valor da área e a incerteza da mesma se considera como a raiz de seu valor, dado que o comportamento estatístico das contagens em cada canal obedece à distribuição de Poisson.

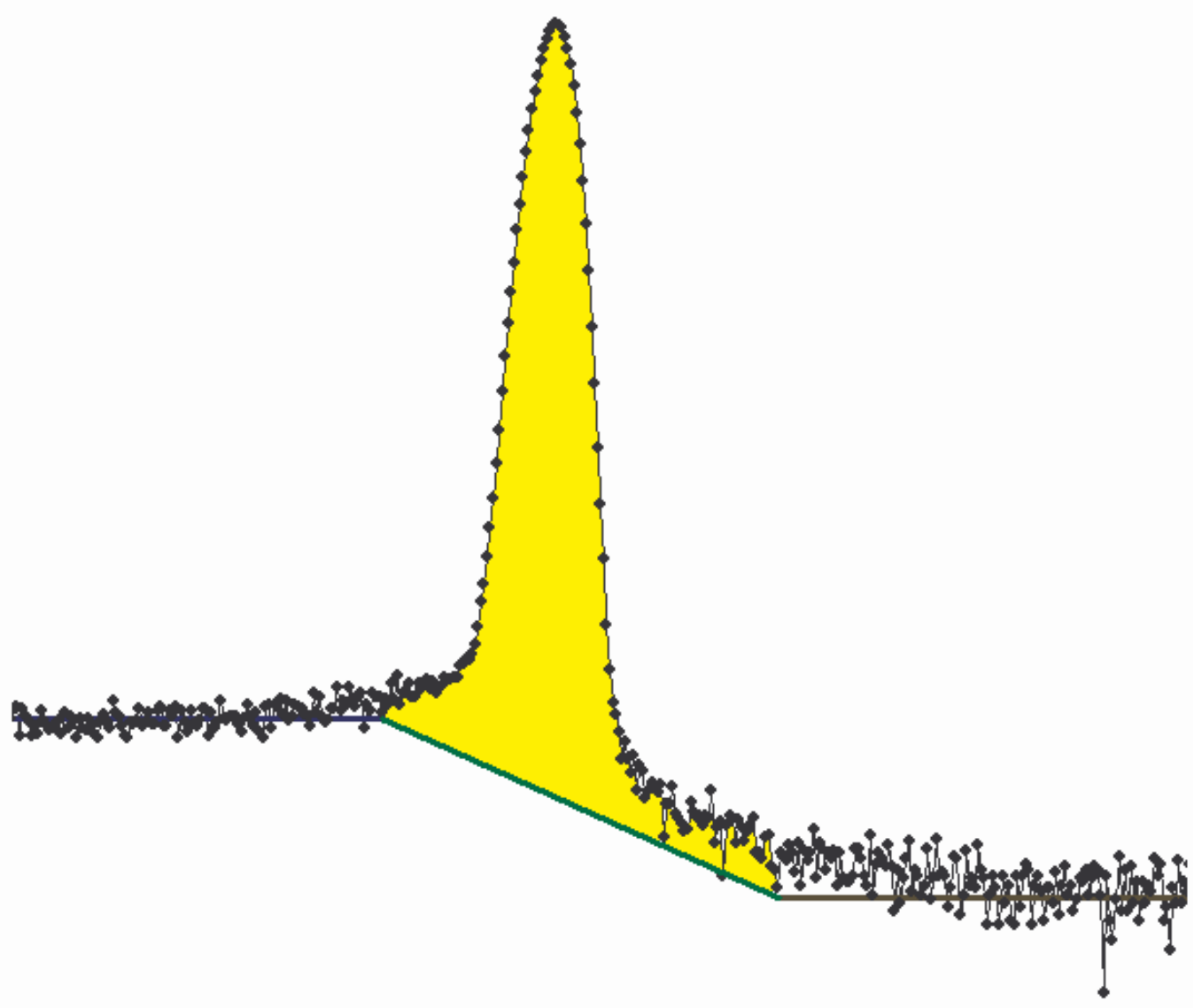

Figura 16:Gráfico ilustrativo do método de determinação da área a mão.

\subsubsection{Calibrações de energia}

As medidas de radiação gama com detectores HPGe das amostras irradiadas resultam em espectros de contagens em canais, onde o número de ordem dos canais, $C$, são relacionados com as energias dos fótons detectados pela seguinte equação:

$$
E_{\lambda}=a_{1}+a_{2} C+a_{3}^{2} C
$$


onde $a_{1}, a_{2}$ e $a_{3}$ são parâmetros a serem determinados através de ajuste.

Esse ajuste é feito considerando os picos dos espectros obtidos das fontes calibradas, cujas energias são bem conhecidas, como apresentado na tabela 3.

\subsubsection{Correção de tempo morto}

A cada pulso recebido do pré-amplificador, o amplificador necessita de um tempo para modificar a forma do pulso; durante esse tempo, o amplificador não aceita novos pulsos, então o amplificador envia ao ADC, por meio da conexão Busy, um sinal de ocupado (como mostrado na figura 5) e este tempo não é considerado como tempo de aquisição, sendo chamado de tempo morto. A duração desse sinal é estendida no ADC para aumentar o tempo de aquisição para compensar a perda de sinais por empilhamento. Foi necessário corrigir a extensão do tempo morto do sistema de aquisição utilizado, pois se percebeu que o tempo estimado pelo ADC estava incorreto. Para isso foi construído um módulo que controla o tempo de ocupação do ADC e o controle dos parâmetros desse módulo foi incorporado à interface do programa de aquisição, de forma que foi possível a cada aquisição escolher um valor fixo para a extensão de tempo morto.

O procedimento adotado para determinar o melhor valor para a extensão de tempo morto foi manter uma fonte de ${ }^{60} \mathrm{Co}$ com baixa atividade a uma distância fixa do detector em que a taxa de contagem não necessitasse de correção por tempo morto e então realizar cinco medidas de curta duração ( 1 a 10 minutos) onde a cada medida se mudava a distância de uma fonte de ${ }^{207} \mathrm{Bi}$ e a cápsula do detector $(20,10,4,2$ e 0 centímetros, aproximadamente). Em seguida os resultados eram analisados e um novo valor para a extensão de tempo morto era escolhido para uma nova série de medidas idêntica a anterior. 

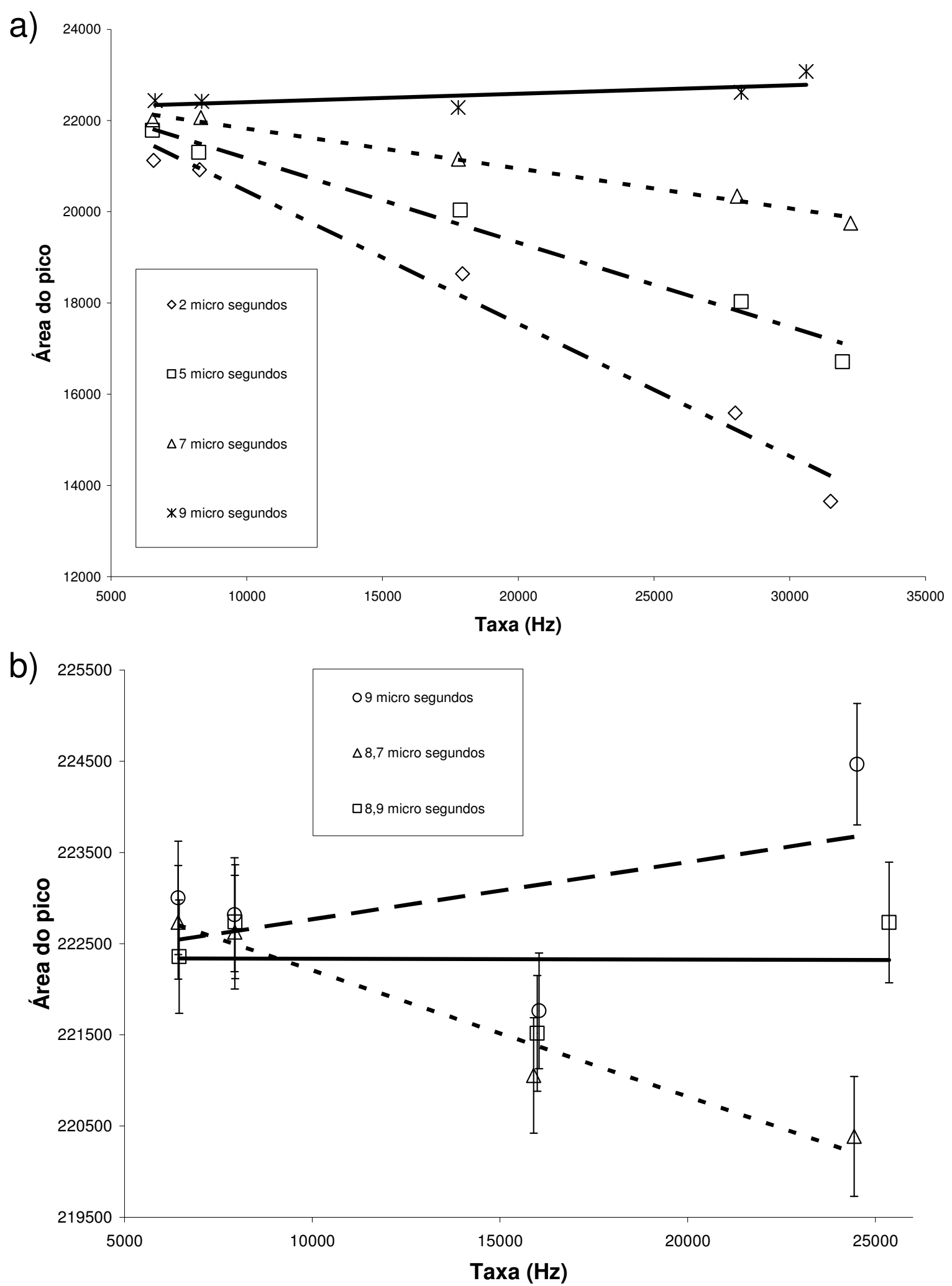

Figura 17: Comparação dos valores das áreas do pico de $1332 \mathrm{keV}$ do ${ }^{60} \mathrm{Co}$ para diferentes tempos de correção, a) modificando o parâmetro grosseiramente (com incertezas menores ou iguais aos tamanhos do pontos) e b) finamente. 
O objetivo desse procedimento é determinar uma extensão de tempo morto que minimize a interferência no valor da área de um pico com a mudança de taxa de contagem. $\mathrm{Na}$ figura 17 é mostrado o resultado das séries de medidas feitas, onde se obteve que o valor de parâmetro procurado é $8,9 \mu$ s.

\subsubsection{Medidas a taxas de contagem elevadas}

O comportamento do sistema de medidas a altas taxas de contagem foi estudado para observar o produto da reação ${ }^{41} \mathrm{~K}(\mathrm{n}, \gamma){ }^{42} \mathrm{~K}(\mathrm{n}, \gamma){ }^{43} \mathrm{~K}$. Quando se mede nessas condições, o sistema de detecção pode chegar a perder a maioria dos sinais do detector e o tempo real das medidas pode se tornar muito longo, devido ao tempo morto.

O tempo morto do amplificador, como explicado na secção anterior, impõe um limite de contagens ao sistema de aquisição, pois durante o tempo em que o amplificador fica ocupado convertendo o sinal recebido, outros pulsos podem chegar ao amplificador e estes não são convertidos. Portanto, há sempre uma probabilidade de se perder contagens devido ao tempo morto e, caso a taxa de eventos no detector exceda um certo limite, haverá diminuição do número de contagens detectadas ou até mesmo, em caso mais extremos, o sistema pode ficar paralisado, incapaz de realizar a medida.

Após a correção do tempo morto foram feitos experimentos com o objetivo de observar o comportamento da taxa de aquisição com o aumento da taxa de pulsos do detector e determinar o limite de taxa de contagem do sistema.

Os experimentos realizados consistiram em medir a taxa de contagem do sistema por meio do número de contagens total nos espectros gama obtidos e medir os pulsos gerados pelo pré-amplificador. Usando o pulso CRM (Count Rate Meter), que tem tempo morto desprezível se comparado ao amplificador, é possível obter um valor bem próximo do 
número de eventos ocorridos no detector e emitidos pelo pré-amplificador. O amplificador usado foi um ORTEC 673 (Gated Integrator) que funciona com constantes de tempo de formação de pulsos menores. A taxa de eventos no detector foi modificada variando a posição de uma fonte de ${ }^{152} \mathrm{Eu}$ com atividade de 0,1 MBq, de forma que a distância fontedetector variasse de $20 \mathrm{~cm}$ a $0 \mathrm{~cm}$. A figura 18 apresenta os resultados obtidos da comparação entre as taxas de contagem.

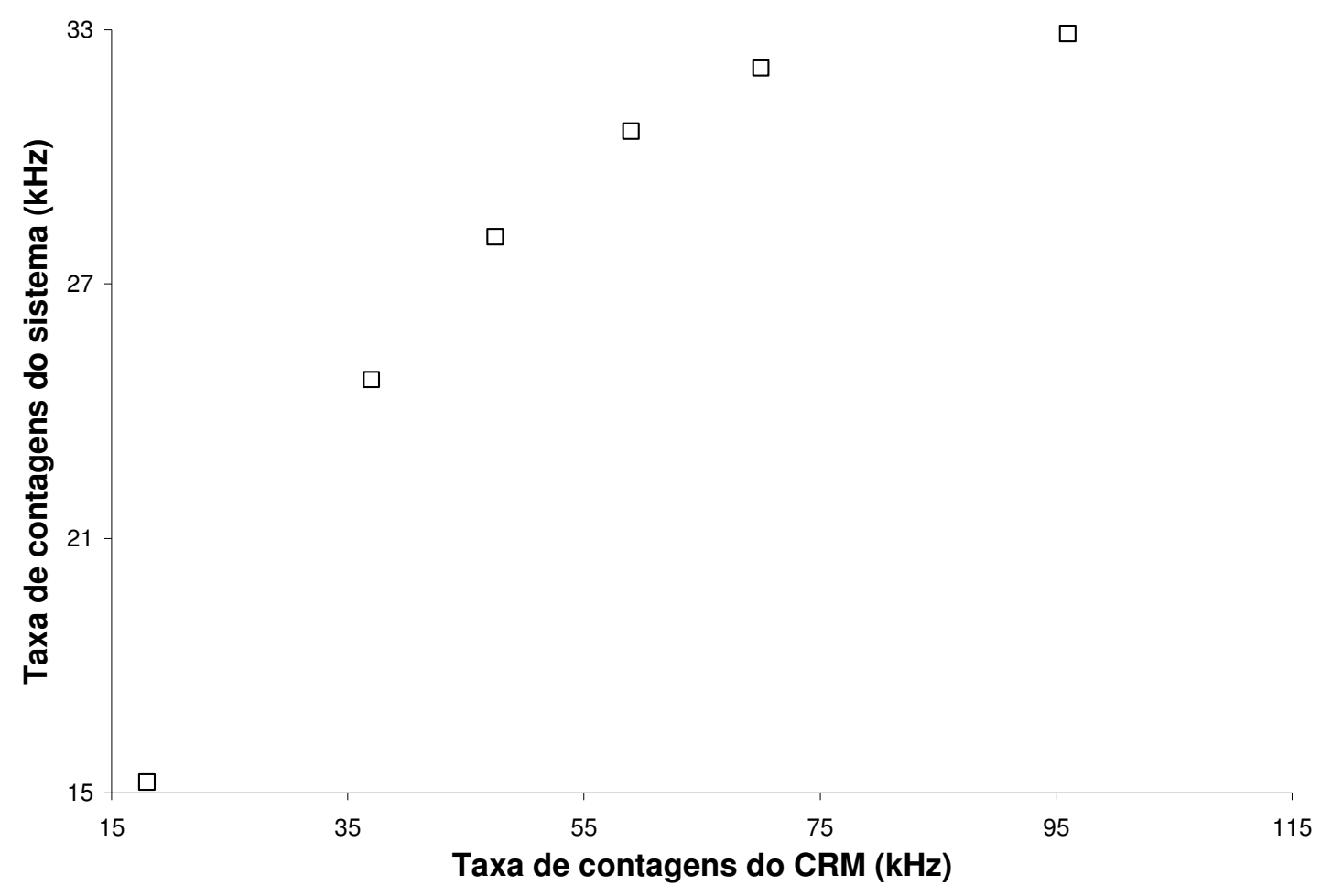

Figura 18: Relação entre taxas de contagem no sistema de aquisição usado (incertezas menores que os tamanhos dos pontos).

Observando o gráfico é possível perceber uma tendência assintótica da taxa de contagens do sistema de aquisição impondo um limite da ordem de $30 \mathrm{kHz}$. Considerando essa interpretação e o tempo morto comparado ao tempo vivo de cada medida, mostrado na tabela 4, as medidas realizadas não ultrapassaram a taxa de $30 \mathrm{kHz}$ no CRM. 
Tabela 4: Resultados das medidas realizadas para observar o limite de taxa de contagem.

\begin{tabular}{ccc}
$\begin{array}{c}\text { Taxa do } \\
\text { CRM }(\mathrm{kHz})\end{array}$ & $\begin{array}{c}\text { Taxa do sistema } \\
\text { de aquisição }(\mathrm{kHz})\end{array}$ & $\begin{array}{c}\text { Tempo morto } \\
\text { relativo (\%) }\end{array}$ \\
\hline 18 & $15,25(12)$ & 26 \\
37 & $24,74(15)$ & 76 \\
47,5 & $28,11(16)$ & 108 \\
59 & $30,6(2)$ & 148 \\
70 & $32,1(2)$ & 224 \\
96 & $32,9(2)$ & 354 \\
\hline
\end{tabular}

\subsubsection{Eficiência}

A eficiência de um detector HPGe varia de acordo com a energia do fóton detectado, podendo ser bem calibrada na faixa de energia de interesse por meio da seguinte relação:

$$
\varepsilon_{\gamma}^{p}\left(E_{\gamma}\right)=e^{p_{1}}\left(\frac{E_{\gamma}}{E_{0}}\right)^{p_{2}} \Rightarrow \ln \left(\varepsilon_{\gamma}^{p}\right)=p_{1}+p_{2} \ln \left(\frac{E_{\gamma}}{E_{0}}\right)
$$

onde $p_{1}$ e $p_{2}$ são os parâmetros a serem ajustados e $E_{0}$ é uma energia de referência.

Tabela 5: Resultados do ajustes da eficiência do detector.

\begin{tabular}{cccc} 
Distância $(\mathrm{cm})$ & $\mathrm{p}_{1}$ & $\mathrm{p}_{2}$ & $\mathrm{P}\left(\chi^{2}\right)$ \\
\hline 14 & $-6,636(7)$ & $-0,777(14)$ & $55 \%$ \\
\hline
\end{tabular}

O valor da energia de referência $E_{0}$ presente na equação (35) foi adotado como $1 \mathrm{MeV}$ pois as energias de interesse estão no intervalo de 0,3 a $2 \mathrm{MeV}$. Os ajustes dessa função aos dados experimentais para o detector utilizado são apresentados na figura 19 e os valores encontrados para os parâmetros são mostrados na tabela 5, onde também é mostrada a probabilidade de se obter um valor de $\chi^{2}$ maior que o encontrado, $\mathrm{P}\left(\chi^{2}\right)$. 


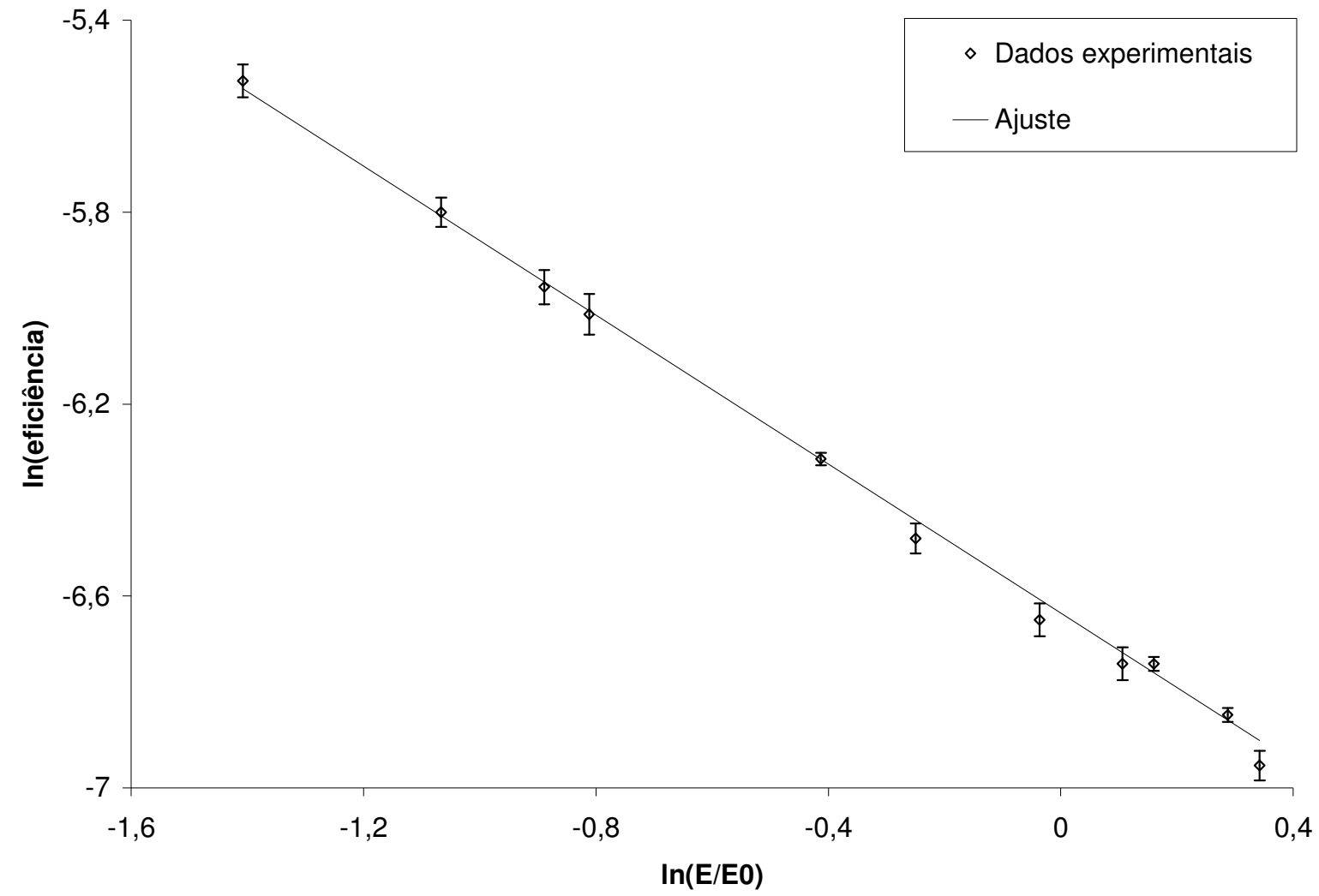

Figura 19: Ajuste da eficiência de detecção aos resultados experimentais para fontes de ${ }^{60} \mathrm{Co},{ }^{137} \mathrm{Cs}$ e ${ }^{152} \mathrm{Eu}$ a $14 \mathrm{~cm}$ de distância fonte-detector. 


\section{Capítulo 4:Simulações}

Durante a realização do trabalho foram feitas simulações utilizando a técnica de Monte Carlo através do código MCNPX (Monte Carlo N-Particle, version X [44]) para calcular fatores de correção dos experimentos realizados.

\subsection{Depressão de fluxo e auto-blindagem}

O fluxo de nêutrons em um certo ponto da piscina do reator é basicamente o resultado do processo de moderação dos nêutrons emitidos na fissão nos elementos combustíveis e pela interferência da aparelhagem envolvida na estrutura do reator. A introdução de um corpo composto por um material com secção de choque de absorção de nêutrons maior que a do material moderador implica numa diminuição local do fluxo devido a mudança de material moderador e maior absorção de nêutrons. Esse efeito é chamado depressão de fluxo e é representado por uma razão $H$ dada por:

$$
H=\frac{\phi_{S}}{\phi}
$$

onde $\phi_{S}$ é o fluxo na superfície do corpo e $\phi$ é o fluxo sem a presença da folha, ou simplesmente o fluxo não perturbado.

Outro efeito que ocorre ao irradiar-se um corpo extenso é a auto-blindagem, que ocorre devido ao fato dos nêutrons serem absorvidos no interior do alvo e implica que as partes mais internas do mesmo ficam expostas a fluxos menores que as mais externas. Esse efeito por sua vez é representado pela razão $G$ dada por: 


$$
G=\frac{\bar{\phi}}{\phi_{S}}
$$

onde $\bar{\phi}$ é o fluxo médio dentro do alvo.

As medidas realizadas no presente trabalho consistiram em inserir corpos extensos na piscina do reator para, em seguida, medir suas atividades, então os efeitos descritos acima devem ser levados em conta. O fluxo que se calcula com a atividade dos alvos é o $\bar{\phi}$ e o que se quer determinar é o $\phi$, portanto o fator $F$ que deve ser utilizado nos cálculos é dado por:

$$
F=G H=\frac{\bar{\phi}}{\phi} .
$$

Então a equação (23) se torna:

$$
\phi_{0}=n v_{0}=\frac{\left(A_{S}-F_{C d} A_{C d}\right) R^{\prime}}{N_{0} \sigma_{0}(g+r s)\left(R^{\prime}-1\right)} \frac{1}{F}
$$

e a equação (20) se torna:

$$
\Phi_{e p i}=\frac{R}{N_{0} I} \ln \left(\frac{2 \mathrm{MeV}}{E_{C d}}\right) \frac{1}{F_{e p i}}
$$

onde $F_{e p i}$ é o fator de correção considerando somente o fluxo epitérmico.

Esse fator pode ser determinado pelo método de Monte Carlo [45] simulando uma irradiação com as mesmas condições de contorno experimentais [46]. 


\subsubsection{Simulação da irradiação}

O código MCNP permite uma modelagem tri-dimensional detalhada da geometria da situação a ser estudada. Então, para simular as irradiações realizadas, primeiramente foi necessário determinar a distribuição da densidade de nêutrons ao redor do alvo.

Como visto na secção 2.2.1, a distribuição da densidade de fluxo de nêutrons após o processo de moderação é dada por uma composição da distribuição maxwelliana (térmica) com a proporcional ao inverso da energia dos nêutrons (epitérmica). Considerando que o fator de correção $r$ do formalismo de Westcott apresentado na secção 2.2.1 pode ser dado por [1]:

$$
r=\frac{\frac{\sqrt{\pi \mu}}{4}}{1+\frac{\sqrt{\pi \mu}}{4} \frac{\Phi_{t h}}{\Phi_{e p i}}} \approx \frac{\Phi_{e p i}}{\Phi_{t h}}
$$

onde $\mu$ é um parâmetro que depende do moderador, que para água vale $\mu \approx 5$. Foi possível, então, por meio do método da diferença de cádmio (secção 2.2.3) com os monitores de fluxo, determinar o valor de $r$ e estimar a distribuição em vigor durante a irradiação.

A primeira série de simulações teve como objetivo calcular a distribuição da densidade de fluxo durante a $5^{\mathbf{a}}$ irradiação. Estas simulações consistiram em calcular a distribuição da densidade de fluxo de nêutrons provindos do centro de uma esfera de água, sendo que a distribuição da densidade de fluxo inicial era dada pela equação (1), que representa o espectro de fissão do ${ }^{235} \mathrm{U}$. A distribuição da fluência na superfície da esfera foi obtida do MCNP por meio de um pedido de registro de fluência (tally F2 [44][47]) ao 
programa, que devolve os valores em nêutrons $/ \mathrm{cm}^{2}$ normalizado pelo número de emissões simuladas. Diferentes valores de raio para essa casca foram atribuídos à esfera até que se encontrasse 0 valor de $r$ para o qual a distribuição calculada era compatível com 0 experimental.

No arquivo de entrada da simulação é possível pedir que o registro de fluência seja dividido por intervalo de energia dos nêutrons; então, nas simulações realizadas, os resultados foram distribuídos em 100 intervalos de energia desde frações de eV até centenas de MeV. A partir disso, o valor de $r$ nas simulações foi dado pela razão entre a soma da fluências no intervalos acima do corte de cádmio (fluência epitérmica) e abaixo do corte de cádmio (fluência térmica).

Os resultados obtidos para algumas dessas simulações, cujas incertezas são menores ou iguais a $0,1 \%$, são apresentados na tabela 6; e a mudança na distribuição da fluência em função da energia dos nêutrons com o raio da esfera de água simulada é mostrada na figura 20.

Tabela 6: Valores do fator $r$ obtidos nas simulações de moderação.

\begin{tabular}{cc}
$\begin{array}{c}\text { Raio da } \\
\text { esfera }(\mathrm{cm})\end{array}$ & $r$ \\
\hline 0 (Fonte de nêutrons) & 4880 \\
0,25 & 11 \\
0,5 & 2 \\
1 & 1 \\
3 & 0,4 \\
10 & 0,04 \\
15 & 0,02 \\
20 & 0,008 \\
\hline
\end{tabular}


O valor experimental obtido para $r$ (cuja determinação experimental detalhada será discutida mais adiante) foi $2,05(4) \times 10^{-2}$, que foi usada nas simulações da irradiação da folha de ouro e da pastilha a distribuição da fluência resultante da simulação com uma esfera de água com $15 \mathrm{~cm}$ de raio.

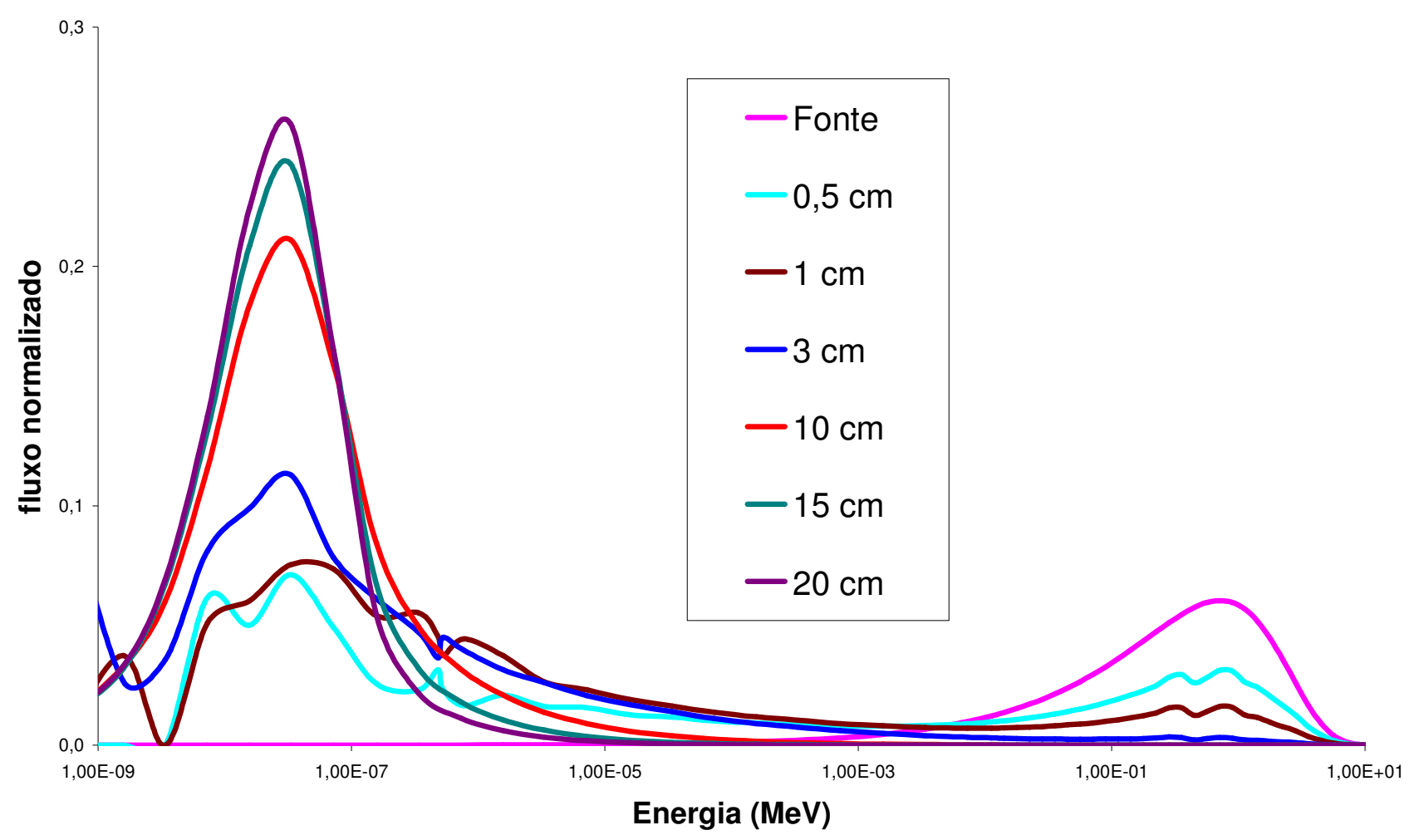

Figura 20: Resultados da distribuição em energia de nêutrons de simulações do processo de moderação.

Dada a distribuição em energia do fluxo, foram feitas simulações de alvos com as mesmas dimensões que os irradiados colocados no centro de uma esfera sem preenchimento de material, onde os nêutrons eram emitidos de pontos aleatórios da superfície cuja distribuição em energia corresponderia àquela moderada, similar à distribuição experimental. Para cada alvo foram realizadas duas simulações, uma da pastilha com sua composição normal e outra com a geometria da pastilha idêntica mas sem preenchimento, para observar a depressão de fluxo, como mostrado na figura 21. Foram 
definidas superfícies dez superfícies concêntricas com diferentes raios e alturas no interior da pastilha simulada de forma a ser possível observar a fluência nessas várias camadas do alvo e conseqüentemente o efeito da auto-blindagem.

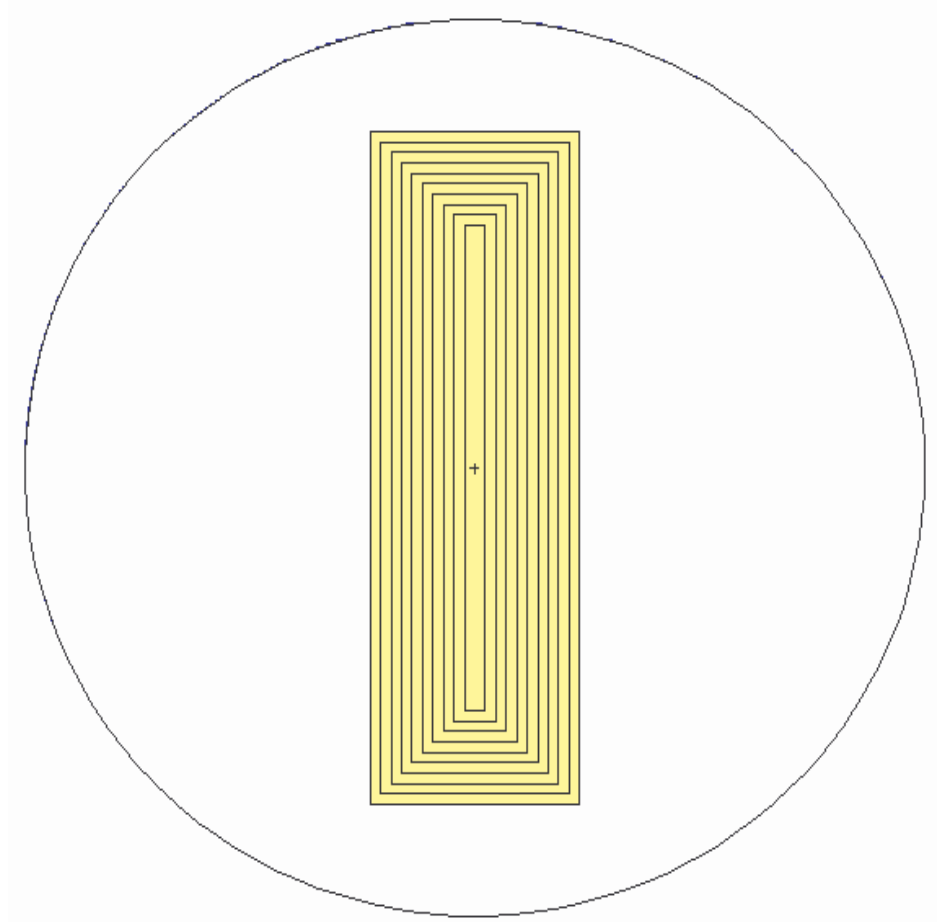

Figura 21: Imagem ilustrativa das superfícies internas à pastilha definidas nas simulações. Figura gerada pelo programa VISED [48].

Tabela 7: Valores obtidos para os fatores de correção nas pastilhas de $\mathrm{KNO}_{3}$ simuladas.

\begin{tabular}{ccccc} 
& \multicolumn{5}{c}{ Espessura da pastilha (mm) } \\
\cline { 2 - 5 } Fator & 1,86 & 1,28 & 1 & 0,66 \\
\hline H & $0,99966(21)$ & $0,99969(23)$ & $0,99976(23)$ & $0,99978(24)$ \\
G & $0,9997(5)$ & $0,9999(5)$ & $1,0000(5)$ & $1,0001(5)$ \\
F & $0,9993(5)$ & $0,9996(5)$ & $0,9997(6)$ & $0,9999(6)$ \\
\hline
\end{tabular}

Foi verificado que as correções de fluxo para monitores usados são desprezíveis [49] realizando simulações semelhantes às das pastilhas, mas com material e dimensões correspondentes às ligas de Au-Al utilizadas. Os valores obtidos para as razões de 
depressão de fluxo e auto-blindagem para diferentes tamanhos de pastilhas de $\mathrm{KNO}_{3}$ assim como os os fatores de correção são apresentados na tabela 7.

Pode-se observar que não há correção para as pastilhas simuladas, pois os valores obtidos são compatíveis com 1 dentro de duas incertezas. Apesar dos resultados apresentarem diminuição sistemática com o aumento da espessura, esse comportamento não pode ser levado em conta, pois os valores são compatíveis entre si dentro de uma barra de incerteza.

\subsection{Correção da eficiência para fontes radioativas volumétricas}

O método de determinação de atividade de uma fonte radioativa por meio da calibração de eficiência de um detector supõe que todas fontes envolvidas no processo tenham a mesma forma. Porém, no presente trabalho, as fontes usadas como padrão de calibração tinham da ordem de $0,5 \mathrm{~mm}^{3}$ de volume enquanto as fontes irradiadas apresentavam volumes da ordem de $50 \mathrm{~mm}^{3}$, de modo que é necessário aplicar um fator de correção para a eficiência.

método para determinar o fator de correção da eficiência foi inicialmente igualar as eficiências dos detectores (virtuais e reais) usando fontes pontuais de referência e, em seguida, simular o material irradiado como fonte de radiação gama.

As fontes de radiação simuladas emitiam fótons monocromáticos, então foi necessário um número de simulações por fonte igual ao número de picos observados no espectro real. A resposta do detector simulada foi observada na simulação por meio de um registro (tally F8 [44][47] ) de distribuição de energias de pulsos criados no corpo virtual que simula o cristal do detector. Como o MCNPX, na modalidade usada no presente trabalho, não prevê efeitos de detecção como soma e empilhamento, as eficiências foram calculadas experimentalmente levando em conta tais correções. 
No experimento de referência foi usada uma fonte de ${ }^{60} \mathrm{Co}$ como padrão, cujos fótons de maior intensidade são apresentados na tabela 3. A primeira série de simulações consistiu no detector HPGe com uma fonte pontual a certa distância e, entre a fonte e o detector, um absorvedor de alumínio $6 \mathrm{~mm}$ a frente da fonte com densidade igual ao absorvedor utilizado no experimento real $\left(523 \mathrm{mg} / \mathrm{cm}^{2}\right)$, assim como apresentado na figura 22.

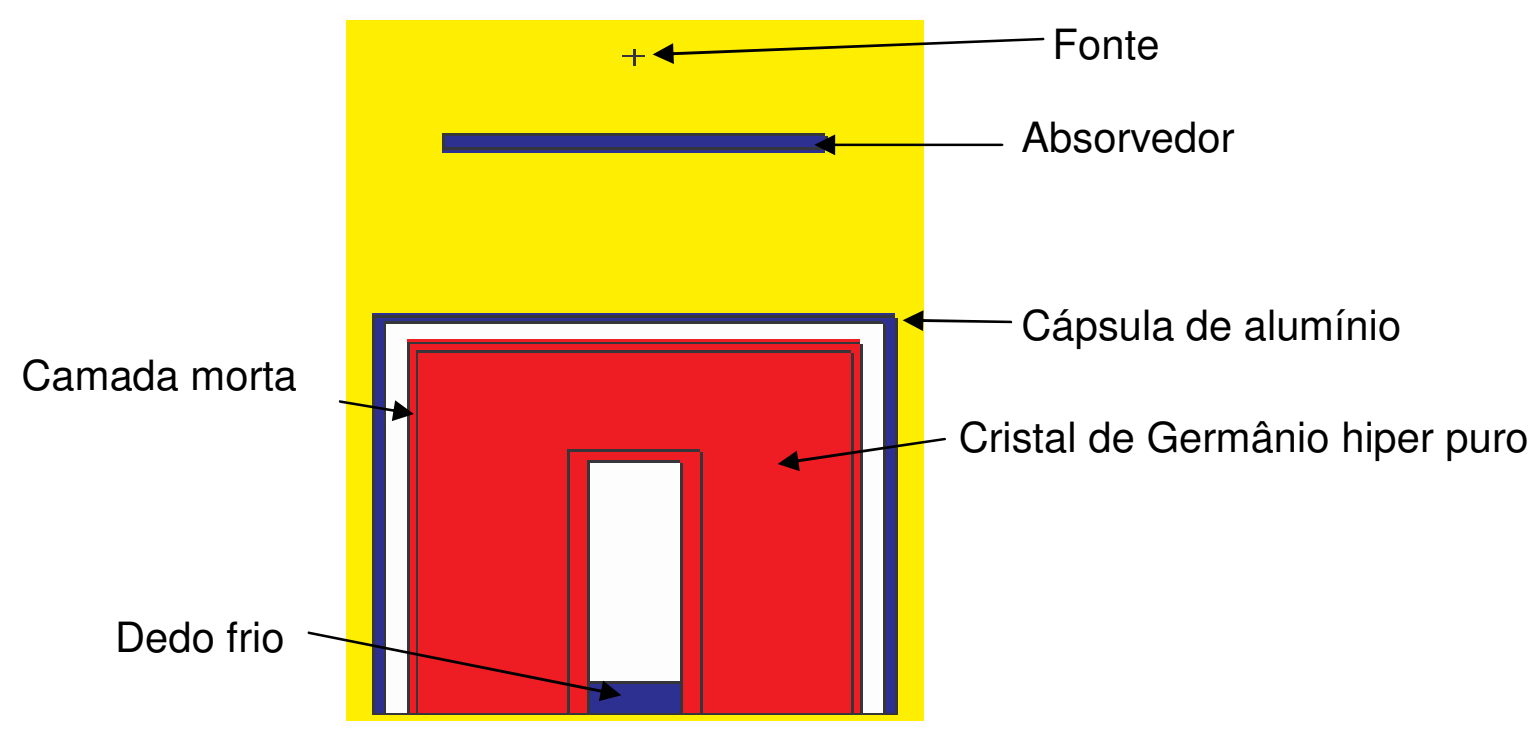

Figura 22: Visualização do arquivo de simulação para correção da eficiência.

As dimensões do interior do detector de germânio como volume ativo, camada morta, distância entre o cristal de germânio e a cápsula de alumínio e raio interno do detector, são dadas em seu manual, porém são valores nominais dados pelo fabricante e não correspondem aos valores reais de cada detector, podendo haver variações desses valores devido o processo de fabricação [50]. Por esse motivo é necessário ajustar esses parâmetros para que a resposta do detector simulado corresponda a do real. O detector usado no presente trabalho já tem um detector virtual efetivo correspondente montado em trabalhos anteriores [51][52]. Então a primeira série de simulações teve como objetivo verificar que a eficiência relativa entre os picos de absorção total correspondentes aos fótons do ${ }^{60} \mathrm{Co}$ do detector virtual correspondem as reais. O espectro resultante de uma dessas 
simulações é apresentado na figura 23 e os valores obtidos para as eficiências relativas são apresentados na tabela 8 .

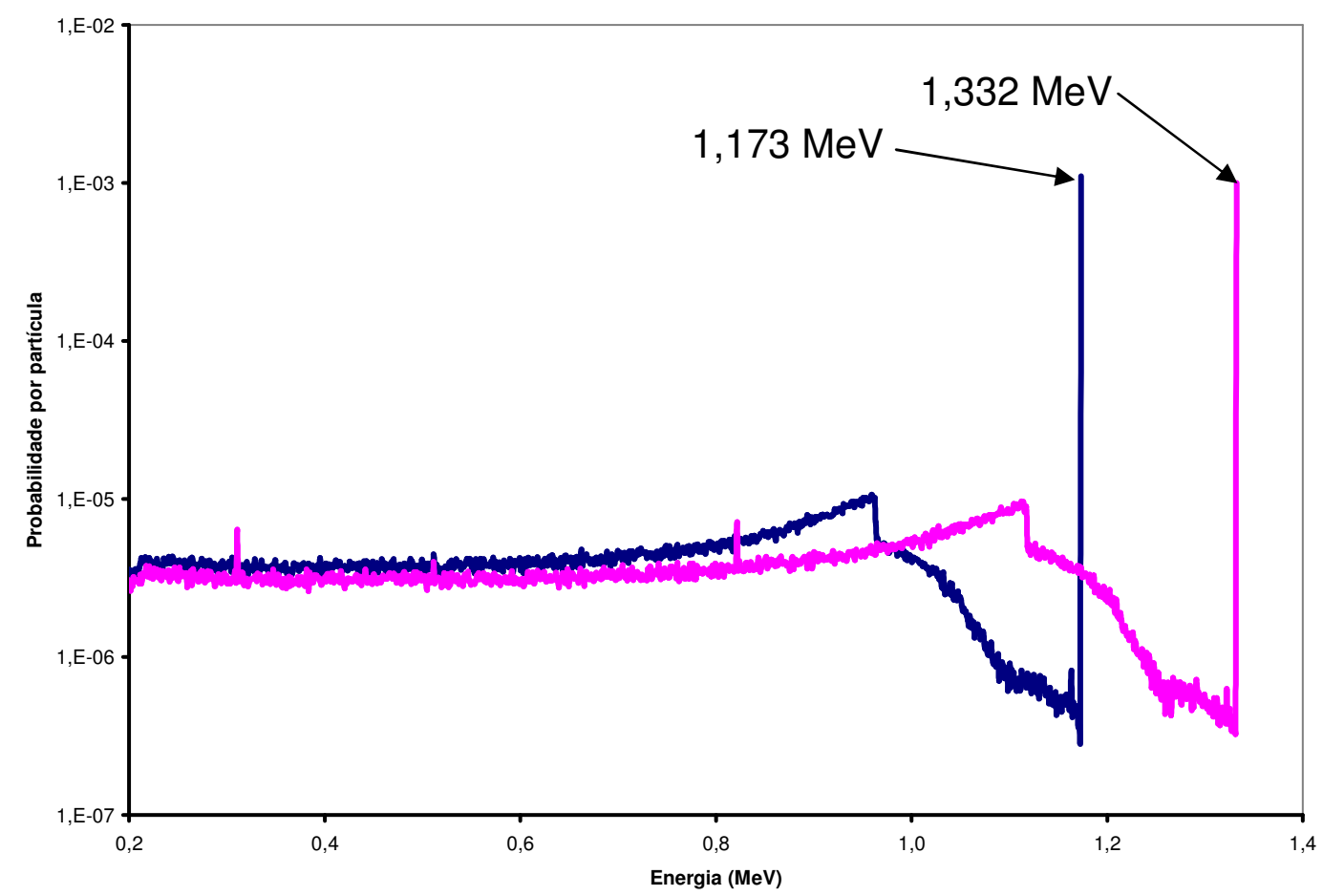

Figura 23: Espectro dos resultados das simulações com fonte pontual a $14 \mathrm{~cm}$ do detector para os fótons do decaimento de uma fonte de ${ }^{60} \mathrm{Co}$.

Tabela 8: Comparação de eficiências no detector real e virtual para os picos de ${ }^{60} \mathrm{Co}$.

\begin{tabular}{ccc}
\hline \multirow{2}{*}{$\begin{array}{c}\text { Energia } \\
(\mathrm{keV})\end{array}$} & \multicolumn{2}{c}{ Eficiência em \% } \\
\cline { 2 - 3 } & Experimental & Simulada \\
\hline 1173,24 & $0,1050(9)$ & $0,1060(3)$ \\
1332,5 & $0,1160(9)$ & $0,1173(3)$ \\
\hline
\end{tabular}

Com os valores de eficiência compatíveis com os experimentais, foram feitas as simulações das amostras de $\mathrm{KNO}_{3}$ para determinar o fator de correção da eficiência de detecção para as fontes extensas. Por causa do formato dos suportes de fonte, as fontes irradiadas foram posicionadas a uma distância fonte-detector 1,9 mm maior que a das fontes 
padrão. Este fato foi considerado nas simulações, implicando que os valores para o fator de correção da eficiência $f_{\gamma}$ apresentados na tabela 9 são devido à distribuição de pontos de emissão dentro de um volume, a atenuação dos fótons no material da fonte e a diferença de posição entre as fontes.

Tabela 9: Fatores de correção obtidos para as fontes extensas para uma distância fonte-detector de $14 \mathrm{~cm}$.

\begin{tabular}{ccc}
\hline $\begin{array}{c}\text { Espessura } \\
\text { da fonte }\end{array}$ & $\begin{array}{c}\text { Energia } \\
(\mathrm{keV})\end{array}$ & Fator de correção \\
\hline 0,127 & 411,8 & $0,975(3)$ \\
& 675,9 & $0,977(3)$ \\
& 1087,7 & $0,973(4)$ \\
\hline $1,28(3)$ & 312,6 & $0,9585(17)$ \\
& 1524,7 & $0,930(4)$ \\
\hline $1,00(3)$ & 312,6 & $0,9633(17)$ \\
& 1524,7 & $0,933(3)$ \\
\hline
\end{tabular}




\section{Capítulo 5:Resultados e discussão}

Os dados experimentais foram interpretados usando os tratamentos estatísticos apresentados na bibliografia [53][54]. As variâncias das grandezas calculadas a partir de dados estatisticamente independentes foram calculadas pela expressão:

$$
\sigma_{y}^{2}=\sum_{i=1}^{n}\left(\frac{\partial y}{\partial x_{i}}\right)^{2} \sigma_{x_{i}}^{2}
$$

onde $\sigma_{y}^{2}$ é a variância de uma grandeza $y, \sigma_{x_{i}}^{2}$ é a variância de uma das $n$ grandezas $x_{i}$. Cada um dos termos da somatória também pode ser calculada como:

$$
\left(\frac{\partial y}{\partial x_{i}}\right)^{2} \sigma_{x_{i}}^{2} \cong\left|y\left(x_{i}+\sigma_{x}\right)-y\left(x_{i}\right)\right|^{2}
$$

escolhendo-se a forma mais prática para cada termo.

Quando as grandezas não são estatisticamente independentes, foram calculadas por meio da relação:

$$
\mathbf{V}_{y} \cong \mathbf{D} \cdot \mathbf{V}_{x} \cdot \mathbf{D}^{t}
$$

onde $\mathbf{V}_{y}$ é a matriz das covariâncias das $m$ grandezas calculadas, $\mathbf{V}_{x}$ é a matriz de covariâncias das $n$ grandezas $x_{i}$ e $\mathbf{D}$ é dado por: 


$$
\mathbf{D}=\left(\begin{array}{cccc}
\partial y_{1} / \partial x_{1} & \partial y_{1} / \partial x_{2} & \cdots & \partial y_{1} / \partial x_{n} \\
\partial y_{2} / \partial x_{1} & \partial y_{2} / \partial x_{2} & \cdots & \partial y_{2} / \partial x_{n} \\
\vdots & \vdots & \ddots & \vdots \\
\partial y_{m} / \partial x_{1} & \partial y_{m} / \partial x_{2} & \cdots & \partial y_{m} / \partial x_{n}
\end{array}\right)
$$

O resultado final para grandezas que foram medidas mais de uma vez é dado pela média entre os dados. A média entre medidas independentes de uma grandeza, $\bar{x}$, é dada por [55]:

$$
\bar{x}=\frac{\sum_{i=1}^{n} \frac{x_{i}}{\sigma_{i}^{2}}}{\sum_{j=1}^{n} \frac{1}{\sigma_{j}^{2}}}
$$

onde $n$ é o número de dados obtidos e cada dado apresenta um valor $x$ e uma incerteza $\sigma$. A incerteza da média $\sigma_{\bar{x}}$ será dada então por:

$$
\sigma_{\bar{x}}=\sqrt{\frac{1}{\sum_{j=1}^{n} \frac{1}{\sigma_{j}^{2}}}}
$$

Todos os ajustes foram possíveis por meio do Método dos Mínimos Quadrados, onde a confiança nos ajustes foi determinada com o auxílio do teste de hipótese baseado na estatística de $\chi^{2}$. 


\subsection{Caracterização das fontes radioativas}

Os espectros resultantes das medidas de radiação gama dos alvos irradiados apresentaram da ordem de dezenas de picos, dos quais apenas alguns eram de interesse, como pode ser visto na figura 10. Assim, o tratamento inicial dado aos espectros teve por objetivo a identificação dos nuclídeos radioativos presentes na fonte incluindo a confirmação da presença dos nuclídeos de interesse.

A identificação dos núcleos se baseou nos seguintes critérios:

a) Probabilidade de produção: Os elementos radioativos produzidos na irradiação que podem ser identificados por espectroscopia gama são normalmente resultados de reações (n., $\gamma$ com núcleos estáveis, então os núcleos com deficiência de nêutrons ou com excesso de dois ou mais nêutrons que o núcleo estável são pouco considerados na identificação a não ser que o processo envolva grandes secções de choque (da ordem de $10^{3}$ barns) ou tenha uma energia limiar baixa para reações com emissão de partículas carregadas do núcleo.

b) Energia do fóton: A partir da calibração de energia e considerando a dispersão do espectro (da ordem de 0,2 keV/canal) é possível determinar com boa precisão a energia dos fótons detectados e identificar possíveis núcleos emissores com o auxílio de tabelas e programas [37][44].

c) Meia vida: Assim como a energia dos fótons emitidos, a meia vida caracteriza o núcleo radioativo e pode ser determinada com uma série de medidas com o mesmo tempo de contagem.

d) Intensidade relativa: A partir da calibração de eficiência é possível comparar as probabilidades de emissão por decaimento dos fótons com os valores conhecidos para os diferentes nuclídeos. 


\subsubsection{Identificação dos núcleos de interesse}

Como visto na secção 3.1 .3 , os alvos foram preparados para que houvesse probabilidade suficiente de observar o produto da reação ${ }^{41} \mathrm{~K}(\mathrm{n}, \gamma)^{42} \mathrm{~K}$ nas cinco primeiras irradiações e da reação ${ }^{41} \mathrm{~K}(\mathrm{n}, \gamma){ }^{42} \mathrm{~K}(\mathrm{n}, \gamma){ }^{43} \mathrm{~K}$ nas duas últimas.

A determinação das constantes de decaimento foi realizada considerando que as equações (30), (31) e (32) resultam na seguinte relação:

$$
\frac{S_{\gamma}}{I_{\gamma} \varepsilon_{\gamma}^{p} A_{0}}=\frac{e^{-\lambda t}}{\lambda}\left(1-e^{-\lambda \Delta t}\right) \approx \Delta t e^{-\lambda t} \Rightarrow \ln S_{\gamma}=\ln \left(I_{\gamma} \varepsilon_{\gamma}^{p} A_{0} \Delta t\right)-\lambda t
$$

tornando possível o ajuste de uma reta aos valores das áreas, obtidas em uma série de contagens com mesmo tempo de duração, para determinar a constante de decaimento de um núcleo. Porém essa aproximação (feita por meio da expansão em série de Taylor do termo $e^{-\lambda \Delta t}$ ) insere um erro sistemático nos cálculos, fazendo com que a precisão dos resultados seja limitada. Além disso, não foram consideradas correções que levam em conta o tempo morto [56]. Como resultado, as incertezas das constantes de decaimento obtidas estão subestimadas.

Os ajustes feitos para determinar as constantes de decaimento dos núcleos de interesse são apresentados nas figuras 24,25 e 26 e os resultados obtidos para a meia vida, por meio da média ponderada pela incerteza dos valores provenientes dos ajustes, são apresentados na tabela 10. 

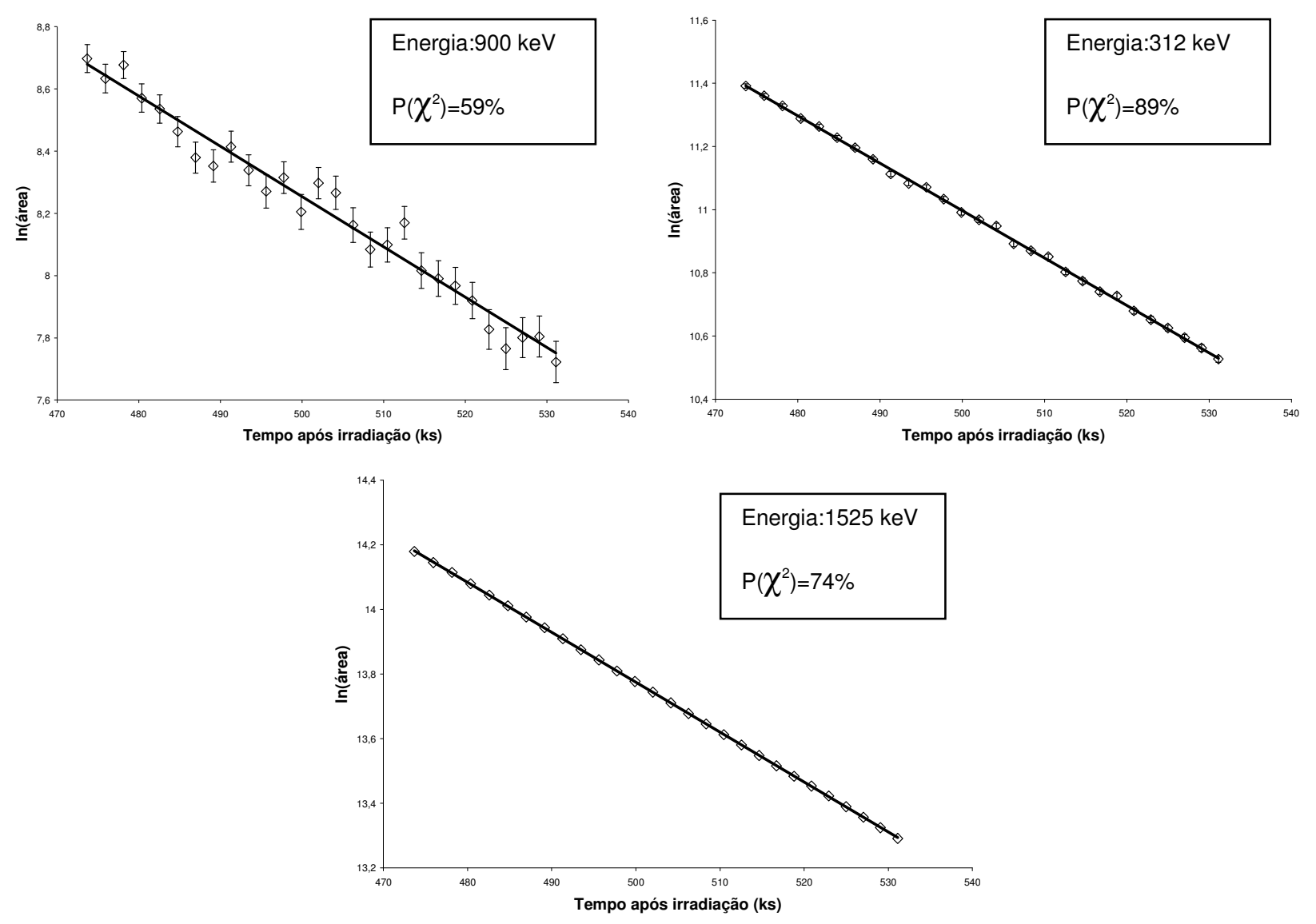

Figura 24:Ajustes sobre os dados obtidos para os picos do ${ }^{42} K$, onde $P\left(\chi^{2}\right)$ representa a probabilidade que o $\chi^{2}$ exceda o valor obtido.
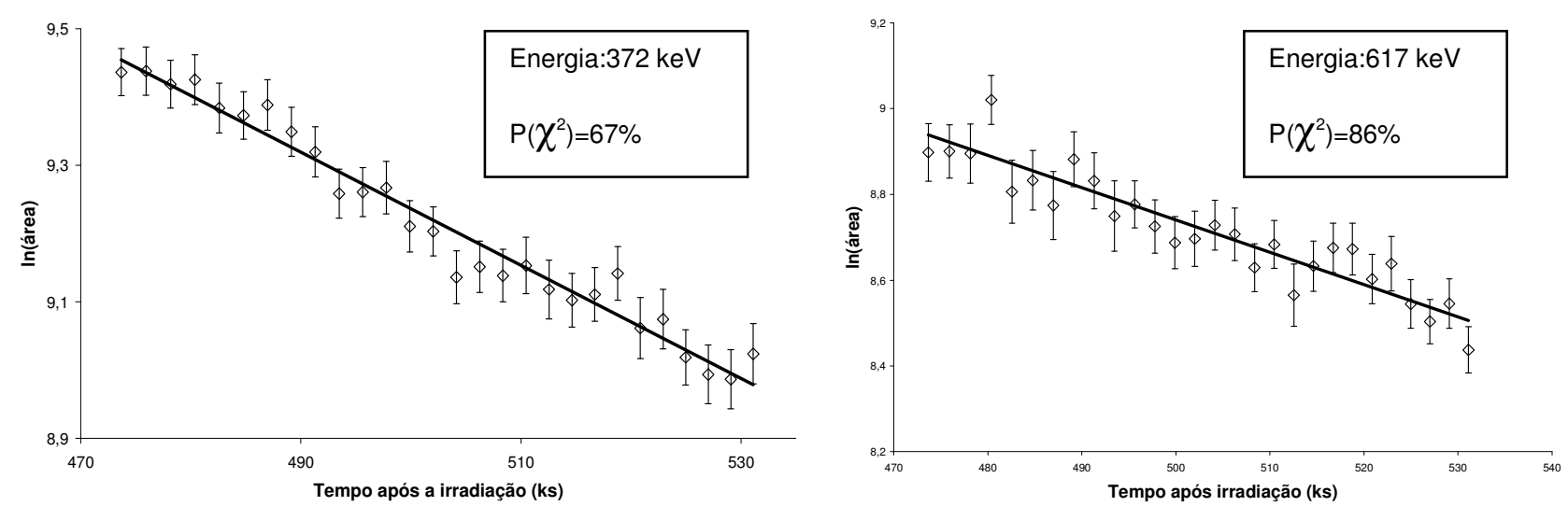

Figura 25: Ajustes sobre os dados obtidos para os picos do ${ }^{43} \mathrm{~K}$, onde $\mathrm{P}\left(\chi^{2}\right)$ representa a probabilidade que o $\chi^{2}$ exceda o valor obtido. 

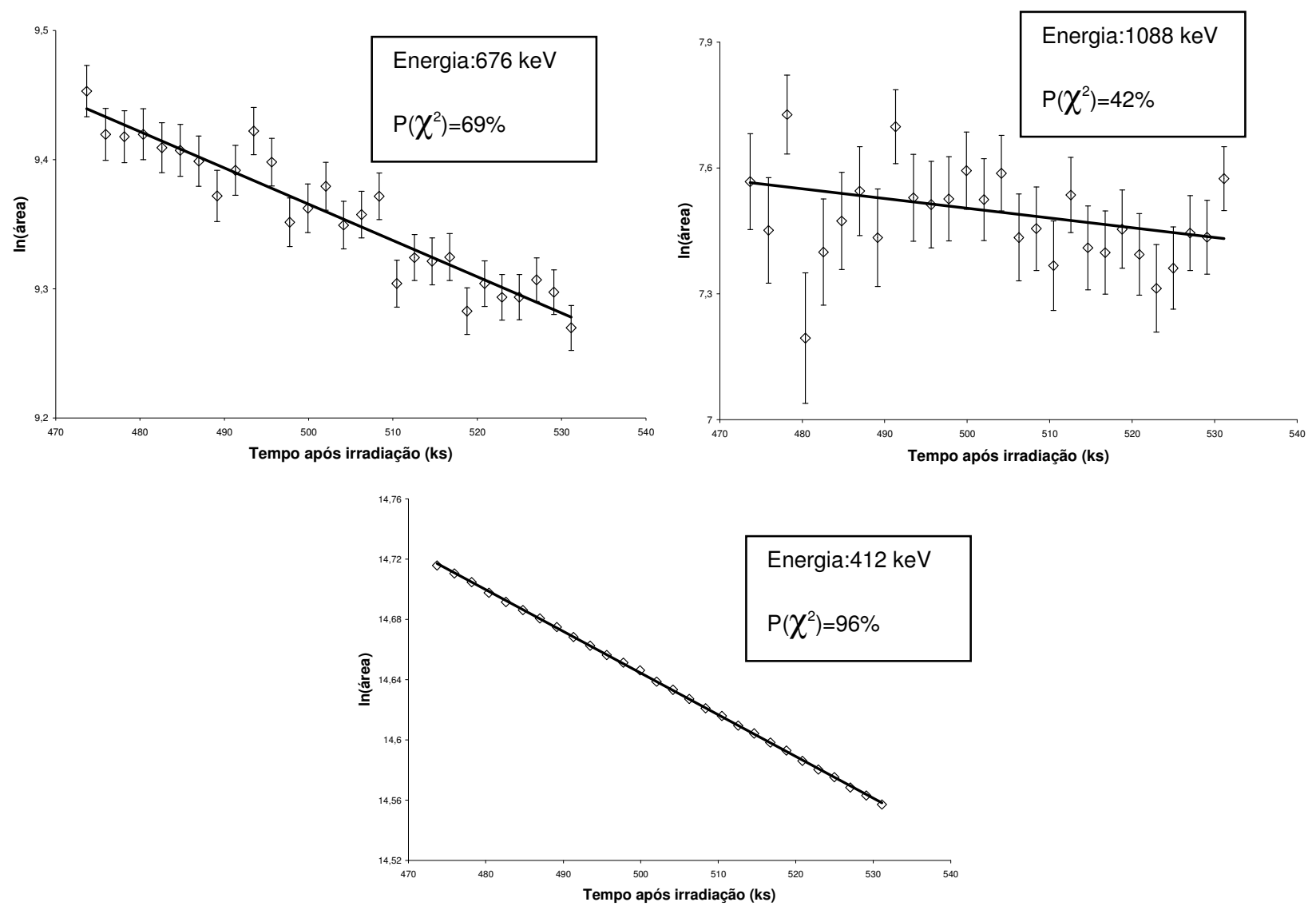

Figura 26: Ajustes sobre os dados obtidos para os picos do ${ }^{198} \mathrm{Au}$, onde $\mathrm{P}\left(\chi^{2}\right)$ representa a probabilidade que o $\chi^{2}$ exceda o valor obtido.

A calibração de energia foi realizada como descrita na secção 3.7.2, porém na determinação da energia dos picos observados foi levada em conta a limitação do sistema de aquisição. Devido o processo de digitalização dos pulsos pelo ADC, por meio de comparações sucessivas, foi imposto à calibração de energia um mínimo de precisão de $0,04 \mathrm{keV}$. Os resultados obtidos são apresentados na tabela 10 e comparados com valores apresentados na bibliografia [31]. 
Tabela 10: Comparação entre dados obtidos e dados apresentados pela bibliografia [39].

\begin{tabular}{ccccccc}
\hline \multirow{2}{*}{ Nuclídeo } & \multicolumn{2}{c}{ Meia vida (horas) } & \multicolumn{2}{c}{ Energia $(\mathrm{keV})$} & \multicolumn{2}{c}{ Intensidade relativa } \\
\cline { 2 - 7 } & bibliografia & obtida & bibliografia & obtida & bibliografia & obtida \\
\hline \multirow{2}{*}{${ }^{42} \mathrm{~K}$} & $12,321(25)$ & $12,456(13)$ & $312,60(25)$ & $312,83(4)$ & $0,0186(11)$ & $0,0181(4)$ \\
& & & $899,7(4)$ & $899,43(5)$ & $0,00288(17)$ & $0,00277(12)$ \\
\hline \multirow{2}{*}{$22,3(1)$} & $23,6(8)$ & $372,760(7)$ & $372,72(4)$ & 1 & 1 \\
${ }^{43} \mathrm{~K}$ & & $617,490(6)$ & $617,53(7)$ & $0,912(7)$ & $0,94(7)$ \\
\hline \multirow{2}{*}{} & & & $411,80205(17)$ & $411,71(4)$ & 1 & 1 \\
${ }^{198} \mathrm{Au}$ & $64,694(7)$ & $69,6(2)$ & $675,8836(7)$ & $675,95(4)$ & $0,00841(3)$ & $0,0076(2)$ \\
& & & $1087,684(3)$ & $1087,95(15)$ & $0,00166(2)$ & $0,00171(19)$ \\
\hline
\end{tabular}

Pode-se observar que a grande maioria dos resultados obtidos concorda com a bibliografia dentro de dois desvios padrões e os resultados discrepantes não têm diferença absoluta grande, portanto podem ser consideradas flutuações estatísticas, levando a crer que foi uma identificação legítima. O valor obtido para a meia vida do ${ }^{42} \mathrm{~K}$ é incompatível com o apresentado na bibliografia devido o fato do tempo de medida ser somente uma ordem de grandeza menor que a meia vida, comprometendo a precisão da aproximação feita na equação (48).

\subsubsection{Identificação de contaminantes}

Observaram-se nos espectros obtidos poucos picos relevantes além dos de interesse, porém ainda se fez necessária a identificação de contaminantes. É importante identificar os elementos inesperados presentes na amostra para se ter certeza que a presença deles não interfere no resultado da medida através de sobreposição de contagens e efeitos de detecção como o efeito soma. 
Seguindo os mesmos critérios e procedimentos apresentados nas duas seções anteriores, foram identificados 5 contaminantes nos alvos de nitrato de potássio. Os núcleos identificados (com auxílio de bases de dados [57][58]) e os valores encontrados para as energias de fóton, constante de decaimento e intensidade relativa são apresentados na tabela 11, assim como os valores apresentados na literatura. 
Tabela 11: Comparação entre resultados obtidos e dados apresentados pela bibliografia [39].

\begin{tabular}{|c|c|c|c|c|c|c|}
\hline \multirow{2}{*}{ Nuclídeo } & \multicolumn{2}{|c|}{ Meia vida (horas) } & \multicolumn{2}{|c|}{ Energia (keV) } & \multicolumn{2}{|c|}{ Intensidade relativa } \\
\hline & bibliografia & obtida & bibliografia & obtida & bibliografia & obtida \\
\hline \multirow{8}{*}{${ }^{82} \mathrm{Br}$} & \multirow{8}{*}{$35,282(7)$} & \multirow{8}{*}{$37,7(7)$} & $776,517(3)$ & $776,50(4)$ & 1 & 1 \\
\hline & & & $554,348(2)$ & $554,32(4)$ & $0,852(16)$ & $0,90(2)$ \\
\hline & & & $619,106(4)$ & $619,09(4)$ & $0,522(10)$ & $0,55(2)$ \\
\hline & & & $698,374(5)$ & $698,38(3)$ & $0,339(7)$ & $0,323(12)$ \\
\hline & & & $1044,002(5)$ & $1044,10(5)$ & $0,339(7)$ & $0,37(2)$ \\
\hline & & & $1317,473(10)$ & $1317,60(6)$ & $0,321(7)$ & $0,31(2)$ \\
\hline & & & $827,828(6)$ & $827,82(4)$ & $0,288(6)$ & $0,295(12)$ \\
\hline & & & $1474,88(1)$ & $1474,85(7)$ & $0,199(4)$ & $0,209(13)$ \\
\hline \multirow{5}{*}{${ }^{72} \mathrm{Ga}$} & \multirow{5}{*}{$14,095(3)$} & \multirow{5}{*}{$13,9(3)$} & $834,03(3)$ & $834,17(4)$ & 1 & 1 \\
\hline & & & $2201,66(7)$ & $2201,0(4)$ & $0,271(5)$ & $0,256(10)$ \\
\hline & & & $629,96(4)$ & $629,97(4)$ & $0,259(5)$ & $0,257(7)$ \\
\hline & & & $894,25(10)$ & $894,39(9)$ & $0,1033(17)$ & $0,087(6)$ \\
\hline & & & $1050,69(5)$ & $1050,74(14)$ & $0,0722(11)$ & $0,066(8)$ \\
\hline \multirow{4}{*}{${ }^{140} \mathrm{La}$} & \multirow{4}{*}{$40,285(3)$} & \multirow{4}{*}{$36,8(13)$} & $1596,21(4)$ & $1596,22(4)$ & 1 & 1 \\
\hline & & & $487,021(12)$ & $486,90(4)$ & $0,477(9)$ & $0,52(2)$ \\
\hline & & & $815,771(19)$ & $815,89(8)$ & $0,244(4)$ & $0,218(16)$ \\
\hline & & & $328,762(8)$ & $328,72(6)$ & $0,213(4)$ & $0,186(11)$ \\
\hline \multirow{2}{*}{${ }^{24} \mathrm{Na}$} & \multirow{2}{*}{$14,997(12)$} & \multirow{2}{*}{$15,09(4)$} & $1368,626(5)$ & $1368,66(4)$ & 1 & 1 \\
\hline & & & $2754,007(11)$ & - & $0,99861(5)$ & - \\
\hline \multirow{2}{*}{${ }^{60} \mathrm{Co}$} & \multirow{2}{*}{$46206(3)$} & \multirow{2}{*}{ - } & $1332,492(4)$ & $1331,70(4)$ & 1 & 1 \\
\hline & & & $1173,228(3)$ & $1173,31(4)$ & $0,9987(3)$ & $1,12(7)$ \\
\hline
\end{tabular}

Como na identificação dos núcleos de interesse, a maioria dos resultados obtidos concorda com a bibliografia dentro de dois desvios padrões e os resultados discrepantes não têm diferença absoluta grande. 
Os núcleos radioativos encontrados são provenientes da ativação de traços de contaminação no alvo, que podem ter origem na própria composição das substâncias químicas que compõem a amostra ou pode até mesmo ser resultado do contato entre o alvo e o dispositivo de irradiação (que envolve alumínio e cádmio).

Os resultados mostraram que não há superposição de picos naqueles de interesse e as contaminações não tiveram influência significativa sobre as regiões de interesse do espectro e sobre a taxa de contagem.

\subsection{Secção de choque da reação ${ }^{41} K(n, \gamma)^{42} K$}

A determinação da secção de choque térmica e integral de ressonância, com todas as correções necessárias, foi feita com os dados obtidos na $5^{\text {a }}$ irradiação que foi realizada em uma posição de irradiação cujo valor do parâmetro $\alpha$ da equação (21) é conhecido.

As medidas de atividade das fontes radioativas foram realizadas em séries de mesmo tempo de contagem, como explicado na secção 3.5, usando o sistema descrito na secção 3.3 e os métodos de espectroscopia descritos na secção 3.7.1. A atividade das fontes foi calculada a partir dos valores de área que corresponderiam à atividade no fim da irradiação $S_{\gamma}^{\prime}$, dado por:

$$
S_{\gamma}^{\prime}=\frac{S_{\gamma}}{e^{-\lambda t_{e}}\left(1-e^{-\lambda \Delta t}\right)}
$$

As atividades foram calculadas a partir das equações (31) e (32), de forma que:

$$
A_{0}=\frac{\lambda \overline{S_{\gamma}^{\prime}}}{\varepsilon_{\gamma} I_{\gamma}}
$$


onde $\overline{S_{\gamma}^{\prime}}$ é a média ponderada pelos desvios padrões dos valores de $S_{\gamma}^{\prime}$, calculada a partir da equação (46). Então, para calcular a razão de cádmio entre as amostras foi necessário considerar as diferentes massas das amostras por meio da expressão:

$$
R_{C d}=\frac{A_{\text {Total }}}{A_{C d}^{\prime}}=\frac{A_{\text {Total }}}{A_{C d}} \frac{N_{0 C d}}{N_{0}}
$$

onde $A_{\gamma}^{\prime}$ é a atividade do alvo sob cádmio corrigida, equivalente à massa do alvo irradiado sem cobertura. A partir destes valores foram calculadas as razões de cádmio mostradas na tabela 12.

Tabela 12: Resultados obtidos para as atividades das amostras ao final da irradiação e razão de cádmio

\begin{tabular}{|c|c|c|c|}
\hline \multicolumn{2}{|c|}{ Amostra } & \multirow{2}{*}{$\begin{array}{c}\begin{array}{c}\text { Atividade } \\
(\mathrm{MBq})\end{array} \\
0,276(4)\end{array}$} & \multirow[t]{2}{*}{$R_{C d}$} \\
\hline & Nua & & \\
\hline Liga Au-Al & $\begin{array}{l}\text { Sob } \\
\text { Cádmio }\end{array}$ & $0,074(2)$ & $3,71(3)$ \\
\hline \multirow[b]{2}{*}{$\mathrm{KNO}_{3}$} & $\mathrm{Nu}$ & $30,2(4)$ & \multirow[b]{2}{*}{$72,9(13)$} \\
\hline & $\begin{array}{c}\text { Sob } \\
\text { Cádmio }\end{array}$ & $0,414(7)$ & \\
\hline
\end{tabular}

Conforme descrito na seç̧ão 3.1.1, foram usadas ligas de Au-Al para determinar os fluxos térmico e epitérmico pelo método da diferença de cádmio, como mostrado na secção 2.2.3. Primeiramente se calculou o fator $r$ usando a equação (22). Depois, considerando que durante as irradiações a temperatura dos nêutrons térmicos em equilíbrio com o moderador do reator foi $303(10) \mathrm{K}$ [59], foram atribuídos os valores $g_{A u}=1,0073(5) \mathrm{e}$ $s_{A u}=17,2$ [25] para os parâmetros $g$ e $s$ das equações (15) e (17), respectivamente, para o ouro. O valor de $r$ obtido é mostrado na tabela 13. 
Os fatores de cádmio [60] e de depressão de fluxo foram calculados (o fator de cádmio em trabalhos anteriores [49] e o de depressão de fluxo na secção 4.1.1) mas ambos foram considerados desprezíveis diante das incertezas. Então, a partir das equações (20) e (23) foi possível determinar, respectivamente, o fluxo epitérmico $\phi_{e p i}$ e o fluxo térmico $\phi_{t h}$. Os valores obtidos para essas grandezas são mostrados na tabela 13.

Tabela 13: Valores obtidos a partir das atividades dos monitores de fluxo

\begin{tabular}{cccc}
\hline$r$ & \multicolumn{2}{c}{$\Phi_{t h}$} & $\Phi_{\text {epi }}$ \\
& $s_{K}$ & $\left(\times 10^{13}\right.$ nêutrons $\left./ \mathrm{cm}^{2} \mathrm{~s}\right)$ & $\left(\times 10^{13}\right.$ nêutrons $\left./ \mathrm{cm}^{2} \mathrm{~s}\right)$ \\
\hline $0,0205(4)$ & $0,177(15)$ & $1,12(3)$ & $0,464(14)$ \\
\hline
\end{tabular}

A partir dos valores da razão de cádmio entre as pastilhas de nitrato de potássio e do fator $r$ é possível calcular o valor de $s$ para a reação ${ }^{41} \mathrm{~K}(\mathrm{n}, \gamma){ }^{42} \mathrm{~K}, s_{K}$, considerando que a seç̧ão de choque obedece ao comportamento $1 / v, \log g_{K}=1$. O valor de $s_{K}$ é dado por:

$$
s_{K}=\frac{\frac{R_{C d K}}{K} \sqrt{\frac{T}{T_{0}}}-\frac{1}{r}}{1-R_{C d K}}=\frac{I_{0 K}}{\sigma_{0 K}} \sqrt{\frac{4 T}{\pi T_{0}}}
$$

O valor de $s_{K}$ obtido a partir desta equação é mostrado na tabela 13.

Considerando as equações (13), (31) e (32) a secção de choque térmica efetiva para a reação ${ }^{41} \mathrm{~K}(\mathrm{n}, \gamma){ }^{42} \mathrm{~K}$ é dada por:

$$
\hat{\sigma}_{K}=\frac{D_{K}}{D_{A u}} \frac{B_{A u}}{B_{K}} \hat{\sigma}_{A u} \sqrt{\frac{\pi T_{0}}{4 T}}
$$

onde as razões entre $D_{K}$ e $D_{A u}$, e entre $B_{A u}$ e $B_{K}$ são dadas por: 


$$
\begin{gathered}
\frac{B_{A u}}{B_{K}}=\frac{f_{412} \varepsilon_{412} I_{412} N_{0 A u}\left(1-e^{-\lambda_{A \mu A} t_{i}}\right)}{f_{1525} \varepsilon_{1525} I_{1525} N_{0 K}\left(1-e^{-\lambda_{K} t_{i}}\right)} \\
\frac{D_{K}}{D_{A u}}=\frac{\lambda_{K}\left(\overline{S_{1525}^{\prime}}-\overline{S_{1525 C d}^{\prime}} \frac{N_{0 K}}{N_{0 K C d}}\right)}{\lambda_{A u}\left(\overline{S_{412}^{\prime}}-\overline{S_{412 C d}^{\prime}} \frac{N_{0 A u}}{N_{0 A u C d}}\right)}
\end{gathered}
$$

Considerando os fatores de Westcott, a secção de choque térmica mostrada na tabela 14 foi calculada por meio da relação:

$$
\sigma_{0 K}=\frac{D_{K}}{D_{A u}} \frac{B_{A u}}{B_{K}} \frac{\left(g_{A u}+r s_{A u}\right)}{\left(g_{K}+r s_{K}\right)} \sigma_{0 A u} \sqrt{\frac{\pi T_{0}}{4 T}}
$$

A integral de ressonância, sem correção do fator $\alpha$, é dada por:

$$
I_{K}=\frac{B_{A u}}{B_{K}} \frac{\lambda_{K} \overline{S_{1525 C d}^{\prime}}}{\lambda_{A u} \overline{S_{412 C d}^{\prime}}} I_{A u}
$$

Considerando que a irradiação foi realizada na posição $24 \mathrm{~A}$ da prateleira 5 e foi medido em trabalhos anteriores [61] que o valor de $\alpha$ para essa posição é 0,0395(55), a correção dada pala equação (21) foi necessária, e a integral de ressonância calculada é apresentada na tabela 14. Nessa mesma tabela são mostradas as covariâncias entre as secções de choque e integral de ressonância das reações ${ }^{41} \mathrm{~K}(\mathrm{n}, \gamma){ }^{42} \mathrm{~K}$ e ${ }^{197} \mathrm{Au}(\mathrm{n}, \gamma){ }^{198} \mathrm{Au}$, que foram calculadas usando a equação (45), sendo que as derivadas parciais contidas na matriz D das fórmulas (44) e (45) foram calculadas numericamente a partir da aproximação (43). 
Tabela 14: Resultados obtidos para a secção de choque e integral de ressonância da reação ${ }^{41} \mathrm{~K}(\mathrm{n}, \gamma){ }^{42} \mathrm{~K}$ e suas covariâncias com os valores da reação de referência ${ }^{197} \mathrm{Au}(\mathrm{n}, \mathrm{g}){ }^{198} \mathrm{Au}[28,29]$.

\begin{tabular}{|c|c|c|c|c|c|c|}
\hline Reação & $\sigma_{0 K}$ (barn) & $I_{K}$ (barn) & \multicolumn{4}{|c|}{ Matriz de covariâncias (barn $\left.{ }^{2}\right)$} \\
\hline \multirow{2}{*}{${ }^{197} \mathrm{Au}(\mathrm{n}, \gamma){ }^{198} \mathrm{Au}$} & $98,65(9)$ & & 0,0081 & & & \\
\hline & & $1560(40)$ & 0 & 1600 & & \\
\hline \multirow{2}{*}{${ }^{41} \mathrm{~K}(\mathrm{n}, \gamma){ }^{42} \mathrm{~K}$} & $1,71(5)$ & & 0,00016 & 0 & 0,003 & \\
\hline & & $0,96(4)$ & $-0,00002$ & 1,2 & 0,0005 & 0,0016 \\
\hline
\end{tabular}

$\mathrm{O}$ resultado obtido para a secção de choque térmica da reação ${ }^{41} \mathrm{~K}(\mathrm{n}, \gamma)^{42} \mathrm{~K}$ é compatível apenas com o resultado obtido por KAMINISHI, 1,57(17) b [9]. O valor obtido para a integral de ressonância concorda apenas com o valor obtido por KÖHLER, 0,96(3) b [6], e é menor que os obtidos por RYVES, 1,39(15) b [7], e KIM, 1,25(4) b [8], como pode ser visto na tabela 15.

Tabela 15: Valores para secção de choque térmica, $\sigma_{0}$, e integral de ressonância, $I$, em barns

\begin{tabular}{ccc}
\multicolumn{4}{c}{ (1 barn=10 $\left.\mathbf{0 ~}^{-24} \mathbf{c m}^{2}\right)}$. \\
Referência (ano) & $\sigma_{0}$ & $I$ \\
\hline \hline KAPPE (1965) [5] & $1,500(45)$ & \\
KÖHLER (1966) [6] & $1,2(1)$ & $0,96(3)$ \\
RYVES (1969) [7] & $1,46(3)$ & $1,39(15)$ \\
KIM (1971) [8] & $1,28(6)$ & $1,25(4)$ \\
KAMINISHI (1982) [9] & $1,57(17)$ & \\
Presente trabalho (2008) & $\mathbf{1 , 7 1 ( 5 )}$ & $\mathbf{0 , 9 6 ( 4 )}$ \\
\hline
\end{tabular}

Note-se que os valores experimentais apresentados na tabela 1 formam um conjunto discrepante. A tabela 16 mostra as médias ponderadas desses valores e os valores de $\chi^{2}$ correspondentes incluindo ou não o resultado obtido neste trabalho. A tabela 17 apresenta 
as médias não-ponderadas com os respectivos desvios-padrões das médias, também incluindo ou não os resultados deste trabalho.

Tabela 16 : Médias ponderadas calculadas com valores publicados da seção de choque térmica e da integral de ressonância, excluindo ou não o valor obtido neste trabalho. $\mathrm{P}\left(\chi^{2}\right)$ é a probabilidade de $\chi^{2}$ exceder o valor obtido.

\begin{tabular}{ccccccc}
\hline \multirow{2}{*}{ Grandeza } & \multicolumn{3}{c}{ Trabalhos anteriores } & \multicolumn{3}{c}{ Incluindo este trabalho } \\
\cline { 2 - 7 } & Média (b) & $\chi^{2}$ & $\mathrm{P}\left(\chi^{2}\right)$ & Media (b) & $\chi^{2}$ & $\mathrm{P}\left(\chi^{2}\right)$ \\
\hline$\sigma_{0_{K}}$ & $1,434(22)$ & 15,6 & 0,004 & $1,480(20)$ & 46 & 0 \\
$I_{K}$ & $1,073(24)$ & 271 & 0 & $1,073(24)$ & 411 & 0 \\
\hline
\end{tabular}

Tabela 17 :Mesmo que na tabela 15, mas com médias não ponderadas.

\begin{tabular}{ccc} 
& Trabalhos anteriores & Incluindo este trabalho \\
\hline$\sigma_{0 K}$ (b) & $1,40(7)$ & $1,45(8)$ \\
$I_{K}$ (b) & $1,20(13)$ & $1,14(11)$ \\
\hline
\end{tabular}

Pode-se observar que o valor experimental da seção de choque térmica obtido neste trabalho é incompatível com o conjunto dos dados anteriores. Foi verificado que desprezar o fator $\left(g_{A u}+r s_{A u}\right)$ da fórmula (56) reduziria o valor obtido a ponto de torná-lo compatível com os obtidos nos demais trabalhos. No entanto, tanto RYVES [7] quanto KIM [8] mencionam ter efetuado essa correção, de modo que é impossível estabelecer com certeza a razão da discrepância.

Em relação à integral de ressonância, embora os três dados anteriores sejam marcadamente incompatíveis entre si, o valor obtido neste trabalho é compatível com a média não ponderada dos dados anteriores dentro de menos que dois desvios padrões. KIM [8] não menciona o desvio da distribuição de nêutrons epitérmicos da lei 1/E, o que pode ter 
distorcido seu resultado, mas RYVES [7] descreve corretamente a aplicação desse fator.

Assim, neste caso também não foi possível determinar a razão da discrepância observada. 


\section{Capítulo 6: Conclusão}

No presente trabalho determinou-se a secção de choque térmica e a integral de ressonância da reação ${ }^{41} \mathrm{~K}(\mathrm{n}, \gamma)^{42} \mathrm{~K}$ usando o reator IEA-R1m. Foi verificada a viabilidade de determinar experimentalmente a secção de choque de absorção de nêutrons para a reação

${ }^{42} \mathrm{~K}(\mathrm{n}, \gamma)^{43} \mathrm{~K}$, para a qual não há dados experimentais na bibliografia, após irradiações longas, de 12 a 48 horas.

Os valores da secção de choque e da integral de ressonância são incompatíveis com os valores médios dos resultados existentes na literatura, embora concordem com resultados anteriores particulares. As incertezas dos dados obtidos são menores que alguns dados apresentados na bibliografia, contribuindo para o conhecimento preciso destas grandezas.

No presente trabalho foram abordados os fundamentos básicos teóricos do transporte de nêutrons para a prática da análise por ativação de nêutrons, como a determinação do fluxo térmico, fluxo epitérmico, secção de choque térmica e integral de ressonância, considerando os fatores de correção relevantes para as medidas realizadas. Também foram expostos neste trabalho as motivações, procedimentos e resultados dos métodos experimentais usados, como o método de ativação de folhas e pastilhas associado ao método da diferença de cádmio e a determinação de atividades de fontes extensas por meio de espectroscopia gama. 


\section{Apêndice A: Correção do efeito soma}

A equação (32) apresentada na secção 2.3 se trata na verdade de uma aproximação para o cálculo teórico da área de um pico no espectro gama; o cálculo mais detalhado e geral dessa grandeza exige um formalismo matricial e mais variáveis a serem consideradas. Essa modelagem mais detalhada contempla a perda de área em um pico decorrente da probabilidade do fóton correspondente ser detectado juntamente com outro fóton resultando em uma contagem fora do pico de absorção total de energia, conhecido como efeito soma. Tal efeito depende do conjunto de fótons que é emitido pela fonte, logo deve ser corrigido para que a eficiência de detecção de diferentes fontes seja comparada.

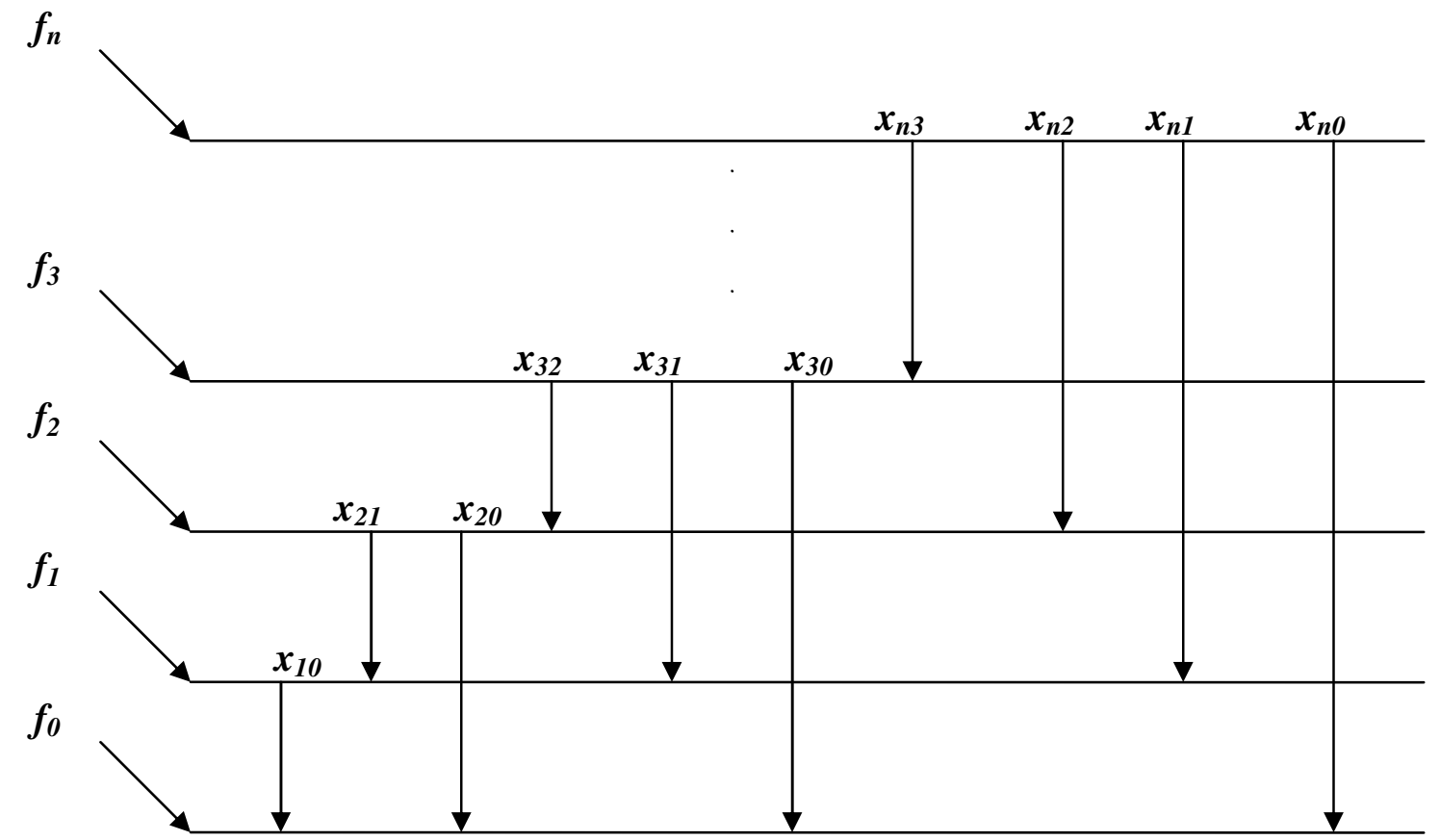

Figura 27: Esquema de decaimento de uma fonte radioativa. Os níveis de energia são numerados na ordem de energia de excitação, começando com 0 para o estado fundamental. 
O decaimento radioativo de um núcleo com $n$ níveis de excitação pode ser representado pelo diagrama apresentado na figura 27 , onde $f_{i}$ são as frações de alimentação do nível $i$ e $x_{i j}$ são as frações de ramificação total de decaimento do estado $i$ para o estado $j$.

Pode-se definir um vetor de probabilidades de alimentação de estados, $\mathbf{f}$ :

$$
\mathbf{f}=\left(f_{0}, f_{1} \cdots f_{n}\right)
$$

e uma matriz $\mathbf{X}$ dada por:

$$
\mathbf{X}=\left(\begin{array}{cccccc}
0 & & & & & \\
x_{10} & 0 & & & & \\
x_{20} & x_{21} & 0 & & & \\
\vdots & \vdots & \vdots & & & \\
x_{n 0} & x_{n 1} & x_{n 2} & \cdots & x_{n n-1} & 0
\end{array}\right)
$$

A partir dessa matriz podemos definir elementos para outras duas matrizes, a e b, considerando a eficiência de detecção para a energia de pico $\varepsilon_{j i}^{p}$, a eficiência de detecção total $\varepsilon_{j i}^{t}$ e o coeficiente de conversão interna $\alpha_{j i}$ :

$$
\begin{gathered}
a_{j i}=\frac{x_{j i} \varepsilon_{j i}^{p}}{1+\alpha_{j i}} \\
b_{j i}=x_{j i}-\frac{x_{j i} \varepsilon_{j i}^{t}}{1+\alpha_{j i}}
\end{gathered}
$$

onde $j>i=0,1, \cdots, n-1$. 
Para considerar todos os possíveis caminhos de decaimento, define-se outras duas matrizes, A e $\mathbf{B}$ :

$$
\begin{gathered}
\mathbf{A}=\sum_{k=i}^{n} \mathbf{a}^{k} \\
\mathbf{B}=\operatorname{diag}(1)+\sum_{k=1}^{n} \mathbf{b}^{k} .
\end{gathered}
$$

Finalmente teremos que a área do pico no espectro gama, $S_{j i}$, será dada por [62]:

$$
\mathbf{S}=N_{d} \operatorname{diag}\left([\mathbf{f B}]_{i}\right) \mathbf{A} \operatorname{diag}\left(B_{i 0}\right)
$$

Considerando que a eficiência de pico é um parâmetro determinado experimentalmente a partir do valor de área observado, o cálculo da correção do efeito soma é iterativo partindo de um valor de eficiência estimado da área obtida experimentalmente sem correção.

Podemos observar por meio do raciocínio acima que o problema da correção do efeito soma na detecção de fótons gama tem solução cuja complexidade depende da quantidade de níveis que precisam ser considerados no decaimento do núcleo de interesse. Pode-se observar que uma solução geral para esse problema não é trivial [63]. No presente trabalho, as correções para as medidas de ${ }^{60} \mathrm{Co}$ foram calculadas individualmente com o auxílio do programa Excel, já as medidas correspondentes ao ${ }^{152} \mathrm{Eu}$ foram corrigidas por meio de programa em MathCad [37][64]. 


\section{Referências Bibliográficas}

[1] BECKURTZ, K.H.; WIRTZ, K. NEUTRON PHYSICS. New York, N. Y.: Springer, 1964.

[2] CLAYTON, D. D. Principles of Stellar Evolution and Nuclear Synthesis. McGraw-Hill Book Company. 1968.

[3] KAPPELER, F. s-Process nucleosynthesis and the interior of Red Giants. Nucl. Phys. A 752, 500C-50 9C, 2005.

[4] DE SMET, L. et al. Experimental determination of the ${ }^{36} \mathrm{CI}(n, p){ }^{33} \mathrm{P}$ reaction cross sections and the consequences on the origin of ${ }^{36}$ S. Physical Review C 75, 034617. 2007.

[5] KAPPE D. S. Pennsylvania State University dissertation abstract 27B 919, 1965.

[6] KÖHLER W.; H. SCHMELZ. Die Bestimmung der Resonanzaktivierungsintegrate von ${ }^{41} \mathrm{~K},{ }^{51} \mathrm{~V}$ und ${ }^{55} \mathrm{Mn}$. Nukleonik. Band 9, Heft 6, pp. 270 to 273. 1966.

[7] RYVES T.B. Activation Measurements of Thermal Neutron Capture Cross-sections and Resonance Integrals. Journal of Nuclear Energy. Vol. 24, pp. 35 to 42.1969.

[8] KIM J.I.; E. GRYNTAKIS. The Thermal Neutron Cross Section and the Resonance Integral of ${ }^{146} \mathrm{Nd},{ }^{148} \mathrm{Nd},{ }^{150} \mathrm{Nd}$ and ${ }^{41} \mathrm{~K}$. Radiochimica Acta. Band 17, Heft 4, pp. 191 to 193, 1971.

[9] KAMINISHI K.; T. SHUIN. Thermal Neutron Cross-section of ${ }^{23} \mathrm{Na}$ and ${ }^{41} \mathrm{~K}$. Japanese Journal of Applied Physics. Vol. 21, No. 4, pp. 636-638. 1982.

[10] MORDECHAI, S.; FORTUNE, H.T.; CLEMENT, C. F. ${ }^{43} \mathrm{~K}$ from the ${ }^{41} \mathrm{~K}(\mathrm{t}, \mathrm{p})$ reaction. Physical Review C, Vol. 30, Num. 2, pp 507-516, 1984.

[11] BEHBEHANI, A.H. et al. High-spin states in ${ }^{43}$ K. J. Phys. G: Nucl. Phys., Vol. 5, No. 7, pp 971-979, 1979.

[12] BENCZER-KOLLER, N.; SCHWARZSCHILD, A.; WU, C. S. Decay of ${ }^{43} \mathrm{~K}$. Physical Review, Vol. 115, No 1, pp 108-114. 1959. 
[13] LINDQVIST, T.; MITCHELL, A. C. G. Desintegration of $\mathrm{K}^{43}$. Physical Review, Vol. 95, No 2, pp 444-446. 1954.

[14] HUCK, A. et al. Levels in ${ }^{43} \mathrm{~K}$ and ${ }^{44} \mathrm{~K}$ excited by the $\beta$ decay of ${ }^{43} \mathrm{Ar}$ and ${ }^{44} \mathrm{Ar}$. Physical Review C, Vol. 18, No 4, pp 1803-1813. 1978.

[15] MORALLES, M. et al. $\gamma$-ray spectroscopy of ${ }^{42} \mathrm{~K}$ and ${ }^{43} \mathrm{~K}$. Physical Review $C$, Vol. 58, No 2, pp 739-748. 1998.

[16] WARBURTON, E. K.; ALBURGER, D. E. ${ }^{43} \mathrm{~K}\left(\beta^{-}\right)^{43} \mathrm{Ca}$ and the structure of ${ }^{43} \mathrm{~K}$ and ${ }^{43} \mathrm{Ca}$. Physical Review C, Vol. 38, No 6, pp 2822-2837. 1988.

[17] W.-M. Yao et al. (Particle Data Group), J. Phys. G 33, 1, 2006. http://pdg.lbl.gov último acesso em 3/7/2008.

[18] WATT, B. E. Energy Spectrum of Neutrons from Thermal Fission of $U^{235}$. Physical Review. Vol. 87, Num 6. 1952.

[19] INTERNATIONAL ATOMIC ENERGY AGENCY. Neutron Fluence Measurements: Technical Report Series 107. Vienna, 1970.

[20] MAIDANA, N.L. Medida de secções de choque para reações de captura de nêutrons no ${ }^{57} \mathrm{Co},{ }^{137} \mathrm{Cs}$ e ${ }^{241} \mathrm{Am}$ considerando a formação de estados isoméricos. Tese de doutorado, Instituto de Pesquisas Energéticas e Nucleares. 2000.

[21] HUGHES; JAMES D. Neutron Cross Sections, N. Y.: Upton, 1952.

[22] WeStCOTT, C. H.; WALKER, W. H.; ALEXANDER, T. K. Effective Cross sections and Cadmium Ratios for the Neutron Spectra of the Thermal Reactors. Ont.: Atomic Energy of Canada, Chalk River (AECL-612). 1958.

[23] WESTCOTT, CH. Effective Cross Section Values for Well-Moderated Thermal Reactor Spectra. Ont.: Atomic Energy of Canada, 3rd Edition Chalk River (CRRP-960). 1960.

[24] WALKER, W. H., WESTCOTT, C. H., and ALEXANDER, T. K. Measurement of Radiative Capture Resonance Integrals in a Thermal Reactor Spectrum, and Thermal Cross Section of Pu-241. Can. J. Phys. 38, 1960. 
[25] DE CORTE, F.; SIMONITS, A. Recommended nuclear data for use in the k0 standardization of neutron activation analysis. Atomic Data and Nuclear Data Tables. Vol. 85. p: 47-67. 2003.

[26] BENJELLOUN, M.; PAULUS, J. M. $\alpha$ Determination in the $E^{-(1+\alpha)}$ epithermal neutron spectrum of the CRN reactor (Strasbourg). Journal of Radioanalytical and Nuclear Chemistry, Articles. Vol. 109, No. 2. 1987.

[27] ONEGA, RONALD J. Radioactivity Calculations. American Journal of Physics. Vol. 37, No 10, pp. 1019-1022. 1969.

[28] ZIJP, W. L.; BAARD, J. H. Nuclear Data Guide for Reactor Neutron Metrology. Nucl. Sci. Technol. Luxemburgo. , Commission of the European Communities (EUR 7164 EN) 1981.

[29] Pronyaev, V.; Meeting on Validation of ENDF/B-VII beta2, Brookhaven National Laboratory.2006.

http://www.nndc.bnl.gov/meetings/valid2006/Pronyaev_01_Stand_B72_Mu06.pdf último acesso em 3/7/2008.

[30] CHUNMEI, Z. Nuclear Data Sheets. 95, 59, 2002.

[31] FIRESTONE, R. B. Table of Isotopes. Ed. Virginia S. Shirley, 1996.

[32] COURSEY, J.S., SCHWAB, D.J., and DRAGOSET, R.A., Atomic Weights and Isotopic Compositions (version 2.4.1). 2005. http://physics.nist.gov/Comp último acesso em 3/7/2008.

[33] ORTEC: Quality assurance data sheet, detector model No GEM-30185-5, serial No 34TP309330A. Relatório Técnico.

[34] EURISYS MEASURES. Specification Sheer for $n$ type coaxial germanium detector. EGC 45-200-TR Serial number: 73061. Relatório Técnico.

[35] GUIMARÃES, C. O. Eficiência de detectores HPGe para fótons de 4 a $10 \mathrm{MeV}$. Dissertação de Mestrado, Instituto de Física da Universidade de São Paulo, 2005. http://www.teses.usp.br/teses/disponiveis/43/43134/tde-28072005-114921/. último acesso em 3/7/2008. 
[36] BARG, D. Aquisição de dados em espectroscopia gama nuclear. Dissertação de Mestrado - Instituto de Pesquisas Energéticas e Nucleares - IPEN/CNEN-SP, São Paulo. 2000.

[37] CASTRO, R. M. Transformando o ${ }^{152} E$ u em um padrão de calibração de eficiência para deteção de gamas. Tese de doutorado. Instituto de Física da Universidade de São Paulo, 2003.

[38] http://www.physics.nist.gov/cgi-bin/Xcom/xcom3_1 último acesso em 3/7/2008.

[39] http://www.nndc.bnl.gov/chart/chartNuc.jsp último acesso em 3/7/2008.

[40] KOKTA, L. Determination of peak area. Nuclear Instruments and Methods. Vol. 112, p: 245-251. 1973.

[41] GOUFFON, P. Manual do Programa IDEFIX, IFUSP-LAL 1983.

[42] GUIMARÃES, Z. O. Programa IDEFIX from Windows, Comunicação Privada, 1999.

[43] KNOLL, G. F. Radiation detection and measurement. John Wiley \& Sons. 1979.

[44] PELOWITZ, D. B. MCNPX User's Manual, Los Alamos, USA, 2005.

[45] TZIKA, F. and STAMATELATOS, I. E. Thermal neutron self-shielding correction factors for large sample instruments neutron activation analysis using the MCNP code. Nuclear Instruments and Methods in Physics Research B. Vol. 213. p. 177-181. 2004.

[46] KIRÁLY, B., SANAMI, T.; CSIKAI, J. Advantages and limitations of thermal and epithermal neutron activation analysis of bulk samples. Applied Radiation and Isotopes. Vol 58, p: 691-695. 2003.

[47] BRIESMESTER, J. F. MCNP A General Monte Carlo N-Particle Transport Code, Version 5. Los Alamos, USA, 2001.

[48] CARTER, L. L. and SCHWARZ, R. A. MCNP Visual Editor Computer Code Manual, 2003. www.mcnpvised.com ultimo acesso em 4/7/2008.

[49] KOSKINAS, M. F. Medida do fluxo térmico, epitérmico e rápido no reator IEA-R1 pelo método de ativação de folhas. Instituto de Energia Atômica. São Paulo, 1979. 
[50] HELMER, R. G. et al. The use of Monte Carlo calculations in the determination of a Ge detector efficiency curve. Nuclear Instruments and Methods in Physics Research A. Vol. 511. p: 360-381. 2003.

[51] MAIDANA, N. L. et al Absolute determination of soluble potassium in tea infusion by gamma-ray spectroscopy. 2008. submetido a publicação.

[52] SERRA, A. S. Produção e utilização do ${ }^{66}$ Ga como padrão de calibração de raios $\gamma$ de altas energias para detectores HPGe. Dissertação de Mestrado, Instituto de Física da Universidade de São Paulo, 2008.

[53] VANIN, V.R.; GOUFFON, P. Topicos Avancados Em Tratamento Estatistico de Dados. 1.ed. São Paulo: IFUSP/LAL, 1996.

[54] HELENE, O. Método dos Mínimos Quadrados com Formalismo Matricial: Guia do Usuário. São Paulo. Editora Livraria da Física, 2006.

[55] HELENE, O. VANIN, V. Tratamento estatístico de dados em física experimental. São Paulo. Editora Edgar Blucher LTDA, 1981.

[56] ADAM, J. et al. Precision half-life measurement of ${ }^{140} \mathrm{La}$ with Ge-detector. Nuclear Instruments and Methods in Physics Research B. Vol. 187. p. 419-426. 2002.

[57] KELLER, J. M. Nuclide Identification Package. Oak Ridge National Laboratory.

[58] REUS, U and WESTMEIER, W. Catalog of Gamma Rays from Radioactive Decay. Atomic Data and Nuclear Data Table. Vol. 29, No 1. 1983.

[59] Técnico do reator. Comunicação pessoal. 2007.

[60] AXTON, E. J. Absolute measurement of the neutron flux density in the A.E.R.E. reactor "GLEEP". Reactor Science and Technology (Journal of Nuclear Energy Parts A/B). Vol. 17. p: 125-135. 1963.

[61] RAJPUT, M. U. et al. Thermal neutron cross-section and resonance integral measurement of ${ }^{165} \mathrm{Ho}(\mathrm{n}, \gamma){ }^{1669} \mathrm{Ho}$ reaction. 2008. Submetido a publicação.

[62] SEMKOW, T. M., MEHMOOD, G., PAREKH, P. P., VIRGIL, M., Coincidence summing in gamma-ray spectroscopy. Nuclear Instruments and Methods in Physics Research A, 290 p. 437-444. 1990. 
[63] NOVKOVIC, D., Kandic, A. et al. Coincidence summing of $X$ - and g-rays in g-ray spectrometry. Nuclear Instruments and Methods in Physics Research A, 578 p. 207-217. 2007.

[64] CASTRO, R. M. Comunicação pessoal, 2008. 